\title{
AUDIT PARTNER STYLE IN KEY AUDIT MATTER REPORTING DECISIONS
}

\author{
Linette M. Rousseau, Ph.D. Candidate \\ University of Wisconsin - Madison \\ lmrousseau@wisc.edu \\ Karla M. Zehms, Ernst \& Young Professor* \\ University of Wisconsin - Madison \\ University of New South Wales Business School Distinguished Scholar \\ karla.zehms@wisc.edu
}

July 2020

* Corresponding author

Professor Zehms acknowledges the financial support from her EY Professorship, along with support from the University of Wisconsin School of Business Andersen Center for Financial Reporting and the University of New South Wales Distinguished Scholar Fellowship. Linette Rousseau acknowledges the financial support from her Deloitte Foundation Doctoral Fellowship. Both co-authors acknowledge the financial support from a PwC INQuires grant. We appreciate the constructive feedback of In Gyun Baek, Jean Bedard, Mandy Cheng, Jonathan Cook, Paulo Guimarães, Noel Harding, Sarowar Hossain, Dan Lynch, Miguel Minutti-Meza, Roger Simnett, Sarka Stepankova, Mary Vernon, Dan Wangerin, Brian Williams, Junwei Xia, workshop participants at the University of Wisconsin-Madison and the University of New South Wales, and participants at the 2020 Auditing Section Midyear Meeting. 


\section{AUDIT PARTNER STYLE IN KEY AUDIT MATTER REPORTING DECISIONS}

ABSTRACT: We examine whether partners have unique decision styles for key audit matters (KAMs), by which we mean stable within-partner similarities and between-partner differences in KAM reporting over time and across clients and industries. Using a sample of UK KAMs, we find unique partner styles in KAM reporting volume, topical diversity, and communication after controlling for client and audit firm variation. Partners with styles for greater KAM volume, topical diversity, and 'insight' verbiage (e.g., "think" or "consider") command higher fees. Further, partners who issue KAMs with more cognitively complex, causal (e.g., "because" or "effect"), or insight verbiage are more likely to be audit fee growth leaders, while partners who issue longer KAMs are less likely to be growth leaders. We find no association between partners' styles and either report delay or audit quality. Our results illustrate that partners make unique KAM reporting judgments, countering concerns about audit firms issuing 'boilerplate' KAMs.

Keywords: audit partner identification, critical audit matters, expanded audit reporting, key audit matters, reporting style, textual analysis.

Data availability: All data are available from publicly available sources. 


\section{AUDIT PARTNER STYLE IN KEY AUDIT MATTER REPORTING DECISIONS I. INTRODUCTION}

We examine whether audit partners have unique decision styles for Key Audit Matter (KAM) reporting and whether those styles are associated with other outcomes including audit fees and fee growth, report delay, and audit quality. Prior literature demonstrates that individual decision makers' unique styles predict various important outcomes, including CEO effects on company policies and performance (Bertrand and Schoar 2003), CFO accounting policy selection (Ge, Matsumoto, \& Zhang 2011), and audit partner pricing and quality effects (Taylor 2011; Gul, Wu, and Yang 2013). Other research reports audit firm-level styles with respect to client financial reporting, audit quality, and audit firm reputation (Francis and Michas 2013; Francis, Pinnuck, and Watanabe 2014; Cook, Kowaleski, Minnis, Sutherland, and Zehms 2020). Against this backdrop, there exist stakeholder concerns that KAMs will become 'boilerplate' based on audit firms' central guidance rather than individual partners' professional judgment about client and engagement specific circumstances, motivating our examination of audit partner decision dynamics in the KAM reporting space (Heffes 2013; Gunn 2016; PCAOB 2019; PwC 2014).

The first purpose of our study is to investigate whether individual partners have unique decision styles in KAM reporting. To inform our investigation, we articulate a conceptual framework of partners' general decision styles to explain how unique audit partner reporting styles may emerge in the context of KAM reporting. We propose that partners' decision styles

arise as a function of their varied expertise, risk attitudes, skepticism, cognition, and institutional and incentive environments. We conceive that these factors have a pervasive influence on each partner's KAM reporting judgements as they evaluate relevant features of the client engagement, develop a mental representation of the KAM reporting decision, and decide the volume and 
topical diversity of KAMs and the manner of communicating these matters in the audit report.

The second purpose of our study is to investigate whether and how audit partners' KAM reporting decision styles may be associated with their other audit outcomes, including the levels of audit fees, growth in audit fees, reporting timing, and audit quality. We anticipate this association not because of the effort involved in preparing the KAMs themselves, but instead because the same factors that shape a partner's unique approach to KAM decision making will influence their ability to command fee premia and fee portfolio growth, conduct their audits efficiently, and deliver high-quality outcomes.

Our sample includes 2,819 company-year observations listed on the London Stock Exchange (LSE) during the period 2013 - 2019 comprising 275 unique audit partners across 11 audit firms. We adapt methodology from Bertrand and Schoar (2003) and Gul et al. (2013) to infer individual differences in partners' KAM reporting styles by examining whether partnerlevel fixed effects add significant explanatory power to regressions modelling KAM reporting outcomes. These fixed effects reveal partner styles by identifying stable within-partner similarities and between-partner differences across clients, industries, and reporting years after controlling for economic circumstances of the client, characteristics of the audit firm, and audit firm-level reporting style. We show that partners have unique styles with respect to KAM volume, topical diversity, average number of words per KAM, readability of the KAMs, and the extent of cognitively complex language with verbiage that includes 'insight' phrases (e.g., “think" or “consider”), 'causal' phrases (e.g., "because” or “effect”) and 'discrepancy' phrases (e.g., "should" or "would"). We measure cognitive complexity using the Linguistic Inquiry Word Count (LIWC) technique (Tausczik and Pennebaker 2010), a textual analysis approach that accounting researchers employ to interpret manager disclosures (Asay, Libby, and Rennekamp 
2018; Rennekamp, Sethuraman, and Steenhoven 2020; Matsumoto, Pronk, and Roelofsen 2011). We find that unique partner styles are much more important to predicting KAM outcomes than audit firm styles: audit firm fixed effects offer from two to five percent improvement in explanatory power when we add them to a model with control variables, while audit partner fixed effects improve explanatory power from 11 to 22 percent when we add them to a model with control variables and audit firm fixed effects.

Utilizing partners' individual fixed effects coefficients to measure their styles for KAM volume, diversity, and communication, we test the relation between partners' KAM reporting decision styles and their other audit outcomes with respect to fees, fee growth, report timing, and quality. We find that partners with styles for issuing a greater number of KAMs, more topically diverse KAMs, and longer KAM reports command higher engagement-year fees, while partners using more cognitively complex verbiage including 'causal' or 'insight' phrases are more likely to rate among the top decile of partners in their audit firm and client industry for two-year fee growth. In economic terms, partners whose styles are in the highest quintile with respect to KAM volume, topical diversity, or verbiage that includes 'insight' phrases charge eight to 12 percent higher fees than their counterparts. We find no significant associations between partners' KAM reporting styles and either audit report delay or audit quality, suggesting that partners' whose styles tend towards providing more comprehensive KAM reports are able to do so without sacrificing audit efficiency or effectiveness. In supplemental analyses, we regress partners' KAM reporting styles on their demographic characteristics, finding adjusted $\mathrm{R}^{2} \mathrm{~s}$ of between one and 22 percent; this suggests that unobservable characteristics such as those in our conceptual model explain the remaining 78 to 99 percent of unique partner decision style. 
Our study provides numerous contributions to research and practice by pursuing two equally important objectives: (1) providing contemporary insight on KAM reporting, and (2) leveraging the KAM setting to advance understanding of audit partner decision style and its effect on other audit outcomes. Prior research presents mixed results regarding whether KAMs are informative to investors and whether the shift to a KAM reporting regime is associated with audit fees, quality, and auditor liability outcomes (e.g., Bédard, Gonthier-Besacier, and Schatt 2019; Gutierrez, Minutti-Meza, Tatum, and Vulcheva 2018; Reid, Carcello, Li, and Neal 2019; Kachelmeier, Rimkus, Schmidt, and Valentine 2019). We contribute to this research by proposing and testing a theory of audit partner-level KAM reporting styles that challenges the implicit assumption in existing event studies and difference-in-difference studies that the consequences of KAM reporting regimes are uniform across partners. We find that partners' unique KAM reporting styles drive variation in KAM reporting outcomes. By answering the call to focus on individual decision makers in accounting research (Kachelmeier 2010; DeFond and Zhang 2014; Lennox and Wu 2018), we illustrate that allowing the effect of KAM reporting to vary at the individual audit partner level may be a fruitful avenue for future research aiming to address the mixed evidence on the consequences of KAM reporting regimes. We also provide evidence relevant to concerns that KAMs will become boilerplate at the audit firm level, showing instead that KAM reporting outcomes vary based on unique partner-level styles after controlling for audit firm-level styles.

Second, we extend the literature examining the effects of individual audit partner decision style on audit outcomes (see Lennox and $\mathrm{Wu} 2018$ for a review) to the KAM disclosure setting. This is a powerful setting in which to observe partner decision styles because KAMs are the direct and sole assertion of the auditor, contained in the audit report to which the partner 
signs his or her name. In contrast, the extant literature examining partner decision styles for audit quality relies on earnings management and misstatement measures as an indirect reflection of partner decision making (Gul et. al. 2013; Ittonen, Johnstone, and Myllymäki 2015; Knechel, Vanstraelen, and Zerni 2015), when in fact financial statement balances are management assertions that the auditor serves to constrain rather than create (DeFond and Zhang 2014). Furthermore, examining KAMs enhances the generlizability of our inferences by allowing us to observe partner decision styles across a wide sample of companies; the vast majority of UK companies receive at least one KAM, with an average of three KAMs per audit report. In contrast, research investigating partner decision style with respect to going concern and modified opinion reporting encompasses only those companies experiencing unusual circumstances of financial distress or noncompliance with accounting standards, thereby limiting the generalizability of the findings (Chen, Sun, and Wu 2010; He, Pittman, Rui, and Wu 2017; Ye, Carson, and Simnett 2011; Hardies, Breesch, and Branson 2014; Sundgren and Svanström 2014; Goodwin and Wu 2016). Further, ours is the first partner decision style study to examine not only the extent of the partner's reporting, but the diversity of audit issues the partner tends to consider and the language the partner utilizes to communicate those issues. Expanding the conception of partner style to the breadth and content, not just the extent, of disclosure allows us to holistically capture partner decision style.

Third, we innovate the 'style' literature by extending the conceptualization of decision style to span multiple dimensions of the audit. Prior research conceptualizes auditor decision style with respect to audit fees (Taylor 2011) and audit quality (Gul et al. 2013) in isolation, not contemplating that partners' decision styles may affect a host of audit outcomes. We argue that partners' decisions on any one audit outcome do not happen in a vacuum; decisions about audit 
fees, audit effort and quality, adherence to time budgets and deadlines, and the contents of the audit report involve myriad trade-offs with varied consequences to the auditor's reputation, liability, compensation, and ability to attract and retain new clients. Each partner must consider these trade-offs within his or her complex incentive environment, the institutional context of their audit firm, and through the lens of their unique cognitive style comprising their individual experience, risk tolerance, and skepticism. Our holistic theory of partner decision making allows us to reach beyond identifying the existence of unique partner KAM reporting styles to understanding what those styles reveal about the partners' approach to other audit decisions and any trade-offs the partner may make. Collectively, our findings motivate future behavioral research investigating the decision process theory that we propose in our conceptual framework, while our holistic conceptualization and new measurement approach for partner KAM reporting style is useful to future archival research in the individual partner decision making space.

We proceed as follows. Section II contains our literature review and hypotheses. Section III articulates methods, Section IV discusses results, and Section V concludes.

\section{LITERATURE REVIEW AND HYPOTHESES}

\section{Institutional Background}

KAMs are audit report disclosures describing matters that are especially important to the audit due to their challenging nature, subjectivity, use of the auditor's professional judgement, and/or use of specialists (IAASB ISA 701). ${ }^{1} \mathrm{KAMs}$ do not serve to disclaim or change the auditor's opinion on the financial statements and are not a substitute for audit procedures necessary for achieving accurate financial reporting (IAASB ISA 701-4). KAM reports typically involve

\footnotetext{
${ }^{1}$ PCAOB Critical Audit Matter (CAM) standards are similar to those governing KAMs, and their recent implementation as of June 2019 is motivating further interest in understanding how these disclosures arise and how they affect users. For simplicity and because our sample comprises European data, we use the acronym KAMs throughout this paper. See Appendix A for examples of KAMs in our sample.
} 
detailed descriptions of significant risks, transactions, events, and/or estimates (IAASB ISA 7019) and are intended to provide decision-useful information about challenging audit areas by explaining the genesis of the KAM and how auditors addressed it (Gunn 2016; IAASB ISA 7012). The Financial Reporting Council (FRC) is an independent regulator in the UK that sets corporate stewardship codes of conduct and began requiring KAM-like 'risk of material misstatement' disclosures in the audit report effective September of 2013. The FRC adopted more formal KAM requirements following IAASB KAM standards effective June of 2017.

Existing research examining IAASB KAMs and PCAOB CAMs reaches mixed conclusions on whether and how expanded audit disclosures affect investor decision making, audit fees and quality, engagement dynamics, and auditor liability outcomes. Bédard et al. (2019), Gutierrez et al. (2018), and Liao, Minutti-Meza, Zhang, and Zou (2019) find that the introduction of expanded reporting regimes in France, the UK, and China, respectively have no effect on investor reactions, audit fees, audit report delay, or audit quality. Conversely, Lennox, Schmidt, and Thompson (2019) find that UK investors react to KAMs over long time horizons; Altawalbeh and Alhajaya (2019) find investor reactions to KAM reporting in Jordan; Reid et al. (2019) find that financial reporting quality in the UK increases after KAM reporting; and Li, Hay, and Lau (2019) find that KAM reporting in New Zealand is associated with increases in both audit fees and audit quality. Experimental studies indicate that auditor liability for subsequent restatements varies in the presence and subject area of KAMs (Kachelmeier et al. 2020; Brasel, Doxey, Grenier, and Reffett 2016), changes in KAMs disclosed from year to year (Vinson, Robertson, and Cockrell 2019), the nature of the misstatement (Kachelmeier et al. 2020), and the precision of accounting standards (Gimbar, Hansen, and Ozlanski 2016). With respect to auditor judgment and auditor-client relationship dynamics, Asbahr and Ruhnke (2019) 
find that auditors propose lower adjustments to accounts discussed in KAMs, Gay and $\mathrm{Ng}$ (2015) show that auditors may be more likely to accept management's reported estimate balances when KAM reporting is required, and Cade and Hodge (2014) find that management is less willing to share privately known information about estimates under expanded reporting.

\section{Do Partners Have Unique KAM Reporting Styles?}

Over the past decade, audit researchers have extended research showing the effects of audit firms and audit offices on various outcomes - especially audit quality - by examining the effects of observable audit partner characteristics on a host of audit outcomes (see Lennox and $\mathrm{Wu}$ [2018] for a review). For example, this literature suggests that fee premia for industry expertise previously characterized as an audit office-level phenomenon may instead be driven by expert partners (Goodwin and Wu 2014), and that individual partners differ in their reactions to economic bonding incentives as compared to office-level reactions (Chen et al. 2010). Research also shows that partners' past decisions affecting audit quality predict future outcomes. Knechel et al. (2015) show that partners' preferences for aggressive versus conservative going concern reporting and earnings management persist over time. Li, Qi, Gaoliang, and Zhang (2017) show that partners with a history of signing off on subsequently restated financial statements are more likely to continue to sign off on misstated financial statements in the future. Further studies show that partner decisions vary with demographics such as age (Goodwin and Wu 2016), gender (Hardies et al. 2014), specialization (Chi and Chin 2011), tenure and busyness (Carey and Simnett 2006; Ye et al. 2011; Sundgren and Svanström 2014), along with client economic importance (Chi, Douthett, and Lisic 2012) and client social ties (Firth, Rui, and Wu 2012).

While these studies investigate associations between observable partner characteristics (demographics, past audit opinions, fees) and audit outcomes, a second line of literature explores 
individual audit partner 'style'. We make an important distinction between these two research approaches. Studies of observable characteristics examine whether partners' membership in certain groups (e.g., gender, education, and willingness to allow client reporting aggressiveness) or position on a relative scale (e.g., fee premia or industry specialization) impacts audit outcomes. In contrast, the style literature allows for between-partner variation across partners who are otherwise identical on observable characteristics (Gul et al. 2013; Taylor 2011). As such, a partner's style encompasses both their observable and unobservable characteristics (e.g., expertise, cognition, and skepticism) important to predicting audit outcomes.

Existing style research finds that CEOs', CFOs', managers', and audit partners' individual styles predict outcomes in various settings after controlling for company characteristics. For example, Bertrand and Schoar (2003) show that individual CEO styles affect companies' investment, financial, and organizational policies, as well as performance. Dyreng, Hanlon, and Maydew (2010) demonstrate that managers possess identifiable tax avoidance styles, and Ge et al. (2011) reveal that CFOs have unique styles for selecting accounting policies. Bamber, Jiang, and Wang (2010) show that CFOs' distinct voluntary disclosure styles persist across multiple employers, and that CFO demographics explain less than 15 percent of the variation in disclosure style. Taylor (2011) illustrates that audit partners have unique profiles with respect to fee discounts and premia, and Gul et al. (2013) show that Chinese audit report signatories have individualized style effects on audit quality, with individual demographics explaining less than three percent of audit signatories' quality style.

Collectively, these literatures examining (a) the role of individual audit partner observable demographics and (b) the role of individual audit partner style on audit outcomes illustrate that, although many members of the engagement team take part in the audit, the lead 
engagement partner has a unique effect on its outcome. The behavioral literature provides insights into the mechanisms underlying these effects, showing that audit outcomes vary in partner leadership, knowledge, and expertise (Bedard and Johnstone 2010; Johnstone, Li, and Luo 2014; Chen, Trotman, and Zhou 2015; Dennis and Johnstone 2018). It is therefore appropriate to conceive of KAM reporting outcomes as reflecting the lead audit partner's individualized decision style while recognizing that several members of the engagement team aside from the signing partner, and especially the engagement review partner, likely contribute to the KAM reporting decision. We further note that lead audit partners have the greatest opportunity to exert individualized control over the KAM report as compared with other audit decisions because identifying and communicating KAMs is less time-intensive and more selfcontained than tasks related to broader audit outcomes, such as auditing the financial statement balances to achieve a particular level of quality. Finally, the prominent placement of KAMs in the audit report to which the lead audit partner signs their name incentivizes the partner's personal involvement to preserve their reputation and minimize their liability.

\section{A Conceptual Framework of Partner-level KAM Reporting Styles}

Based on these studies and the large body of behavioral research investigating partner decision making on various complex audit tasks (Bonner, Davis, and Jackson 1992; Christ 1993; Griffith, Hammersley, and Kadous 2015), we propose a conceptual framework depicting our views on the genesis of audit partners' unique decision styles (see Figure 1). We posit that audit partners make decisions by evaluating the facts and circumstances of individual client engagements, developing a mental representation of decision-relevant information, and making the decision, all within the context of the partners' institutional and incentive environments. We theorize that a given partner's unique decision style arises as the following factors exert their 
pervasive influence on the partner's decision process: (a) relevant expertise, (b) risk attitudes, (c) professional skepticism, (d) elements of the audit firm environment (e.g., culture, training and resources, guidance, and compensation policies), and (e) competing incentives (e.g., complying with audit standards, maximizing decision usefulness, and minimizing liability). ${ }^{2}$

\section{[INSERT FIGURE 1 ABOUT HERE]}

While archival research cannot directly observe these underlying factors influencing partners' general decision style, our theory conceptualizes KAM reporting style as providing a visible signal of a partner's profile, environment, and cognition along these dimensions. The KAM standards enable this type of signaling by requiring partners to describe, in their own words and in the high-visibility audit report with its myriad conflicting incentives, the most difficult applications of their professional judgment in the course of the audit. ${ }^{3}$ We therefore operationalize our conceptual framework of partner decision style by measuring partners' stable patterns for the number of KAMs they report, the diversity of topical areas their KAMs address, and how the partner communicates those KAMs in the audit report. ${ }^{4}$ Based on this theory, we make the following non-directional predictions:

\footnotetext{
${ }^{2}$ Extensive literature exists relating to these factors. For example, research reveals that knowledge develops through experience and is an important determinant of expertise (Bédard 1989; Bédard and Chi 1993; Libby and Luft 1993; Libby and Tan 1994; Ramsay 1994; Jamal and Tan 2001) and specialization (Solomon, Shields, and Whittington 1999; Balsam, Krishnan, and Yang 2003; Ferguson, Francis, and Stokes 2003; Francis, Reichelt, and Wang 2005; Chin and Chi 2009; Chi and Chin 2011; Zerni 2012; Ittonen et al. 2015) and that partners have stable individual differences in risk attitudes (Newton 1977; Lewis 1980), which affect various audit decisions (Johnstone and Bedard 2004; Klersey and Roberts 2010; Amir, Kallunki, and Nilsson 2014).

${ }^{3}$ Unlike other sections of the audit report, KAMs are "not expressed in standardized language," but must be "related directly to the specific circumstances of the entity" (FRC ISA 701 16-2). Anecdotal evidence from our discussions with partners reveals careful consideration about individual words in KAMs (e.g., "we're thinking a lot about precision and avoiding ambiguity, similar to guidance about agreed-upon-procedures where we can't use verbs with uncertain meanings or whose meanings would be confused with terms defined in auditing standards").

${ }^{4}$ To illustrate variation in audit partner style along these dimensions, consider two partners from our sample: Richard Porter and Ian Chambers. Both are partners in PwC's London office, each auditing three clients across three different industries during our sample period. Mr. Porter issues a total of 17 KAMs across five topical categories, while Mr. Chambers issues 39 KAMs across seven topical categories. Mr. Porter uses an average of 339 words to describe each KAM, with a readability index indicating 17 years of education is necessary to understand the report
} 
H1: Audit partners possess unique KAM reporting styles with respect to:

a. the number of KAMs in the audit report.

b. the diversity of KAM topics in the audit report.

c. communication of KAMs in the audit report.

Despite making these predictions, we note that certain features of the KAM reporting regime work against finding support for H1. First, KAMs are not designed to disclose information that the client company has not already made public (FRC ISA 701). The client's economic activities and disclosure choices are therefore closely tied to what will ultimately be reported as KAMs, which may leave little room for partners to develop unique KAM reporting styles. Second, audit firms aim to provide a homogenous level of audit quality across audit partners, employing central trainings, guidance, and organizational behaviors to standardize the audit product (Covaleski, Dirsmith, Heian, and Samuel 1998; Cooper and Robson 2006; Suddaby, Gendron, and Lam 2009). From an incentive perspective, there is widespread concern among stakeholders that audit firms will prefer boilerplate KAMs that minimize litigation risk and decision effort rather than encouraging individual partners to tailor their KAM judgments to the facts and circumstances of specific engagements. ${ }^{5}$ Anecdotal evidence reveals that some audit firms' central guidance contains lists of words that partners should consider including and excluding from their KAM reports, and that some firms require a central review of KAM reports before issuance. Audit firm-level style and reporting preferences may therefore subsume the space for partners to develop and express a unique KAM decision style.

and a Linguistic Inquiry Word Count (LIWC) cognitive complexity score of 11.79. Mr. Chambers uses an average of 319 words per KAM with a readability index of 19 and LIWC cognitive complexity score of 8.62.

${ }^{5} \mathrm{~A}$ PwC report on the implementation of KAM standards cautions that "forcing the pace of change might have adverse consequences - especially in litigious environments - and this could result in a retreat back to boilerplate ... If both companies and the profession do not see the benefits of the new reporting model, and approach the new reports as a necessary compliance exercise only, there is a very real risk of longer reports with simply more boilerplate language" (PwC 2014). 


\section{Implications of Partner-level KAM Reporting Styles for Audit Pricing, Report Timing, and Quality}

We next turn to investigating potential implications of partners' KAM reporting styles for their audit pricing, report timing, and quality. Recall from the conceptual framework in Figure 1 that an audit partner's KAM reporting decision style results from his or her relevant expertise, risk attitudes, professional skepticism, elements of the audit firm environment, and competing incentives; these factors are not unique to KAMs, but pervasive across a host of audit decisions. We therefore expect that KAM decision styles are associated with various audit outcomes not because of the effort involved in preparing the KAMs themselves, but because the same factors that shape a partner's unique KAM style will influence their ability to command fee premia and fee portfolio growth, conduct audits efficiently, and deliver high-quality outcomes.

Audit Fee Implications. We posit that partner styles reflecting a higher volume (number) and topical diversity of KAMs signal that the partner has: (1) the expertise necessary to consider a large volume and broad range of audit issues, and (2) the willingness to exert the effort required to do so. Prior literature outside the KAMs setting reveals that partners with greater expertise, as measured by their industry and public client specialization, are able to command fee premia (Goodwin and Wu 2014; Ittonen et al. 2015). Further, partner bids will often reflect anticipated incremental effort and risk (e.g., Bedard and Johnstone 2004; Johnstone, Bedard, and Ettredge 2004). We therefore predict that:

H2a: Audit partner KAM reporting styles with respect to volume and topical diversity are positively associated with audit fees.

The implications of partners' KAM communication styles for audit fees are less clear.

FRC 701-A34 summarizes the objective of communicating KAMs as to provide "a succinct and balanced explanation to enable intended users to understand why the matter was one of the most 
significance in the audit and how the matter was addressed." Therefore, longer KAMs with greater word counts may either demonstrate a partner's commitment to greater transparency or reveal a shortcoming in expressing the KAM in the succinct manner that the standard prescribes. Similarly, partners who report more readable KAMs may be construed as successful in "limiting the use of highly technical auditing terms" (FRC 701-A34), or as potentially oversimplifying the KAM such that the report user is not able to acquire a complete understanding of the audit issue. Likewise, partners communicating KAMs in language with more cognitive complexity may be characterized as either providing detailed and well-considered disclosure or as failing to "provide useful information in a concise and understandable form" (FRC 701-A34). We therefore propose the following non-directional prediction:

H2b: Audit partner KAM reporting styles with respect to communication are associated with audit fees.

Audit Delay Implications. With respect to the time it takes a partner to issue the audit report, we anticipate two competing possibilities. From one perspective, if an audit partner's unique style reflects a relatively higher volume and diversity of KAMs and a more complex communication style the partner may be expending more effort, possibly necessitating more time to complete the audit and issue the report (Krishnan and Yang 2009; Dao and Pham 2014; Habib 2015; Hussin, Nordin, Bamahros, and Shukeri 2018). Further, the partner's tendency to employ that incremental effort with respect to KAMs may signal that the partner exerts higher effort across other areas of the audit. From an opposing perspective, if an audit partner's style reflects greater KAM volume, diversity, and communication complexity it may be that the audit partner has greater expertise in complex audit decisions, which may yield efficiencies in the audit. We therefore make the following non-directional prediction: 
H2c: Audit partner KAM reporting styles with respect to volume, topical diversity, and communication are associated with audit report delay.

Audit Quality Implications. The relation between partners' KAM reporting styles and audit quality is likewise ambiguous. The IAASB posits that partners' attentional focus on matters to be communicated as KAMs could indirectly result in an increase in audit quality (IAASB 2015); this suggests that partners reporting a higher volume, wider topical range, and more detailed KAM disclosures signal a commitment and ability to deliver higher audit quality. Conversely, other stakeholders in the expanded audit reporting debate express concern that audit partners' discussions and negotiations with management over the content and wording of KAM reports will reduce the partners' negotiation capital with respect to audit adjustments (PCAOB 2017b). This suggests that partners reporting fewer, less-detailed KAMs may be deciding to focus their energies on constraining management discretion in the fair presentation of financial statement balances. We therefore make the following non-directional prediction:

H2d: Audit partner KAM reporting styles with respect to volume, topical diversity, and communication are associated with audit quality.

\section{METHODS}

\section{Sample Selection}

We examine KAMs in audit reports of London Stock Exchange companies with fiscal years ending from the first month of KAM disclosures (September 2013) through the most recent month with available financial data (March 2019). We employ KAMreg, an indicator variable equal to one for fiscal year-ends after June $15^{\text {th }} 2017$, to control for the effect of the change in the FRC's KAM reporting regulations to conform with IAASB KAM standards. We obtain data on KAM reporting outcomes, audit partner identities, and audit-related control variables from the Audit Analytics Europe database. We obtain corporate financial information from FactSet. We 
include only partners who sign at least five unique audit reports across at least two different clients during the sample period; the first criterion ensures a sufficient number of observations to observe the partner's unique KAM reporting style and reliably estimate a partner fixed effect, while the second allows us to disentangle the partner's style from the circumstances of each specific client. We require that an audit firm have at least three partners meeting this description to ensure that we can separate firm-level versus partner-level reporting styles. Our main analysis includes 2,819 company-year observations from 275 partners and 11 audit firms (see Table 1). ${ }^{6}$

[INSERT TABLE 1 ABOUT HERE]

\section{Empirical Design}

We present predictive validity frameworks (i.e., conceptual and operational-level models; Libby, Bloomfield, and Nelson 2002) summarizing our empirical approach to testing $\mathrm{H} 1$ and $\mathrm{H} 2$ in Figure 2. We follow the methodology in Bertrand and Schoar (2003) and Gul et al. (2013) to estimate individual audit partners' effects on KAM reporting after controlling for other potential explanatory factors. See Appendix B for detailed variable definitions. We estimate Model (1) using linear regression with high-dimensional fixed effects (Correia 2016):

KAM_Outcome ${ }_{i t}=\beta X_{i t}+\sum \sigma_{t}$ Year $_{t}+\sum \pi_{\mathrm{it}}$ Industry $_{\mathrm{it}}+\sum \lambda_{j}$ AuditFirm $_{j}+\sum \delta_{k}$ AuditPartner $_{k}+\varepsilon_{i t}$

where $i, t, j$, and $k$ index client engagements, fiscal years, audit firms, and partners, respectively.

\section{[INSERT FIGURE 2 ABOUT HERE]}

In our tests of KAM reporting volume, we operationalize the dependent variable KAM_Outcome as the number of KAMs in the audit report de-meaned by (i.e. minus) the

\footnotetext{
${ }^{6}$ Our results are robust to using a connected sample, in which only those audit firms connected by a partner moving between firms are included in the analysis to allow estimation of order-independent fixed effects and zero-centered fixed effect coefficients following Torres, Portugal, Addison, and Guimarães (2018) and Koester, Stomberg, Williams, and Xia (2020). We elect not to use a connected sample in our primary analysis because the order of partners nested within audit firms is not ambiguous and the connection requirement eliminates 30 percent of the observations, 30 percent of the partners, and 55 percent of the audit firms in our sample.
} 
industry-year average number of KAMs $\left(N u m \_K A M s \_d m\right) .{ }^{7}$ We measure the topical diversity of

KAMs with an industry-year weighted measure:

$$
\text { wtd_Diversity }=\sum_{\mathrm{c}=1}^{\mathrm{c}=9} I_{c} *\left(1-\text { percent of firms in the industry year for which } I_{c}=1\right)
$$

where ' $c$ ' indexes the following KAM topical categories: complex estimates, revenue

recognition, business combinations, taxes, inventory, internal control, financial statement

presentation and disclosure, compensation, and complex instruments and ' $\mathrm{I}$ ' is an indicator variable equal to one for firms receiving a KAM in category ' $c$ '. ${ }^{8}$

In our tests of KAM communication outcomes, we measure KAM length with the industry-year de-meaned number of words in the KAMs portion of the audit report divided by the number of KAMs reported (wrdsperKAM_dm). We measure readability of the KAM report with an industry-year de-meaned Gunning Fog index (Fog_dm); the Fog index estimates the years of education required to understand a written text (Loughran and McDonald 2016). ${ }^{9} \mathrm{We}$ use Linguistic Inquiry Word Count (LIWC; Tausczik and Pennebaker 2010), an algorithm for identifying words from psychologically meaningful categories, to infer the partner's unique

\footnotetext{
${ }^{7}$ We identify client industries using two-digit Standard Industrial Classification (SIC) codes.

${ }^{8}$ We develop the categories by aggregating the 64 narrow KAM topic descriptions available in Audit Analytics into 15 broad KAM categories. Appendix C contains our categorization scheme, as well as a count of the frequency of each narrow topic and broad category of KAMs. We exclude six categories related to infrequently occurring client circumstances (going concern, fraud risks, accounting changes and error corrections, compliance, expense reporting, and other) because including them would artificially deflate the diversity measure for partners who never face client circumstances where considering these types of KAMs is appropriate. The categories we include comprise 95 percent of the KAMs in our sample.

${ }^{9}$ We note Loughran and McDonald's (2016) criticisms of applying readability indices to financial documents. We believe that readability measures are appropriate to the KAM setting because standards encourage auditors to "provide a succinct and balanced explanation...limiting the use of highly technical auditing terms ... to enable intended users who do not have a reasonable knowledge of auditing to understand" (FRC 701-A34). Additionally, de-meaning by industry year removes the effect of common polysyllabic words on the readability measure. For example, R\&D-intensive industries often use the words 'intellectual property'. Readers will recognize and understand the term, but 'intellectual' has six syllables, which increases the Fog index. In this case, partners with portfolios containing R\&D-intensive clients would otherwise be inappropriately categorized as issuing lowreadability KAMs, even though report uses will understand the meaning. Appendix A illustrates variation in readability: Mr. Gibbons' KAM has a Fog index of 14.3, while Ms. Loizou's KAM has a Fog index of 24.6.
} 
thinking style from the language they use in their KAM reports. Our approach is based on the idea that "depth of thinking can vary between people and situations; certain words can reveal those differences" (Tausczik and Pennebaker 2010, pp. 35). Consequently, we use LIWC to examine linguistic cognitive complexity: "the extent to which someone differentiates between multiple competing solutions and the extent to which someone integrates among solutions" (Tausczik and Pennebaker 2010, p.p. 35). We employ four LIWC variables to measure the cognitive complexity of the KAMs portion of the audit report: the composite variable CogProc, and the component dimensions of Insight (e.g., "think", "know", "consider"), Cause (e.g., “because”, “effect”, “hence”), and Discrepancy (e.g., "should”, “would”, “could”) verbiage.

We de-mean all of the KAM_Outcome variables (i.e., volume, diversity, and communication) by industry-year averages to better identify the extent to which unique audit partner styles explain individualized KAM reporting outcomes, i.e., those that are not merely standard for the industry-year. We winsorize continuous variables at the $1^{\text {st }}$ and $99^{\text {th }}$ percentiles to avoid the potentially confounding effects of influential observations. We cluster on client company to address the possibility of serial correlation. ${ }^{10} \Sigma$ Year, $\Sigma$ Industry, $\Sigma$ Audit Firm, and $\Sigma$ Audit Partner are sets of indicator variables we use to implement the fixed effects of interest. We add $\Sigma$ Audit Firm and $\Sigma$ Audit Partner to the base Model (2) sequentially to analyze the incremental effect of audit firms and partners on explaining KAM outcomes:

$$
\text { KAM_Outcome }{ }_{i t}=\beta X_{i t}+\Sigma \sigma_{t} \text { Year }_{t}+\sum \pi_{\mathrm{it}} \text { Industry }_{\mathrm{it}}+\varepsilon_{i t}
$$

where $X_{i t}$ denotes a vector of control variables encompassing features of clients and auditors. We draw on previous investigations of KAM determinants (Sierra-García, Gambetta, García-Benau,

\footnotetext{
${ }^{10}$ Following Cameron and Miller (2015) we do not cluster on any of the variables for which we estimate fixed effects because the fixed-effect groups do not have balanced sample sizes and doing so could therefore result in biased standard errors.
} 
and Orta-Pérez 2019; Pinto and Morais 2019), to select controls for client complexity (Size, Subs), and performance (ROA, Sales_Vol, Leverage, BTM, Loss). We also control for economic activities of the client that are likely to give rise to KAM-reportable accounting items. These include indicators for acquisitions (Acq) and external financing (Fin_Issue), and continuous measures for the intensity of revenue $(R e v)$, inventory and accounts receivable (Inv_AR), goodwill and intangibles (GW_Intan), pension liabilities (Pension), PPE, tax volatility (Tax_Vol), various impairments (GW_Impair, Intan_Impair, PPE_Impair), research and development (RD_Exp), investments (Invest), and legal liabilities (Legal_Liability). We include industry fixed effects to capture complex accounting issues and significant activities common to specific industries. We include year fixed effects to control for macroeconomic conditions.

We choose to include coarse controls for client economic circumstances rather than client fixed effects because client fixed effects can lead to false-positive findings of individual decision maker style by overcontrolling for similarities in clients that choose to hire similar individuals (Fee, Hadlock, and Peirce 2013). In the context of manager style effects, Fee et al. (2013) describe this phenomenon as follows: "correlated firm-level policy choice biases across multiple employers ... suggests that experiences matter in the selection of corporate leaders and that styles developed by working in certain environments are relevant for working in similar new environments" (Fee et al. 2013, p. 570). As a result, relying on coarser client control variables rather than client fixed effects mitigates endogeneity risks to the extent that clients similar on these controls demand auditors with similar reporting styles. Our findings of individual partner reporting styles are robust to including client fixed effects.

With respect to the auditor, $X_{i t}$ controls for fees $\left(L o g \_A u d \_F e e\right)$, which measure both auditor effort and the auditor-client economic bond (DeFond and Zhang 2014). We control for 
Big4 firm membership in Model (2), and remove the control after adding the audit firm fixed effect to avoid perfect collinearity. We control for audit partner busyness (Ptr_Busyness) with the log of the number of public clients the partner audits each year (Ittonen et al. 2015). We include an indicator variable equal to one if the client has a December year-end (DecYrEnd), following Reid et al. (2019). We control for the economic ties between the auditor and client with the percent of total fees attributable to the client at the audit firm (AudFirm_Econ_Bond), and audit partner (AudPtr_Econ_Bond) level. Similarly, we measure industry specialization (Ind_Spec) as the percent of total audit fees generated from the client industry at (1) the audit firm level, and (2) the audit partner level. We include year fixed effects to control for the effects of increasing partner experience with KAM reporting in later sample years.

H1 anticipates that partners have unique KAM reporting styles with respect to KAM volume, diversity, and communication outcomes. We test $\mathrm{H} 1$ with a battery of tests examining whether the partner fixed effects in Model (1) meaningfully explain KAM outcomes as compared to a model with control variables and audit firm, industry, and year fixed effects only:

$$
\text { KAM_Outcome }{ }_{i t}=\beta X_{i t}+\Sigma \sigma_{t} \text { Year }_{t}+\sum \pi_{\mathrm{it}} \text { Industry }_{\mathrm{it}}+\sum \lambda_{j} \text { AuditFirm }_{j+} \varepsilon_{i t}
$$

To test the significance of partner fixed effects, we first implement an exclusion restriction $(F$ test) examining whether all partners' fixed-effect indicator variables jointly increase explanatory power (Wooldridge 2012, pp. 143-149). Second, we calculate the incremental change and percentage change in the adjusted $\mathrm{R}^{2}$ from adding partner fixed effects to Model (3). Third, we calculate the Vuong (1989) likelihood statistic to test whether the change in $\mathrm{R}^{2}$ from including partner fixed effects is statistically significant. Finally, we calculate the percentage of individual partners whose fixed effects are significant at a $p \leq 0.05$ level and compare this to the five 
percent tolerable error rate; incidences of significant partner fixed effects in excess of five percent are unlikely to be driven by random error. ${ }^{11}$

We test $\mathrm{H} 2 \mathrm{a}$, that partner KAM reporting styles with respect to volume and diversity are positively associated with fees, and $\mathrm{H} 2 \mathrm{~b}$, that communication style is associated with fees, using the following linear regression:

$$
\text { Fee_Outcome }=\alpha_{i t}+\beta \text { Style }_{k}+\beta \mathrm{V}_{i t}+\varepsilon_{i t}
$$

Following Gul et al. (2013), we measure partners' Style as the $\delta_{k}$ coefficient on the partner fixed effect in Model (1) for each of the operational measures of the KAM_Outcome dependent variable. ${ }^{12} \delta_{k}$ captures a partner's propensity to report higher volume (Volume_Style), more topically diverse (Diversity_Style), longer (CommStyle_Words), and less readable KAMs (CommStyle_Fog), with cognitively complex (CommStyle_CogProc), insight (CommStyle_Insight), causal (CommStyle_Cause), and discrepancy verbiage (CommStyle_Discrep). $\delta_{k}$ measures partners' stable styles across clients and reporting years after controlling for client economics, features of the engagement, industry, year, and the idiosyncratic influence of the audit firm. This fixed-effects approach is able to capture partners' decision styles separate from client-driven factors because our requirement that a partner issue at least five opinions across at least two clients to be included in the sample means that the fixed effect

\footnotetext{
${ }^{11}$ We recognize that Fee et al. (2013) criticize using a fixed-effect approach to detect idiosyncratic CEO styles because CEO turnover events are likely endogenous, occurring when the board of directors wishes to make broader changes to the company's direction, making it appear that the incoming CEO has an especially distinct style. Our setting avoids this issue because a company does not have to switch auditors to be in our sample; we separate auditor styles from client-company styles using observations from the auditor's other clients. Mandatory audit partner rotation in the UK means that many partner changes are exogenous, and a minimum acceptable level of auditor independence means that a client cannot choose the number, topics, and language of the KAMs they receive in the audit report by changing audit firms or audit partners. We address Fee et. al.'s econometric concerns about the reliability of $F$-tests for non-asymptotic fixed effect group sizes by supplementing our analysis with the calculation of the Vuong $\chi^{2}$ statistic, the change in $\mathrm{R}^{2}$, and incidence of significant fixed effects.

${ }^{12}$ We operationalize style in Model (4) using partners' fixed-effect coefficients $\delta_{k}$ from a modified version of Model (1) that excludes the fee related control variables Log_Aud_Fee, auditor industry specialization (Ind_Spec), and auditor-client economic bond (Econ_Bond) to avoid inducing a mechanical relation between Style and fees.
} 
coefficients for partners whose styles are inconsistent across clients will attenuate towards zero and tend towards statistical insignificance.

We operationalize the partners' fee outcomes in terms of their current engagement-year fee $\left(\log _{-} A u d_{\_} F e e_{i t}\right)$ and their status as a fee growth leader in their client industry (IndFeeGrwthLdr) and audit firm (AudfirmFeeGrwthLdr), which we measure with indicator variables set equal to one if the partner is in the top decile for fee growth as compared with all other partners in the same client industry and audit firm, respectively, where:

$$
\text { FeeGrowth }_{k t}=\left[\left(\frac{\sum \text { Fees }_{k t}-\sum F e e s_{k t-1}}{\sum F e e s_{k t-1}}\right)+\left(\frac{\sum \text { Fees }_{k t-1}-\sum F e e s_{k t-2}}{\sum F e e s_{k t-2}}\right)\right]
$$

$\mathrm{V}_{\text {it }}$ is a vector of control variables related to client complexity, financial risk, and auditor characteristics that are common fee determinants (Carcello and Li 2013; Gutierrez et al. 2018).

We test $\mathrm{H} 2 \mathrm{c}$, that partner KAM reporting styles for volume, diversity, and communication are associated with audit delay, using the following linear regression:

$$
\text { Audit_Delay }{ }_{i t}=\alpha_{i t}+\beta \text { Style }_{k}+\beta \mathrm{U}_{i t}+\varepsilon_{i t}
$$

where Audit_Delay is the number of days between the client's fiscal year end and the signature date of the audit report, $\mathrm{U}$ is a vector of control variables relevant to determining delay (Reid et al. 2019), and all other variables are as we define above.

We test $\mathrm{H} 2 \mathrm{~d}$, that partner KAM reporting styles for volume, diversity, and communication are associated with audit quality, using the following linear regression:

$$
A b s A c c_{i t}=\alpha_{i t}+\beta \text { Style }_{k}+\beta \mathrm{W}_{i t}+\varepsilon_{i t}
$$


where $A b s A c c_{i t}$ is the absolute value of total current accruals. ${ }^{13}$ Our control variables, $\mathrm{W}_{i t}$, include Size, Leverage, ROA, Loss, OCF, Big4, BTM, lagged AbsAcc, Fin_Issue, Sales_Vol, and Rev, following Gul et al. (2013), Guiterrez et al. (2018), and Carcello and Li (2013).

\section{RESULTS}

\section{Descriptive Statistics}

Table 2, Panel A presents descriptive statistics. Auditors in our sample report a mean of 2.84 KAMs per audit opinion, with the average KAM possessing a Fog Index of 18.45 and comprising 289.53 words. On average, KAM reports have a Linguistic Inquiry Word Count (LIWC) aggregate cognitive processing complexity score of 10.52, with 4.51 percent, 2.72 percent, and 0.48 percent of verbiage from the insight, causal, and discrepancy component dimensions, respectively. Regarding other (non-KAM) audit outcomes, the mean engagement fee equals about one million US dollars. The mean Audit_Delay is 74.12 days, and the average absolute value of current accruals $(A b s A c c)$ comprises 6 percent of total assets.

\section{[INSERT TABLE 2 ABOUT HERE]}

With regard to client-related control variables, mean client SIZE (antilog) equals $\$ 4,331$ million in total assets and mean $R O A$ equals 4.0 percent. About 29 percent of sample companies report investments in unconsolidated subsidiaries, and 23 percent report a Loss. With respect to estimate and risk-intensive activities likely to give rise to KAMs, we find that revenues, inventory and accounts receivable, goodwill and intangibles, and pension benefit obligations comprise a mean of $60,13,15$, and 15 percent of total assets, respectively.

\footnotetext{
${ }^{13}$ We measure accruals quality with the absolute value of current accruals rather than a residuals-based discretionary accruals measure because Chen, Hribar, and Melessa (2018) warn of statistical bias when using residuals-based measures as dependent variables in second-stage regression models. Our findings for $\mathrm{H} 2 \mathrm{~d}$ are robust to operationalizing audit quality as signed current accruals, the absolute value of working capital accruals, and indicator variables equal to one if the client has a small profit $(\leq \$ 0.01)$ or a small earnings increase $(\leq \$ 0.01)$.
} 
Auditor-related control variables show that Big4 auditors comprise 79 percent of our sample, 45 percent of clients have a December year-end, and the typical partner audits 2.9 publicly-traded clients a year. At the partner level, audit fees are typically 58 percent concentrated in the audit partners' industry specialty and 37 percent concentrated in any given client. Audit firms typically obtain seven percent of their audit fees from any one industry (Audfirm_Ind_Spec) and one percent of their total fees from any one client (Audfirm_Econ_Bond). Forty-four percent of engagements have a fiscal year-end after June 15, 2017, and 83 percent of clients are traded on the LSE Main Market. Partner demographic characteristics reveal that 15 percent of the sample are female, 23 percent ( 26 percent) have an advanced degree (were an accounting major), and 84 percent have BigN experience. Thirty-three percent (13 percent) of partners have spent time on an international (client) secondment. Sixtyfive percent are practice leaders, and the mean years of experience is 27.5.

Table 2, Panel B presents correlations between KAM reporting and audit outcomes (fees, delay, and quality). This bivariate analysis allows us to understand whether these variables measure different dimensions of the partners' decision styles as we intend, rather than being highly correlated. We find correlations that are significant at $p \leq 0.05$ from a low of $\mathrm{r}=-0.0419$ $\left(N u m \_K A M s \_d m\right.$ and $\left.A b s A c c\right)$ to a high of $\mathrm{r}=0.6795($ CogProc_dm and Insight_dm $)$; the latter is as expected given that insight language is one dimension of overall cognitive complexity. We find that the average significant correlation takes on an absolute value of $r=0.1605$, implying that the operational variables measure partners' decisions along multiple distinctive dimensions. Predicting KAM Volume, Topical Diversity, and Communication

We present the results of estimating Models (1), (2), and (3) in Table 3. Panel A reports results for KAM volume, Panel B for topical diversity, and Panels C-E for communication 
(wrdsperKAM_dm, Fog_dm, and Cogproc_dm). In each panel, we show how the explanatory power (adjusted $\mathrm{R}^{2}$ ) changes across three regression specifications: (a) the base Model (2) comprising only control variables and industry-year fixed effects, (b) the addition of audit firm fixed effects (Model 3), and (c) the addition of partner fixed effects (Model 1). We present the results in this manner to illustrate how the introduction of partner-level style effects impacts our ability to understand and predict KAM reporting outcomes.

With respect to directional associations between the control variables and our KAM outcomes of interest, Panel A shows positive relations between KAM volume (Num_KAMs_dm) and losses, acquisition activity, pension obligations, audit fees, and partner and audit firm industry specialization; in contrast, PPE impairments, investing activities, and the partner-client economic bond are negatively associated with $N u m \_K A M s \_d m$. Panel B reports results for KAM topical diversity (wtd_Diversity), revealing a positive association with acquisition activity, inventory and receivables intensity, goodwill and intangibles, audit fees, audit partner industry specialization, and operating cash flows; sales volatility and a December 31 year-end are negatively associated with wtd_Diversity.

\section{[INSERT TABLE 3 ABOUT HERE]}

Concerning KAM communication outcomes, Panel $\mathrm{C}$ reveals a positive association between the length of the KAMs (wrdsperKAM_dm) and the book-to-market value of stock, goodwill impairments, audit fees, a December 31 year-end, partner- and audit firm-client economic bond, and stock that is traded on the LSE Main Market; acquisition activity, pension obligations, and tax-rate volatility are negatively associated with wrdsperKAM_dm. Panel D shows sales volatility, investing activities, audit fees, audit firm industry specialization and stock that is traded on the LSE Main Market are associated with less readable KAMs (higher Fog_dm); 
total assets, revenue growth, goodwill impairments, audit partner industry specialization, audit firm-client economic bond, partner busyness, and Big 4 membership are associated with more readable KAMs (lower Fog_dm). Finally, Panel E shows that the linguistic cognitive complexity of the KAM section of the audit report (CogProc_dm) is positively associated with sales volatility, goodwill and intangibles, pension obligations, audit fees, and operating cash flows and negatively associated with size, losses, the audit firm-client economic bond, and Big 4 audit firm.

\section{Tests of H1: Audit Partners' Unique KAM Reporting Styles}

We present the results of testing $\mathrm{H} 1$ in Table 4. Panel A reveals that audit partner fixedeffect indicators are important to explaining KAM volume, diversity, length, readability, and cognitive complexity of the KAM verbiage in aggregate (cogproc_dm) and along the component dimensions of insight, cause, and discrepancy verbiage. F-statistics testing whether the partner fixed effects jointly increase predictive power range from a low of 7.97 (CogProc_dm; $p=$ 0.000 ) to 9.92 (Discrep_dm; $p=0.000$ ). We find that adding partner fixed effects to a model with audit firm fixed effects increases the adjusted $\mathrm{R}^{2}$ of the regressions by between 11 and 22 percent, yielding a 28 to 380 percent improvement in predictive power. We test whether these changes in explanatory power are statistically significant using the Vuong (1989) Chi-squared test, finding statistical significance at the $p \leq 0.01$ level for all of our KAM outcome measures. Finally, we count the number of partners whose fixed-effect coefficients are significant at the $p \leq$ 0.05 level and divide that number by the total partners in the sample. We find that between 15 and 38 percent of partners in our tests have significant fixed-effect coefficients, well exceeding the five percent rate we would expect due to random error. Collectively, these results support H1 by showing that unique partner style effects significantly explain KAM outcomes.

[INSERT TABLE 4 ABOUT HERE] 
Table 4, Panel B presents the results of using the same fixed-effects approach to test whether audit firms have unique effects on KAM outcomes. We find that audit firm fixed effects are important to predicting KAM outcomes for volume, diversity, and communication, with Fstatistics significant at the $p \leq 0.01$ level and an incidence of significant fixed-effect coefficients ranging from 20 to 70 percent (well in excess of the five percent tolerable error rate). We find that adding audit firm fixed effects to the base Model (2) with control variables and industry-year fixed effects yields a two to five percent increase in adjusted $\mathrm{R}^{2}$ and a nine to 186 percent improvement in explanatory power, with Vuong statistics significant at the $p \leq 0.01$ level. Collectively, this evidence suggests that audit firms possess unique KAM reporting styles, but that firm-level styles are less important to predicting outcomes than partner-level styles.

\section{Tests of H2: The Association Between Partner KAM Reporting Styles and Other Audit Outcomes}

$\mathrm{H} 2$ predicts that partner KAM reporting styles are associated with audit fees, fee growth, audit delay, and audit quality. Table 5, Panel A shows a positive association between Log_Aud_Fees and Volume_Style $(\beta=0.072, p \leq 0.01)$, Diversity_Style $(\beta=0.203, p \leq 0.01)$, CommStyle_Words $(\beta=0.001, p \leq 0.10)$, CommStyle_Fog $(\beta=0.027, p \leq 0.10)$, and CommStyle_Insight $(\beta=0.058, p \leq 0.01)$ and a negative association with CommStyle_Cause $(\beta=$ $-0.043, p \leq 0.10$ ). Collectively, this implies that the underlying factors driving a partner to develop a decision style for reporting more KAMs, more topically diverse KAMs, longer KAMs, more complexly written KAMs, and KAMs with more insight verbiage are associated with that partner's ability to command higher fees. Conversely, a partner's style for including more causal explanation in their KAMs is marginally negatively associated with their ability to command fee premia. In economic terms, we find that partners in the uppermost quintile of Volume_Style charge 11 percent higher fees, partners in the uppermost quintile of Diversity_Style charge 7.6 
percent higher fees, partners in the uppermost quintile of CommStyle_Wrds charge 9.7 percent higher fees, and partners in the uppermost quintile of CommStyle_Insight charge 12 percent higher fees than their counterparts. In contrast, partners in the lowest quintile of CommStyle_Cause command 11.5 percent higher fees.

\section{[INSERT TABLE 5 ABOUT HERE]}

In Table 5, Panels B and C we examine the association between partners' KAM reporting styles and their status as fee growth leaders in their audit firm (AudFirmGrwthLdr) and in the client's industry (IndGrwthLdr), respectively. In Panel B, we show that partners who issue KAMs with more cognitively complex, causal, and insight verbiage are more likely to be audit firm fee growth leaders, while partners who issue longer KAMs are less likely to have that status. In economic terms, partners in the uppermost quintiles of CommStyle_CogProc, CommStyle_Insight, and CommStyle_Cause are 6.5 percent, 3.4 percent, and 8 percent more likely to be firm fee growth leaders, respectively. In Panel C, we find that industry fee growth leader partners are more likely to issue a higher volume, more topically diverse, and shorter KAMs containing more cognitive processing, insight, and causal explanation verbiage. In untabulated results, we find that partners using more discrepancy language are less likely to be industry fee growth leaders. Collectively, Table 5 Panels A-C provide support for H2a and H2b.

We present the results of testing the association between KAM reporting style and audit delay (H2c) and audit quality (H2d) in Table 5, Panels D and E. We find no significant associations between any dimension of partner KAM reporting style (volume, diversity, and communication) and either audit delay or audit quality, thereby failing to support $\mathrm{H} 2 \mathrm{c}$ or $\mathrm{H} 2 \mathrm{~d}$. These results imply that a partner's decision style in producing more comprehensive KAM reports does not inhibit his or her audit efficiency or ability to deliver a high-quality audit 


\section{Supplemental Tests}

Audit Partner Demographic Characteristics. Our conceptual framework proposes that partners' unique decision styles arise out of unobservable variation in expertise, risk attitude, skepticism, and institutional/incentive environments. We address the alternative explanation that demographic, rather than unobservable, factors drive partners' KAM reporting styles using the following OLS regression:

$$
\text { Style }_{k}=\alpha_{k}+\beta Z_{k}+\varepsilon_{k}
$$

where $Z$ is a vector of partners' demographics and $\varepsilon_{k}$ is the error term. We hand-collect demographic data from partners' publicly available LinkedIn pages, audit firm profiles, and audit firm press releases; of the 275 partners in our main sample, 161 have available data. We present the results for Model (7) in Table 6. We find that partners' style for KAM volume is positively associated with having an advanced degree, while partners' style for topical diversity is positively associated with having been an accounting major and is negatively associated with Big $\mathrm{N}$ experience. With respect to partner communication styles, we find that Big $\mathrm{N}$ experience is associated with partners' styles for greater readability (lower values of CommStyle_Fog), greater use of cognitively complex (CommStyle_CogProc) and causal (CommStyle_Cause) verbiage, and less use of insight verbiage (CommStyle_Insight). We find that international secondments are positively associated with styles for using more cognitively complex and cause verbiage. The adjusted $\mathrm{R}^{2}$ values reveal that observable demographics explain from one to 22 percent of partners' KAM reporting styles, implying that unobservable characteristics such as those in our conceptual model explain the remaining 78 to 99 percent of unique decision style. Further, the demographics most associated with reporting style (experience and education) are those most likely to affect KAM outcomes through their effect on partners' decision approaches. 


\section{[INSERT TABLE 6 ABOUT HERE]}

\section{Exogenous Audit Partner Rotations}

Given the endogeneity of partner-client matching, there exists a risk that our findings of partners' unique KAM reporting styles confound client demand idiosyncrasies with audit partners' unique decision processes. To address this concern, we repeat our tests of H1 (Table 4) in a subsample of partners with at least one exogenous partner rotation during the sample period. ${ }^{14}$ We identify exogenous partner rotations as those instances in which: (1) the audit partner changed, (2) the audit firm did not change, and (3) the audit client experiences only one such change during the 7-year sample period. These requirements yield 258 rotation events for 149 partners across eight audit firms. ${ }^{15}$ In untabulated analyses, we find that these 'exogenous rotation partners' have unique reporting styles, with fixed effects that improve adjusted $\mathrm{R}^{2}$ from seven to 20 percent over the audit firm fixed effects Model (3) with F-statistics and Vuong $\chi^{2}$ statistics significant at the $p \leq 0.01$ level and incidences of significant fixed effects in excess of five percent for all KAM outcome variables. The robustness of our results to this subsample rules out the alternative explanation that our finding of unique partner KAM reporting styles is due to client demand idiosyncrasies rather than individual differences in partner decision making.

\section{Falsification Test of Hypothesis 1}

We address the econometric concern that estimating large numbers of fixed effects with small within-group sample sizes may drive false positive findings of significant individual effects with a falsification test of H1 (Fee et al. 2013). Following Dyreng et al. (2010) and Gul et

\footnotetext{
${ }^{14}$ During our sample period the UK was subject to a European Union regulation requiring mandatory audit partner rotations every seven years (Cameran, Negri, and Pettinicchio 2015).

${ }^{15}$ Once we identify a partner as involved in a rotation event, we utilize their remaining engagements to allow a sufficient number of observations to reliability estimate partner fixed effects, resulting in a total of 1,796 observations across the 149 partners.
} 
al. (2013), we re-estimate Model (1) by randomly shuffling partners to match with clients that they did not actually audit. We repeat this random shuffling 1,000 times and compare the distribution of the F-statistics, Adjusted $\mathrm{R}^{2}$, and incidence of partner fixed-effect coefficients significant at the $p \leq 0.05$ level from the randomized data to our actual findings. In untabulated results, we find that the incidence of significant partner fixed-effect coefficients in the randomized data is similar to the five percent level expected due to random error; in contrast, our actual findings reveal that between 16 and 38 percent of partners take on significant fixed effect coefficients (see Table 4). Further, we find that the adjusted $\mathrm{R}^{2}$ for the actual data is higher than the maximum adjusted $\mathrm{R}^{2}$ in all of the 1,000 randomized simulations. Finally, we find that the Fstatistics on the actual data are 4.4 to 5.5 times higher than the average F-statistics from the 1,000 random simulations. Collectively, these results confirm that our findings of significant individual partner effects in the real data is attributable to partners' unique reporting styles rather than econometric misspecification.

\section{CONCLUDING REMARKS}

We demonstrate that audit partners have unique KAM reporting styles with respect to the number of KAMs they issue in their audit reports, the topical diversity of those KAMs, and the manner in which they communicate the KAMs; further, these styles are associated with partners' audit fees and fee growth within their client portfolios. We show that partners with styles for using more cognitively complex, insight, and causal KAM verbiage are more likely to be fee growth leaders in both their client industries and audit firms. These results are consistent with our conceptual framework, which predicts that partners' unique expertise, risk attitudes, skepticism, cognition, and institutional and incentive environments drive between-partner heterogeneity in decision making across a host of audit outcomes. We find no association 
between partners' KAM styles and audit delay or audit quality, suggesting that partners with the ability to consider a wide number of diverse KAM issues and communicate them in a thoughtful manner are able to do so without sacrificing audit efficiency or effectiveness.

Our study offers several unique contributions. First, revealing that partners have unique KAM reporting styles contributes to the conflicting literature on whether KAMs impact audit outcomes and investor decision making. Our results suggest that these outcomes vary based upon the unique decision styles of individual audit partners rather than varying based on the presence or absence of KAM disclosures in the audit report. Second, we provide evidence relevant to regulators' concerns that KAMs may become boilerplate at the audit firm level by demonstrating that individual partners from the same firms exhibit stable heterogeneities with respect to KAM outcomes. Next, we extend the literature on partner reporting style to a setting that allows us to directly observe partner decisions (KAMs) across a wide variety of companies. In contrast, prior literature on partners' audit quality styles uses indirect measures of earnings quality that confound audit and financial reporting quality, while extant research on partner reporting style focuses on clients with going concern or modified opinions, which are difficult to generalize to the average client company and do not provide insights on partners' communication styles due to the standardized language of those opinions. Finally, we extend the extant literature's conceptualization of style by demonstrating that partner style on one audit outcome (KAMs) is tied to other outcomes (audit fees and fee growth) based on our theory that the underlying factors that drive partners' decision approaches are not unique to any one audit decision, but have a pervasive influence across various audit outcomes. Future research might consider whether partner KAM style is associated with outcomes such as client satisfaction and audit firm turnover/tenure and the nature or extent of KAM-related litigation. 
We acknowledge several limitations to our research approach. First, we note that our sample does not allow us to directly observe whether the factors in the conceptual framework do, in fact, drive our findings that partners have unique KAM reporting decision styles. We address two alternative explanations with our demographic and exogenous rotation tests, but acknowledge that this does not rule out other possibilities. We leave it to future experimental and qualitative research to test the mechanisms that give rise to partners' unique KAM reporting styles. Second, we recognize that the statistical necessities requiring that a partner be present in at least five observations from two clients and that an audit firm have at least three partners meeting this description may bias our sample towards larger audit firms and partners with larger client portfolios. Finally, we note that our measures of partner KAM reporting styles speak only to relative differences among partners. Auditing standards do not specify what constitutes a 'good' KAM report in terms of volume, topical diversity, or length, so we make no claims as to the relative superiority of any particular partner style in complying with standards.

There exist a host of opportunities for future research relating to heterogeneity in KAM reporting styles that can extend our study. One relates to recent Critical Audit Matter (CAM) reporting in the United States. CAM data will enable future research to examine audit officelevel effects, which are impossible to detect in our study given limited audit office dispersion for companies listed on the London Stock Exchange. Another relates to exploring differences in audit procedures, reporting styles, and reporting outcomes based upon heterogenous litigation regimes and regulatory requirements of IAASB/FRC KAMs versus PCAOB CAMs. Finally, future research might fruitfully inquire as to audit partner and audit firm reactions to situations in which KAM reporting is subsequently revealed as inadequate or inaccurate. 


\section{REFERENCES}

Altawalbeh, M. A. F., and M. E. S. Alhajaya. 2019. The investor reaction to the disclosure of key audit matters: Empirical evidence from Jordan. International Business Research 12 (3): 50-57.

Amir, E., J.-P. Kallunki, and H. Nilsson. 2014. The association between individual audit partners' risk preferences and the composition of their client portfolios. Review of Accounting Studies 19 (1):103-133.

Asay, H. S., R. Libby, and K. Rennekamp. 2018. Firm performance, reporting goals, and language choices in narrative disclosures. Journal of Accounting and Economics 65 (2): 380-398.

Asbahr, K., and K. Ruhnke. 2019. Real effects of reporting key audit matters on auditors' judgment and choice of action. International Journal of Auditing 23 (2):165-180.

Balsam, S., J. Krishnan, and J. S. Yang. 2003. Auditor industry specialization and earnings quality. Auditing: A Journal of Practice \& Theory 22 (2):71-97.

Bamber, L., J. Jiang, and I. Wang. 2010. What's my style? The influence of top managers on voluntary corporate financial disclosure. The Accounting Review 85 (4): 1131-62.

Bédard, J. 1989. Expertise in auditing: Myth or reality? Accounting, Organizations and Society 14 (1): 113-131.

Bédard, J., and M. T. H. Chi. 1993. Expertise in auditing. Auditing: A Journal of Practice \& Theory 12 (2): 21-45.

Bédard, J., N. Gonthier-Besacier, and A. Schatt. 2019. Consequences of expanded audit reports: Evidence from the justifications of assessments in France. Auditing: A Journal of Practice \& Theory 38 (3): 23-45.

Bedard, J. C., and K. M. Johnstone. 2004. Earnings manipulation risk, corporate governance risk, and auditors' planning and pricing decisions. The Accounting Review 79 (2): 277304.

Bedard, J. C., and K. M. Johnstone. 2010. Audit partner tenure and audit planning and pricing. Auditing: A Journal of Practice \& Theory 29 (2): 45-70.

Bertrand, M., and A. Schoar. 2003. Managing with style: The effect of managers on firm policies. Quarterly Journal of Economics 118 (4): 1169-1208.

Bonner, S. E., J. S. Davis, and B. R. Jackson. 1992. Expertise in corporate tax planning: The issue identification stage. Journal of Accounting Research 30: 1-28.

Brasel, K., M. M. Doxey, J. H. Grenier, and A. Reffett. 2016. Risk disclosure preceding negative outcomes: The effects of reporting critical audit matters on judgments of auditor liability. The Accounting Review 91 (5): 1345-1362.

Cade, N., and F. Hodge. 2014. The effect of expanding the audit report on managers' communication openness. Working Paper.

Cameron, A. C., and D. L. Miller. 2015. A practitioner's guide to cluster-robust inference. Journal of Human Resources 50 (2):317-372.

Carcello, J. V. C., and C. Li. 2013. Costs and benefits of requiring an engagement partner signature: Recent experience in the United Kingdom. The Accounting Review 88 (5): 1511-1546.

Carey, P., and R. Simnett. 2006. Audit partner tenure and audit quality. The Accounting Review 81 (3): 653-676. 
Chen, W. E. I., P. Hribar, and S. Melessa. 2018. Incorrect inferences when using residuals as dependent variables. Journal of Accounting Research 56 (3): 751-796.

Chen, S., S. Y. J. Sun, and D. Wu. 2010. Client importance, institutional improvements, and audit quality in China: An office and individual auditor level analysis. The Accounting Review 85 (1): 127-158.

Chen, X. C., K. T. Trotman, and F. H. Zhou. 2015. Nominal versus interacting electronic fraud brainstorming in hierarchical audit teams. The Accounting Review 90 (1): 175-198.

Chi, H.-Y., and C.-L. Chin. 2011. Firm versus partner measures of auditor industry expertise and effects on auditor quality. Auditing: A Journal of Practice \& Theory 30 (2): 201-229.

Chi, W., E. B. Douthett, and L. L. Lisic. 2012. Client importance and audit partner independence. Journal of Accounting and Public Policy 31 (3): 320-336.

Chin, C.-L., and H.-Y. Chi. 2009. Reducing restatements with increased industry expertise. Contemporary Accounting Research 26 (3): 729-765.

Christ, M. Y. 1993. Evidence on the nature of audit planning problem representations: An examination of auditor free recalls. The Accounting Review 68 (2): 304-322.

Cook, J., Z. T. Kowaleski, M. Minnis, A. Sutherland, and K. M. Zehms. 2020. Auditors are known by the companies they keep. Journal of Accounting and Economics 69 (2-3): 118.

Cooper, D. J., and K. Robson. 2006. Accounting, professions and regulation: Locating the sites of professionalization. Accounting, Organizations and Society 31: 415-444.

Correia, S. 2016. A feasible estimator for linear models with multi-way fixed effects. Working Paper.

Covaleski, M. A., M. W. Dirsmith, J. B. Heian, and S. Samuel. 1998. The calculated and the avowed: techniques of discipline and struggles over identity in Big Six public accounting firms. Administrative Science Quarterly 43 (2): 293-327.

Dao, M., and T. Pham. 2014. Audit tenure, auditor specialization and audit report lag. Managerial Auditing Journal 29 (6): 490-512.

DeFond, M., and J. Zhang. 2014. A review of archival auditing research. Journal of Accounting and Economics 58 (2): 275-326.

Dennis, S. A., and K. M. Johnstone. 2018. A natural field experiment examining the joint role of audit partner leadership and subordinates' knowledge in fraud brainstorming. Accounting, Organizations and Society 66: 14-28.

Dyreng, S., M. Hanlon, and E. Maydew. 2010. The effects of executives on corporate tax avoidance. The Accounting Review 85 (4): 1163-89.

Fee, C. E., C. J. Hadlock, and J. R. Pierce. 2013. Managers with and without style: Evidence using exogenous variation. Review of Financial Studies 26 (3): 567-601.

Ferguson, A., J. Francis, and D. Stokes. 2003. The effects of firm-wide and office-level industry expertise on audit pricing. The Accounting Review 78 (2): 429-448.

Financial Reporting Council (FRC). 2016. International standard on auditing (UK) 701: Communicating key audit matters in the independent auditor's report.

Firth, M. A., O. M. Rui, and X. Wu. 2012. Rotate back or not after mandatory audit partner rotation? Journal of Accounting and Public Policy 31 (4): 356-373.

Francis, J. R., and P. N. Michas. 2013. The contagion effect of low-quality audits. The Accounting Review 88 (2): 521-552. 
Francis, J. R., K. Reichelt, and D. Wang. 2005. The pricing of national and city-specific reputations for industry expertise in the U.S. audit market. The Accounting Review 80 (1): 113-136.

Francis, J. R., M. L. Pinnuck, and O. Watanabe. 2014. Auditor style and financial statement comparability. The Accounting Review 89 (2): 605-633.

Gay, E. H. T., and T. B.-P. Ng. 2015. Effects of key audit matter standard and audit committee proactiveness on auditors' communication to the audit committee and decisions on client's accounting estimates. Working Paper.

Ge, W., D. Matsumoto, and J. L. Zhang. 2011. Do CFOs have style? An empirical investigation of the effect of individual CFOs on accounting practices. Contemporary Accounting Research 28 (4): 1141-1179.

Gimbar, C., B. Hansen, and M. E. Ozlanski. 2016. The effects of critical audit matter paragraphs and accounting standard precision on auditor liability. Accounting Review 91 (6):16291646.

Goodwin, J., and D. Wu. 2014. Is the effect of industry expertise on audit pricing an office-level or a partner-level phenomenon? Review of Accounting Studies 19 (4): 1532-1578. . 2016. What is the relationship between audit partner busyness and audit quality? Contemporary Accounting Research 33 (1): 341-377.

Griffith, E. E., J. S. Hammersley, and K. Kadous. 2015. Audits of complex estimates as verification of management numbers: How institutional pressures shape practice. Contemporary Accounting Research 32 (3): 833-863.

Gul, F. A., D. Wu, and Z. Yang. 2013. Do individual auditors affect audit quality? Evidence from archival data. The Accounting Review 88 (6): 1993-2023.

Gunn, J. 2016. The new auditor's report: Speech to the 6th Brazilian conference on accounting and independent auditing. Sao Paolo, Brazil.

Gutierrez, E., M. Minutti-Meza, K. W. Tatum, and M. Vulcheva. 2018. Consequences of adopting an expanded auditor's report in the United Kingdom. Review of Accounting Studies 23 (4): 1543-1587.

Habib, A. 2015. The new Chinese accounting standards and audit report lag. International Journal of Auditing 19 (1): 1-14.

Hardies, K., D. Breesch, and J. Branson. 2014. Do (fe)male auditors impair audit quality? Evidence from going-concern opinions. European Accounting Review 25 (1): 7-34.

He, X., J. A. Pittman, O. M. Rui, and D. Wu. 2017. Do social ties between external auditors and audit committee members affect audit quality? The Accounting Review 92 (5): 61-87.

Heffes, E. M. 2013. Mid-market board members opine on financial reporting and governance issues. Corporate Governance 7.

Hussin, W., W. Nordin, H. M. Bamahros, and S. N. Shukeri. 2018. Lead engagement partner workload, partner-client tenure and audit reporting lag: Evidence from Malaysia. Managerial Auditing Journal 33 (3): 246-266.'

International Auditing and Assurance Standards Board (IAASB). 2015. Auditor reporting - key audit matters: Guidance and support tools. Available from https://www.ifac.org/system/files/publications/files/Auditor-Reporting-Toolkit-KAMOverview.pdf. . 2016. International standard on auditing 701: Communicating key audit matters in the independent auditor's report. 
Ittonen, K., K. Johnstone, and E.-R. Myllymäki. 2015. Audit partner public-client specialisation and client abnormal accruals. European Accounting Review 24 (3): 607-633.

Jamal, K., and H.-T. Tan. 2001. Can auditors predict the choices made by other auditors? Journal of Accounting Research 39 (3): 583-597.

Johnstone, K. M., and J. C. Bedard. 2004. Audit firm portfolio management decisions. Journal of Accounting Research 42 (4):659-690.

Johnstone, K. M., J. C. Bedard, and M. L. Ettredge. 2004. The effect of competitive bidding on engagement planning and pricing. Contemporary Accounting Research 21 (1): 25-53.

Johnstone, K. M., C. Li, and S. Luo. Client-auditor supply chain relationships, audit quality, and audit pricing. Auditing: A Journal of Practice \& Theory 33 (4): 119-166.

Kachelmeier, S. J. 2010. Introduction to a forum on individual differences in accounting behavior. The Accounting Review 85 (4): 1127-1128.

Kachelmeier, S. J., D. Rimkus, J. J. Schmidt, and K. Valentine. 2019. The forewarning effect of critical audit matter disclosures involving measurement uncertainty. Working Paper.

Klersey, G. F., and M. L. Roberts. 2010. Audit partners' individual risk preferences in client retention decisions. Academy of Accounting and Financial Studies Journal 14 (2): 115129.

Knechel, R. W., A. Vanstraelen, and M. Zerni. 2015. Does the identity of engagement partners matter? An analysis of audit partner reporting decisions. Contemporary Accounting Research 32 (4): 1443-1478.

Koester, A., B. Stomberg, B. Williams, and J. Xia. 2020. How much do auditors affect discretionary financial reporting? Evidence from the income tax account. Working Paper.

Krishnan, J., and J. S. Yang. 2009. Recent trends in audit report and earnings announcement lags. Accounting Horizons 23 (3): 265-288.

Lennox, C. S., J. J. Schmidt, and A. M. Thompson. 2019. Are expanded audit reports informative to investors? Evidence from the U.K. Working Paper.

Lennox, C. S., and X. Wu. 2018. A review of the archival literature on audit partners. Accounting Horizons 32 (2): 1-35.

Lewis, B. L. 1980. Expert judgment in auditing: An expected utility approach. Journal of Accounting Research 18 (2): 594-602.

Li, H., D. Hay, and D. Lau. 2019. Assessing the impact of the new auditor's report. Pacific Accounting Review 31 (1): 110-132.

Li, L., B. Qi, T. Gaoliang, and G. Zhang. 2017. The contagion effect of low-quality audits at the level of individual auditors. The Accounting Review 92 (1): 137-163.

Liao, L., M. Minutti-Meza, Y. Zhang, and Y. Zou. 2019. Consequences of the adoption of the expanded auditor's report: Evidence from hong kong. Working Paper.

Libby, R., and J. Luft. 1993. Determinants of judgment performance in accounting settings: Ability, knowledge, motivation, and environment. Accounting, Organizations and Society 18 (5): 425-450.

Libby, R., and H.-T. Tan. 1994. Modeling the determinants of audit expertise. Accounting, Organizations and Society 19 (8): 701-716.

Libby, R., R. Bloomfield, and M. W. Nelson. 2002. Experimental research in financial accounting. Accounting, Organizations and Society 27: 775-810.

Loughran, T. I. M., and B. McDonald. 2016. Textual analysis in accounting and finance: A survey. Journal of Accounting Research 54 (4):1187-1230. 
Matsumoto, D., M. Pronk, and E. Roelofsen. 2011. What makes conference calls useful? The information content of managers' presentations and analysts' discussion sessions. The Accounting Review 86 (4): 1383-1414.

Newton, L. K. 1977. The risk factor in materiality decisions. The Accounting Review 52 (1): 97108.

Public Company Accounting Oversight Board (PCAOB) 2017a. AS 3101: The auditor's report on an audit of financial statements when the auditor expresses an unqualified opinion. . 2017b. PCAOB release No. 2017-001. The auditor's report on an audit of financial statements when the auditor expresses an unqualified opinion and related amendments to $P C A O B$ standards. Washington, D.C.

- 2019. Staff guidance: Implementation of critical audit matters: A deeper dive on the determination of CAMs.

Pinto, I., and A. I. Morais. 2019. What matters in disclosures of key audit matters: Evidence from Europe. Journal of International Financial Management \& Accounting 30 (2): 145162.

PricewaterhouseCoopers (PwC). 2014. Delivering the value of the audit: New insightful audit reports.

Ramsay, R. J. 1994. Senior/manager differences in audit workpaper review performance. Journal of Accounting Research 32 (1): 127-135.

Reid, L. C., J. V. Carcello, C. Li, and T. L. Neal. 2019. Impact of auditor report changes on financial reporting quality and audit costs: Evidence from the United Kingdom. Contemporary Accounting Research 36 (3): 1501-1539.

Rennekamp, K. M., M. Sethuraman, and B. A. Steenhoven. 2020. Engagement in earnings conference calls: A multi-method examination. Working Paper.

Sierra-García, L., N. Gambetta, M. A. García-Benau, and M. Orta-Pérez. 2019. Understanding the determinants of the magnitude of entity-level risk and account-level risk key audit matters: The case of the United Kingdom. The British Accounting Review 51 (3): 227240.

Solomon, I., M. D. Shields, and O. R. Whittington. 1999. What do industry-specialist auditors know? Journal of Accounting Research 37 (1): 191-208.

Suddaby, R., Y. Gendron, and H. Lam. 2009. The organizational context of professionalism in accounting. Accounting, Organizations and Society 34: 409-427.

Sundgren, S., and T. Svanström. 2014. Auditor-in-charge characteristics and going-concern reporting. Contemporary Accounting Research 31 (2): 531-550.

Tausczik, Y. R., and J. W. Pennebaker. 2010. The psychological meaning of words: LIWC and computerized text analysis methods. Journal of Language and Social Psychology 29 (1):24-54.

Taylor, S. D. 2011. Does audit fee homogeneity exist? Premiums and discounts attributable to individual partners. Auditing: A Journal of Practice \& Theory 30 (4): 249-272.

Torres, S., P. Portugal, J. T. Addison, and P. Guimarães. 2018. The sources of wage variation and the direction of assortative matching: Evidence from a three-way high-dimensional fixed effects regression model. Labour Economics 54:47-60.

Vinson, J. M., J. C. Robertson, and R. C. Cockrell. 2018. The effects of critical audit matter removal and duration on jurors' assessments of auditor negligence. Auditing: A Journal of Practice \& Theory 38 (3): 183-202. 
Vuong, Q. H. 1989. Likelihood ratio tests for model selection and non-nested hypotheses. Econometrica 57 (2): 307-333.

Wooldridge, J. M. 2012. Introductory econometrics: A modern approach. Fifth edition. Mason, Ohio : South-Western Cengage Learning.

Ye, P., E. Carson, and R. Simnett. 2011. Threats to auditor independence: The impact of relationship and economic bonds. Auditing: A Journal of Practice \& Theory 30 (1): 121148.

Zerni, M. 2012. Audit partner specialization and audit fees: Some evidence from Sweden. Contemporary Accounting Research 29 (1): 312-340. 


\section{APPENDIX A}

\section{Panel A: Example of a select KAM from KPMG Partner Ruaidhri Gibbons 2017 Audit Report for Independent News \& Media PLC.}

KAM Title: Carrying amount of goodwill (2017: $€ 19.7$ million; 2016: $€ 19.7$ million), intangible assets with indefinite lives (2017: $€ 6.6$ million: 2016: $€ 19.9$ million) and property, plant and equipment (2017: $€ 40.1$ million; 2016: €41.6 million)

\section{Description:}

- The Group has significant goodwill, intangible assets with indefinite lives and property, plant and equipment.

- There is a risk that these and other assets might be impaired. Recoverability is based on forecasting and discounting future cash flows and significant judgement is involved in relation to the assumptions used in the impairment models, in particular the discount rates and the cash flow forecasts.

- The Group recognised an impairment of $€ 12.7$ million (2016: €nil) in relation to intangible assets with indefinite lives during the period.

Response:

The procedures that we performed, among others, to assess the carrying value of goodwill, intangible assets with indefinite lives and property, plant and equipment, included:

- Examining the design and implementation of the controls over impairment testing.

- Assessing the Group's impairment testing models. We considered the appropriateness of the impairment methodology and considered the appropriateness of the cash-generating units ('CGUs') identified, taking into account the current management structure and reporting lines in place in the Group.

- Evaluating the key assumptions used by the Group, including forecasted cash flow based on budgeted EBITDA as adjusted for expenditure necessary to maintain the asset or CGU at its current standard of performance, discount rates and terminal value multiples. We compared the Group's assumptions, where possible, to externally-derived data and challenged the reasonableness of the underlying cash flow forecasts.

- Comparing the discount rates applied to the Group's CGUs to peer data as well as involving our own internal valuations expert to assist in assessing the key components of the discount rates calculation.

- Testing the mathematical accuracy of the Group's impairment calculations.

- Examining the sensitivity analyses prepared by management, taking into consideration the reasonableness and mathematical accuracy of their analysis. In addition, we performed further sensitivity testing of our own of the key assumptions and of the key drivers of the cash flow forecasts for the individual CGUs. Having identified the extent of change required in those assumptions to give rise to further impairments, we considered the likelihood of such a movement in those assumptions arising.

- Assessing whether the related disclosures in the financial statements are appropriate. As a result of our work, we determined that the quantum of the impairment recognised in intangible assets of $€ 12.7$ million was appropriate. For the CGUs where the Group determined that no impairment was required, we found that these judgements were supported by reasonable assumptions. We found the disclosures to be adequate.

This KAM report has Fog $=14.30$, CogProc $=12.90$, Insight $=7.60$ percent, Cause $=2.53$ percent, and Discrep $=0.00$. 


\section{APPENDIX A (continued)}

\section{Panel B: Example of a select KAM from PwC Partner Anna Loizou's 2018 Audit Report for TCS Group Holding PLC.}

Title: Credit loss allowance for loans and advances to customers, using the expected credit loss mode/ in line with the requirements of IFRS 9 "Financial Instruments" including impact of adoption on January 2018.

Description: We focused on this area because this is a new and complex accounting standard for which new models have been developed by the Group to calculate expected credit losses ("ECL") on adoption of IFRS as of January 2018 and for the year ended 31 December 2018 and significant judgement and estimates are involved in estimating expected credit losses on loan and advances to customers. The basis of credit loss allowance under IFRS 9 is significantly different from the impairment provision basis previously applied under LAS 39 and additional new enhanced disclosure requirements are also introduced together with the adoption of IFRS 9. Therefore we applied additional focus to the design and application of the new comprehensive "expected credit loss" models introduced by the Management for the purpose Of compliance with IFRS 9. detailed description of these models is disclosed in Note 3 "Significant accounting policies" and Note 34 "Financial risk management" to the consolidated financial statements. An assessment of the credit loss allowance for loans and advances to customers is performed on a portfolio basis, with the key assumptions being the probability Of an account falling Into arrears and subsequently defaulting (which is impacted by the definition of significant increase in credit risk and the definition of default), the estimated recoveries from defaulted loans and lifetime period for revolving credit facilities. Statistical models are used for the assessment $O$ f the probability of default, recovery rate and lifetime period for revolving credit facilities. In addition, calculation of the expected credit loss allowance incorporates forward-looking information, taking into consideration different macro-economic scenarios and adjusting the probability of default. Note 3 "Significant Accounting Policies", Note 4 "Critical Accounting Estimates and Judgments in plying Accounting Policies", Note 5 "Adoption O New Or Revised Standards and Interpretations", Note 9 "loans and Advances to Customers" and Note 34 "Financial Risk Management" to the consolidated financial statements provide detailed information on the credit loss allowance for loans and advances to customers and the effect of adoption of new credit loss allowance models.

Response: In relation to implementation of the new ECL models for measuring credit loss allowance both on adoption of IFRS 9 on 1 January 2018 and as at 31 December 2018, we assessed the appropriateness of the key assumptions used in the methodologies and models of the Group and their compliance with the requirements of IFRS 9. We engaged our credit risk technical experts to assist us in undertaking this assessment. We tested on a sample basis the design and operating effectiveness of the key controls over the implementation Of the new credit loss allowance models in the systems. For a sample of loans we recalculated probabilities Of default on the basis Of the new methodologies and compared the results with the models' outputs. Additionally, we reviewed the Group's backtesting of probabilities of default estimated on the basis of the models by comparing them to the actual default rates evidenced in the loan portfolios. With regard to the controls relating to the credit loss allowance, we assessed and tested on a sample basis the design and operating effectiveness of the key controls over credit loss data and calculations. These key controls included those over loan classification by type of loan portfolio, allocation of cash received from customers to respective loans and advances to customers, identification Of the overdue loans and the data transfer from source systems to the credit loss allowance models. We determined that we could place reliance upon these key controls for the purposes of our audit. In addition, we tested on a sample basis the correctness Of loan classification by type Of loan portfolio and performed testing on a sample basis of the statistical models used to calculate credit loss allowance. This testing of the models varied by portfolio including testing of the coding used, re- performance of the calculation including calculation of the effect of forward looking information on credit loss allowance and testing the extraction Of data used in the models. We tested a sample of post model accounting adjustments where applicable, including considering the basis for the adjustment, the logic applied, the source data used and the key assumptions adopted. We assessed the disclosures made against the relevant accounting standards for their completeness and accuracy. Based on the evidence obtained we found the models used to be appropriate and the outputs from the models to be reasonable.

This KAM report has Fog $=24.60$, CogProc $=13.00$, Insight $=4.87$ percent, Cause $=6.96$ percent, and Discrep $=0.84$ percent. 


\title{
APPENDIX B Variable Definitions
}

\author{
Dependent Variables for KAM Reporting Outcomes \\ Reporting Volume Outcomes \\ Num_KAMs Number of KAMs in the audit report. \\ Num_KAMs_dm Number of KAMs in the audit report minus average number of KAMs for that industry-year. \\ Reporting Diversity Outcomes \\ Industry-year weighted topical diversity of KAMs, calculated as: \\ $\sum_{\mathrm{c}=1}^{\mathrm{c}=9} I_{c} *\left(1\right.$-percent of firms in the industry year for which $\left.I_{c}=1\right)$ \\ wtd_Diversity where "c" indexes the following KAM topical categories: complex estimates, revenue \\ recognition, business combinations, taxes, inventory, internal control, financial statement \\ presentation and disclosure, compensation, and complex instruments and " $\mathrm{I}$ " is an indicator \\ variable equal to one for firms receiving a KAM in category "c". \\ Communication Outcomes (Note: the suffix ' $d m$ ' indicates that a variable is de-meaned by industry-year average.) \\ Fog \\ Fog_dm \\ wrdsperKAM \\ wrdsperKAM_dm \\ CogProc \\ CogProc_dm \\ Insight \\ Insight_dm \\ Cause \\ Cause_dm \\ Discrep \\ Discrep_dm \\ Gunning-Fog Index for the KAMs portion of the audit report measuring the number of years of \\ education needed to comprehend the KAMs. \\ Gunning-Fog Index for the KAMs portion of the audit report minus the industry-year average Fog \\ index. \\ Number of words in the KAMs portion of the audit report divided by the number of KAMs. \\ Number of words in the KAMs portion of the audit report divided by the number of KAMs, minus \\ the industry-year average wrdsperKAM. \\ Percentage of words in the KAMs portion of the audit report included in the Linguistic Inquiry \\ Word Count (LIWC) cognitive processing language category, reflective of "the extent to which \\ someone differentiates between multiple competing solutions and ... integrates among solutions" \\ (Tauscik and Pennebaker 2010, pp. 35). \\ Percentage of words in the KAMs portion of the audit report included in the LIWC cognitive \\ processing category minus the industry-year average percent of cognitive processing words. \\ Percentage of words in the KAMs portion of the audit report included in the LIWC insight \\ language category (e.g., "think", "know", "consider"). \\ Percentage of words in the KAMs portion of the audit report included in the LIWC insight \\ language category minus the industry-year average percent of insight words. \\ Percentage of words in the KAMs portion of the audit report included in the LIWC causal \\ language category (e.g., "because", "effect", "hence"). \\ Percentage of words in the KAMs portion of the audit report included in the LIWC causal \\ language category minus the industry-year average percent of causal words. \\ Percentage of words in the KAMs portion of the audit report included in the LIWC discrepancy \\ language category (e.g., "should", "would", "could"). \\ Percentage of words in the KAMs portion of the audit report included in the LIWC discrepancy \\ language category minus the industry-year average percent of discrepancy words.
}




\section{APPENDIX B \\ Variable Definitions (continued)}

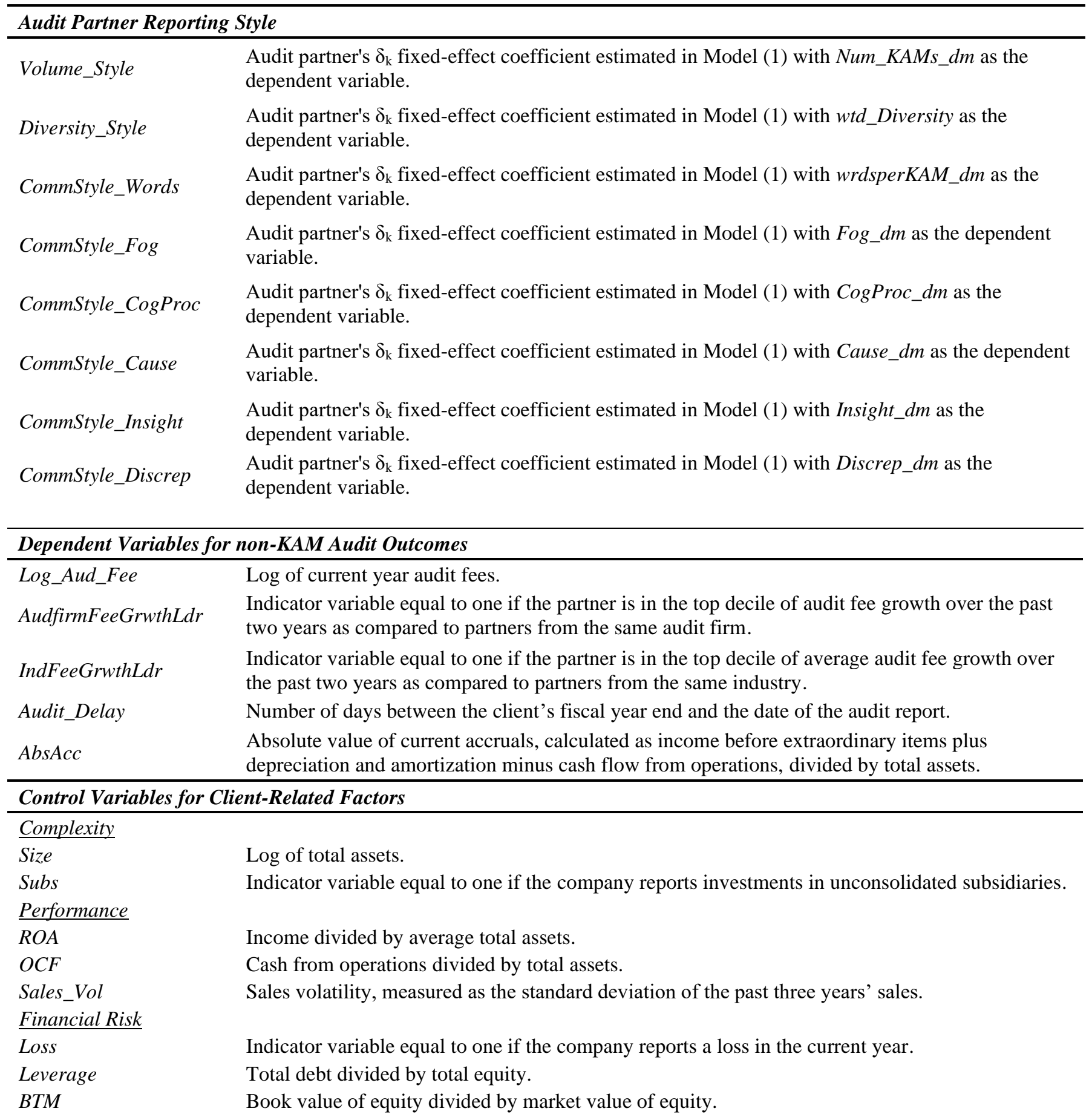




\section{APPENDIX B Variable Definitions (continued)}

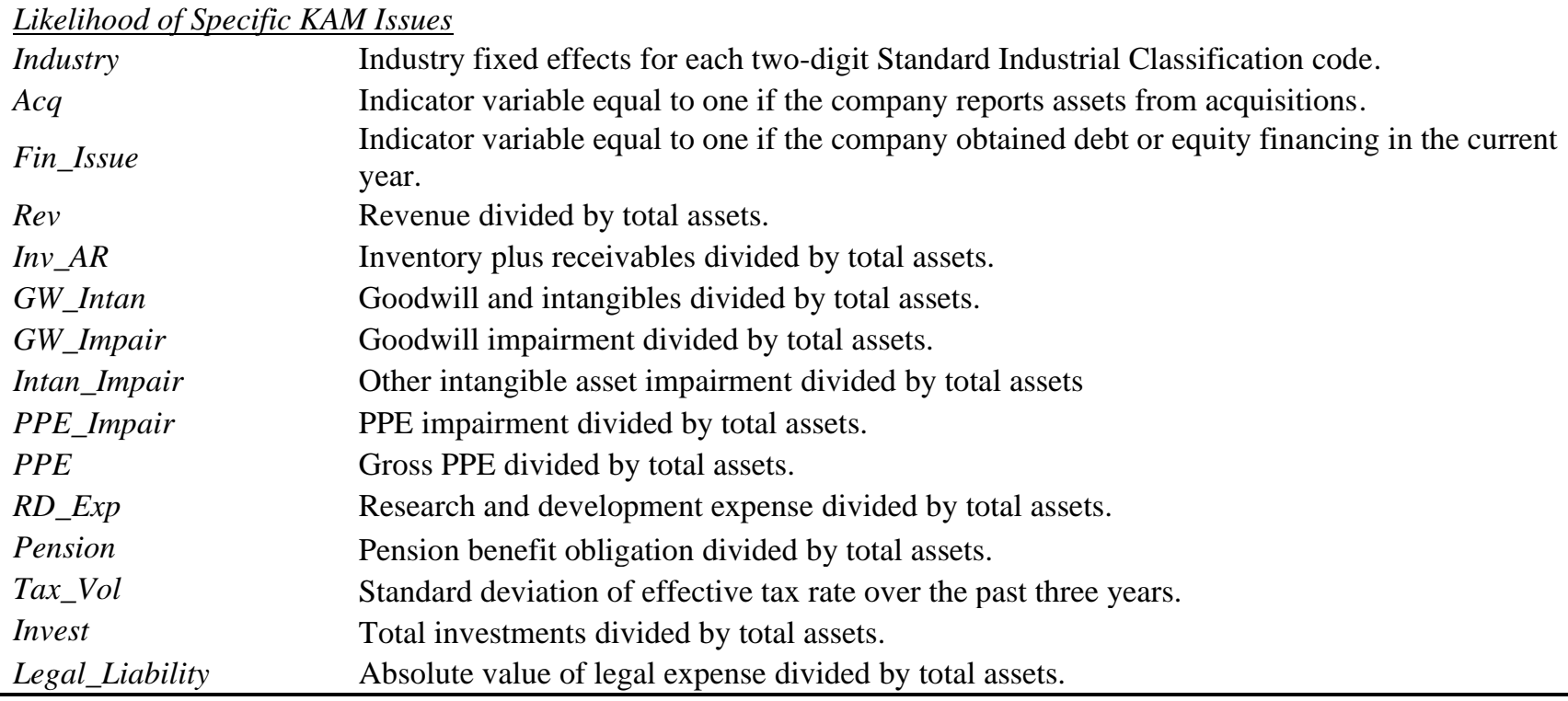

Control Variables for Auditor-Related Factors

Audit Firm Fixed Effect Set of indicator variables equal to one if the observation is associated with a specific audit firm.

Big4

DecYrEnd Indicator variable equal to one if the audit was conducted by KPMG, EY, PwC or Deloitte.

Ptr_Busyness Indicator variable equal to one if the company has a December year-end.

Year Log of the number of clients for which the partner signs an audit report each year. Year fixed effect.

Ind_Spec Industry specialization, measured as percentage of audit fees earned from the client's industry measured at the (1) audit firm level and (2) at the individual partner level.

Econ_Bond Auditor's dependence on client fees. Measured as the percentage of total audit fees attributable to

KAMreg a specific client measured at the (1) audit firm level and (2) at the individual partner level. Indicator variable equal to one if the audit is for a fiscal year ended after June 15th, 2017. Indicator variable equal to one if the client firm is traded on the LSE Main Market and has a four-

MainMkt month filing deadline; equal to zero if traded on the Alternate Investment Market with a sixmonth filing deadline.

\section{Partner Demographic Characteristics}

$\begin{array}{ll}\text { Female } & \text { Indicator variable equal to one if the partner is female. } \\ \text { Adv_Degree } & \text { Indicator variable equal to one if the partner holds a Master's degree or higher. } \\ \text { Acct_Major } & \text { Indicator variable equal to one if the partner majored in accounting. } \\ \text { BigN_Exp } & \text { Indicator variable equal to one if the partner has experience at a Big } 4 \text { accounting firm. } \\ \text { Int_Second } & \text { Indicator variable equal to one if the partner has completed an international secondment. } \\ \text { Client_Second } & \text { Indicator variable equal to one if the partner has completed a client secondment. } \\ & \text { Indicator variable equal to one if the partner has held a leadership role in their firm's audit } \\ \text { Prctc_Ldr } & \text { practice. } \\ & \text { Years of experience in public accounting, measured as } 2017 \text { minus the year the partner started in } \\ \text { Exp_Yrs } & \text { public accounting plus one. }\end{array}$




\section{APPENDIX C Categorization of KAM Topics}

KAM Category and Related Audit Analytics KAM Topics

Frequency in Frequency in all LSE Firms sample firms

\section{Complex Estimates}

Accounts/Loans Receivable

Allowance For Credit Losses

Asset Retirement And Environmental Obligations

Cash And Cash Equivalents

Contingent Liabilities (Including Litigation \& Restructuring)

Contract Liabilities

Deferred And Capitalized Costs

Depreciation And Amortization

Impairment - Property, Plant, And Equipment

Impairment - Trade/Accounts Receivables

Industry-Specific Issue (Insurance)

Industry-Specific Issue (Mining)

Industry-Specific Issue (Oil And Gas)

Insurance Contract Liabilities

Investment Valuation - Property

Investment Valuation - Securities And Financial Instruments

Land And Stores Under Construction

Leases

Long-Term Investments

Other Intangible Assets

Other Liabilities And Provisions

Other Or Unspecified Accounting Estimates

Pension And Other Post-Employment Benefits

Research And Development Expenses

Warranty Liabilities

Revenue Recognition

Revenue And Other Income

Revenue From Customer Contracts

Revenue Recognition - Gift Card And Loyalty Programs, Including Breaka

Sales Return And Allowances

Business Combinations-Acquisitions, Divestures, and Goodwill

Business Combinations

Consolidation

Disposals, Discontinued Operations, And Accounting For Sales/Divestitur

Equity Investments And Joint Ventures

Goodwill

Goodwill And Intangible Assets

Subsidiary/Affiliate

6,819

3,079

144

48

112

16

63

35

17

401

2

404

60

605

303

88

83

120

75

497

1807

52

26

325

536

366

39

623

17

54

$\mathbf{3 , 5 2 0}$

2945

482

17

76

$\mathbf{3 , 3 0 1}$

758

45

190

260

754

850

444 


\begin{tabular}{|c|c|c|}
\hline \multicolumn{3}{|c|}{$\begin{array}{c}\text { APPENDIX C } \\
\text { Categorization of KAM Topics (continued) }\end{array}$} \\
\hline Taxes & 861 & 495 \\
\hline Deferred Income Taxes & 210 & 102 \\
\hline Other Income Taxes & 452 & 280 \\
\hline Uncertain Tax Positions & 199 & 113 \\
\hline Inventory & 821 & 422 \\
\hline Inventory & 663 & 344 \\
\hline Vendor/Supplier Rebates & 158 & 78 \\
\hline Going Concern & 579 & 186 \\
\hline Going Concern & 579 & 186 \\
\hline Internal Control & 529 & 198 \\
\hline Information Technology & 93 & 33 \\
\hline Internal Controls & 421 & 160 \\
\hline Transformation Initiatives & 15 & 5 \\
\hline Financial Statement Presentation and Disclosure & 390 & 202 \\
\hline Financial Statements And Disclosures & 73 & 32 \\
\hline Presentation - Exceptional Items And Non-Gaap Measures & 317 & 170 \\
\hline Other & 318 & 110 \\
\hline Debt Covenants & 26 & 15 \\
\hline First Year Audit & 8 & 3 \\
\hline Listing/Delisting & 18 & 1 \\
\hline Other Comprehensive Income & 45 & 24 \\
\hline Segment Reporting & 7 & 3 \\
\hline Significant One-Off Transactions & 214 & 64 \\
\hline Deferred, Stock-Based, and/or Executive Compensation & 265 & 119 \\
\hline Deferred And Stock-Based Compensation & 265 & 119 \\
\hline Accounting for Complex Instruments & 221 & 72 \\
\hline Debt, Quasi-Debt, Warrants \& Equity ( Bcf) Security & 93 & 22 \\
\hline Derivatives And Hedging & 84 & 35 \\
\hline Foreign Currency, Inflation, And Related Disclosures & 44 & 15 \\
\hline Compliance with Laws and Regulations & 148 & 64 \\
\hline Bribery And Corruption & 11 & - \\
\hline Compliance With Laws And Regulations & 137 & 64 \\
\hline Fraud Risks, Including Related Party Transactions & 88 & 26 \\
\hline Fraud Risks & 6 & 3 \\
\hline Related Party Transactions & 82 & 23 \\
\hline Accounting Changes and Error Corrections & 84 & 21 \\
\hline Error Corrections & 10 & 4 \\
\hline Policy Changes & 74 & 17 \\
\hline Expense Reporting & 32 & 13 \\
\hline Other Expenses & 25 & 11 \\
\hline Selling, General And Administrative Expenses & 7 & 2 \\
\hline Grand Total & 17,976 & $8, \mathbf{0 3 0}$ \\
\hline
\end{tabular}

Notes: The total of 17,976 represents includes all the LSE KAMs that Audit Analytics has recorded since KAM reporting started in the UK in 2013; the 8,030 represents the KAM topic frequency for our sample. 
FIGURE 1

Conceptual Framework of Audit Partner Decision Style

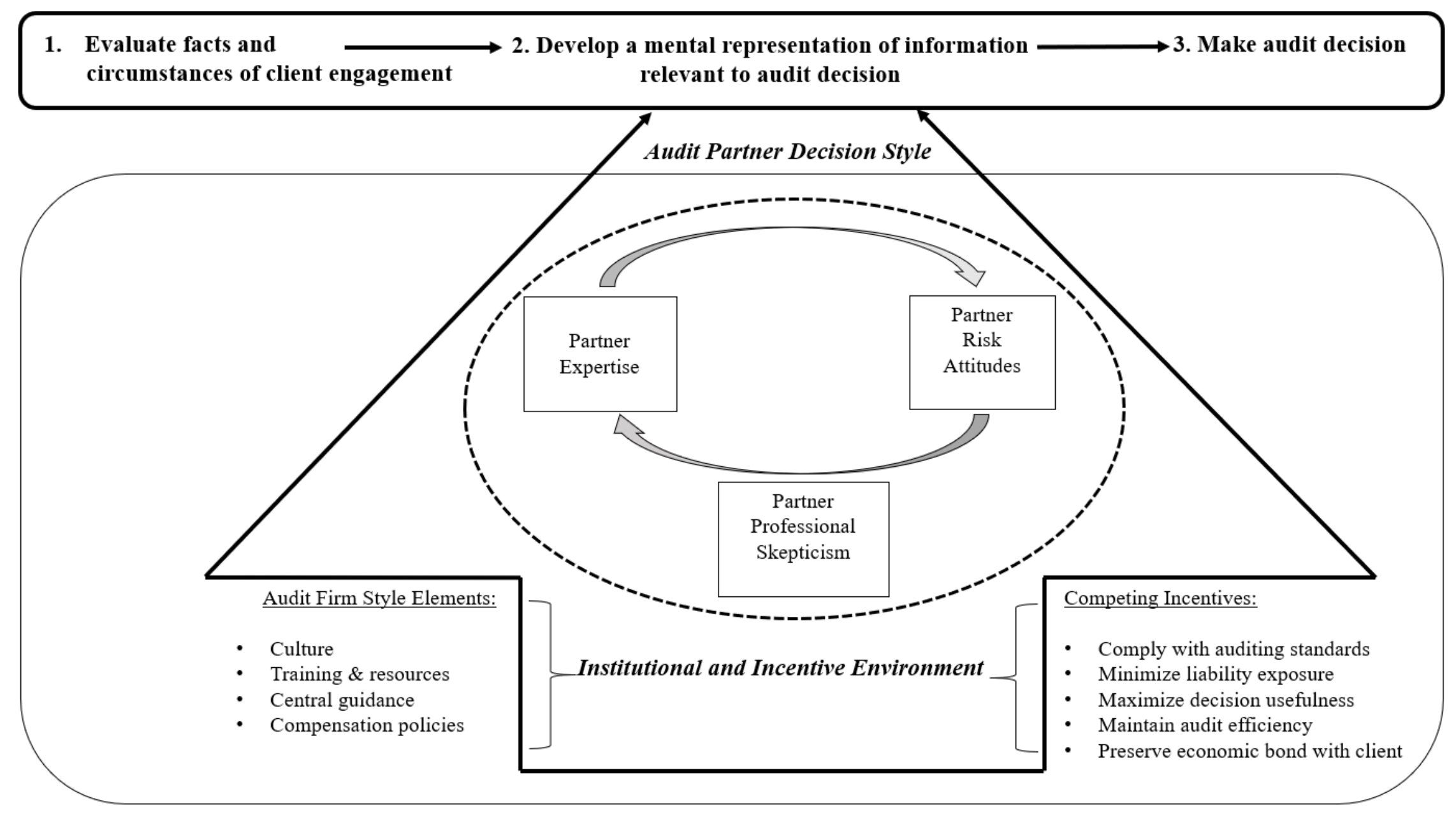


FIGURE 2

Panel A: Hypothesis 1

Predictive Validity Frameworks - Hypothesis 1 and Hypothesis 2

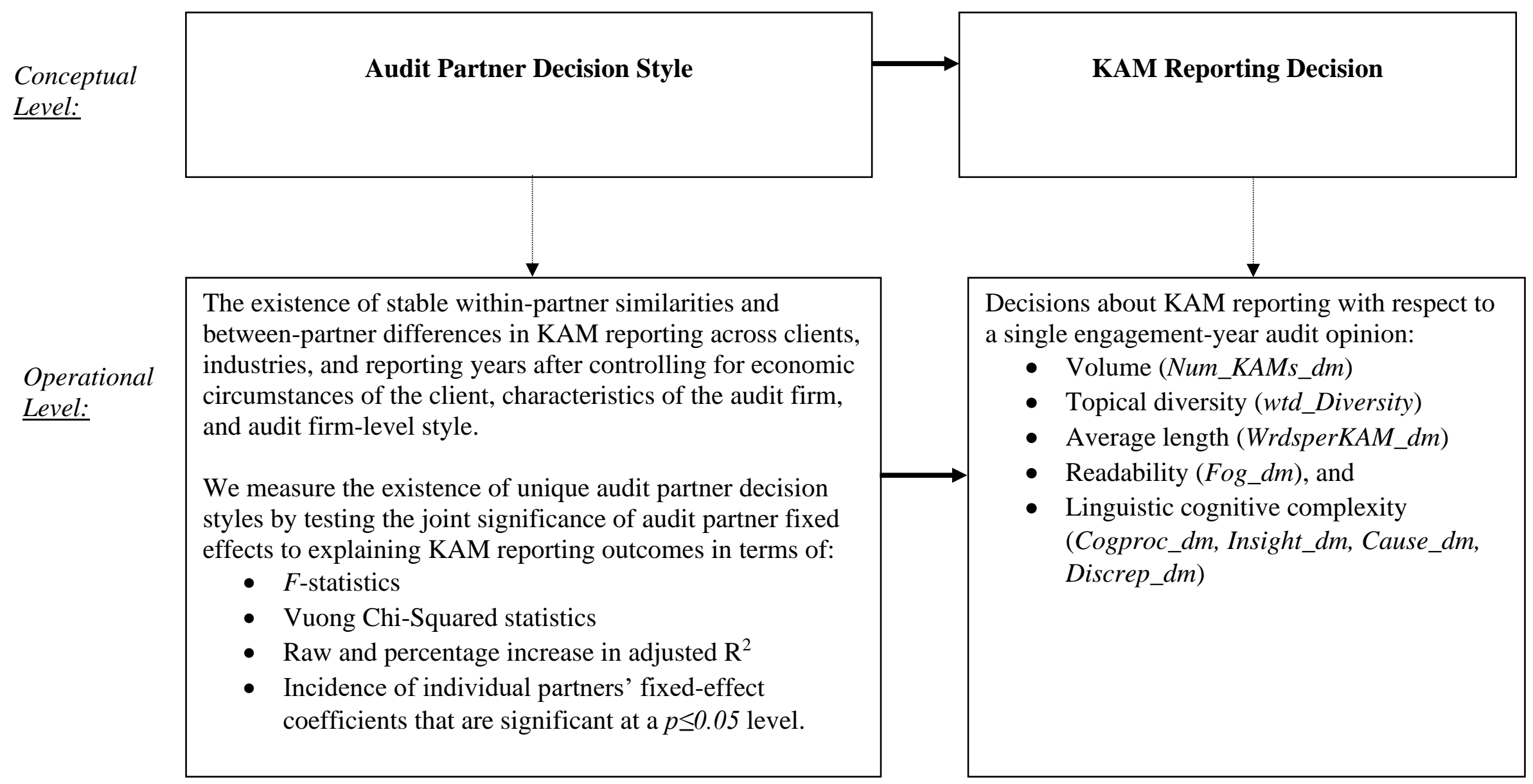


FIGURE 2

Panel B: Hypothesis 2

Predictive Validity Frameworks - Hypothesis 1 and Hypothesis 2 (Continued)

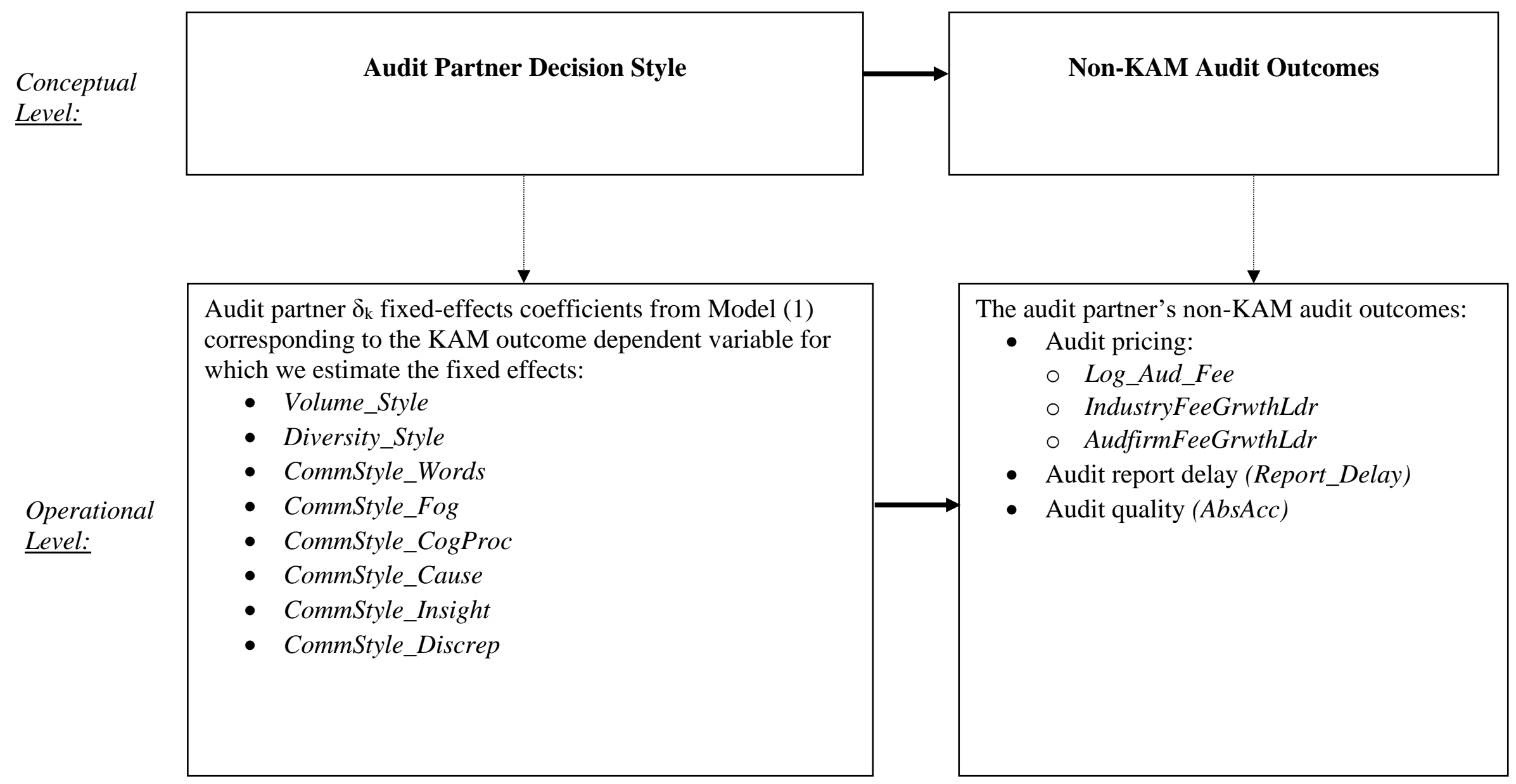




\section{TABLE 1 \\ Sample Composition}

\section{Panel A: Main Sample Composition}

Number of London Stock Exchange companies with data in Audit Analytics

Europe in the KAM regulation period (September 2013-March 2019) 6,056

Less: observations missing Audit Analytics data on auditor-related variables

Less: observations missing Factset International Fundamentals Annual data on financial control variables

Less: observations not meeting sample criteria (that audit partners have at least five observations from two unique clients and that audit firms have at least three partners meeting this description)

Number of observations

Number of partners

Number of audit firms

\section{Panel B: Subsample Composition}

Number of observations with available data included in:

Log_Aud_Fees analysis:

FirmFeeGrwthLdr and IndFeeGrwthLdr analysis:

2,623

Audit_Delay analysis:

2,718

Audit Quality analysis (AbsAcc):

2,437

Number of partners with demographic information publicly available on LinkedIn and audit firm profiles: 
TABLE 2

Descriptive Statistics

Panel A: Univariate Descriptive Statistics

\begin{tabular}{|c|c|c|c|c|c|}
\hline Variable & Obs & Mean & Std. Dev. & Min & Max \\
\hline \multicolumn{6}{|c|}{ KAM Reporting Outcomes } \\
\hline Num_KAMs & 2,819 & 2.84 & 1.39 & 1.00 & 9 \\
\hline Wtd_Diversity & 2,819 & 0.78 & 0.63 & 0.00 & 2.82 \\
\hline Fog & 2,819 & 18.45 & 2.00 & 14.08 & 26.14 \\
\hline wrdsperKAM & 2,819 & 289.53 & 120.82 & 27.33 & 731.50 \\
\hline CogProc & 2,819 & 10.52 & 1.88 & 1.45 & 17.12 \\
\hline Insight & 2,819 & 4.51 & 1.37 & 0.00 & 10.20 \\
\hline Cause & 2,819 & 2.72 & 0.93 & 0.00 & 6.96 \\
\hline Discrep & 2,819 & 0.48 & 0.39 & 0.00 & 4.55 \\
\hline \multicolumn{6}{|c|}{ Other (Non-KAM) Audit Outcomes } \\
\hline Log_Aud_Fee & 2,819 & 12.33 & 1.66 & 9.96 & 16.56 \\
\hline AudfirmFeeGrwthLdr ${ }^{+}$ & 2,623 & 0.13 & 0.33 & 0.00 & 1 \\
\hline IndFeeGrwthLdr & 2,623 & 0.10 & 0.30 & 0.00 & 1 \\
\hline Audit_Delay & 2,718 & 74.12 & 24.72 & 27.00 & 187 \\
\hline$A b s A c c$ & 2,437 & 0.06 & 0.09 & 0.00 & 0.75 \\
\hline \multicolumn{6}{|c|}{ Client-Related Control Variables } \\
\hline Size & 2,819 & 5.69 & 2.06 & 0.65 & 12.29 \\
\hline Subs & 2,819 & 0.29 & 0.46 & 0.00 & 1 \\
\hline$R O A$ & 2,819 & 0.04 & 0.15 & -0.95 & 0.35 \\
\hline$O C F$ & 2,819 & 0.04 & 0.12 & -0.85 & 0.37 \\
\hline Sales_Vol & 2,819 & 157.40 & 572.49 & 0.00 & $6,646.62$ \\
\hline Loss & 2,819 & 0.23 & 0.42 & 0.00 & 1 \\
\hline Leverage & 2,819 & 0.47 & 1.09 & -6.32 & 13.51 \\
\hline BTM & 2,819 & 0.81 & 0.68 & -0.36 & 11.42 \\
\hline$A c q$ & 2,819 & 0.29 & 0.46 & 0.00 & 1 \\
\hline Fin_Issue & 2,819 & 0.68 & 0.47 & 0.00 & 1 \\
\hline $\operatorname{Rev}$ & 2,819 & 0.60 & 0.70 & -0.10 & 3.78 \\
\hline$I n v_{-} A R$ & 2,819 & 0.13 & 0.17 & 0.00 & 0.78 \\
\hline$G W \_I n t a n$ & 2,819 & 0.15 & 0.22 & 0.00 & 0.84 \\
\hline GW_Impair & 2,819 & 0.00 & 0.01 & 0.00 & 0.14 \\
\hline Intan_Impair & 2,819 & 0.00 & 0.01 & 0.00 & 0.09 \\
\hline PPE_Impair & 2,819 & 0.00 & 0.02 & -0.01 & 0.35 \\
\hline$P P E$ & 2,819 & 0.28 & 0.40 & 0.00 & 1.75 \\
\hline
\end{tabular}


TABLE 2

Descriptive Statistics (continued)

Panel A: Univariate Descriptive Statistics (continued)

\begin{tabular}{|c|c|c|c|c|c|}
\hline Variable & Obs & Mean & Std. Dev. & Min & Max \\
\hline \multicolumn{6}{|c|}{ Client-Related Control Variables (continued) } \\
\hline$R D \_\operatorname{Exp}$ & 2,819 & 0.01 & 0.05 & 0.00 & 0.64 \\
\hline Pension & 2,819 & 0.15 & 0.37 & 0.00 & 3.53 \\
\hline Tax_Vol & 2,819 & 0.28 & 1.31 & 0.00 & 24.14 \\
\hline Invest & 2,819 & 0.34 & 0.43 & 0.00 & 1.00 \\
\hline Legal_Liability & 2,819 & 0.00 & 0.00 & 0.00 & 0.10 \\
\hline \multicolumn{6}{|c|}{ Auditor-Related Control Variables } \\
\hline Big4 & 2,819 & 0.79 & 0.41 & 0.00 & 1.00 \\
\hline DecYrEnd & 2,819 & 0.45 & 0.50 & 0.00 & 1.00 \\
\hline Ptr_Busyness & 2,819 & 1.26 & 0.77 & 0.00 & 3.00 \\
\hline Audptr_Ind_Spec & 2,819 & 0.58 & 0.34 & 0.03 & 1.00 \\
\hline Audptr_Econ_Bond & 2,819 & 0.37 & 0.32 & 0.01 & 1.00 \\
\hline Audfirm_Ind_Spec & 2,819 & 0.07 & 0.08 & 0.00 & 0.50 \\
\hline Audfirm_Econ_Bond & 2,819 & 0.01 & 0.02 & 0.00 & 0.26 \\
\hline KAMreg & 2,819 & 0.44 & 0.50 & 0.00 & 1.00 \\
\hline MainMkt & 2,819 & 0.83 & 0.38 & 0.00 & 1.00 \\
\hline \multicolumn{6}{|c|}{ Partner Demographic Characteristics } \\
\hline Female & 161 & 0.15 & 0.36 & 0.00 & 1.00 \\
\hline Adv_Degree & 161 & 0.23 & 0.43 & 0.00 & 1.00 \\
\hline Acct_Major & 161 & 0.26 & 0.44 & 0.00 & 1.00 \\
\hline BigN_Exp & 161 & 0.84 & 0.37 & 0.00 & 1.00 \\
\hline Int_Second & 161 & 0.33 & 0.47 & 0.00 & 1.00 \\
\hline Client_Second & 161 & 0.13 & 0.34 & 0.00 & 1.00 \\
\hline Prctc_Ldr & 161 & 0.65 & 0.48 & 0.00 & 1.00 \\
\hline Exp_Yrs & 161 & 27.5 & 5.96 & 12.00 & 43.00 \\
\hline
\end{tabular}

We report all monetary figures in US dollars.

${ }^{+}$Note: AudfirmFeeGrwthLdr, an indicator variable measuring whether a partner is in the top decile of average audit fee growth over the past two years, is equal to 13 percent because we calculate the descriptive statistics for the entire sample and, by construction, partners have more than one engagement in the sample 
TABLE 2

Descriptive Statistics (continued)

\section{Panel B: Correlations Between Partner Decision Outcomes of Interest}
(1)
(2)
(3) (4)
(5)
(6)
(7)
(8)
(9)
(10) (11)
(12)

(1) Num_KAMs_dm

$0.5914 * \quad 1$

(3) $F o g \_d m-0.1156 *-0.0824 *$

(4) wrdsperKAM_dm

$\begin{array}{lll}-0.0196 & -0.0285 & 0.1696^{*}\end{array}$

$\begin{array}{llll}0.0645 * & 0.0770 * & 0.1994 * & -0.0114\end{array}$

$\begin{array}{llllll}0.0111 & 0.0218 & 0.3244 * & -0.0197 & 0.6795^{*}\end{array}$

(6) Insight_dm

$0.0601 * 0.0617 *-0.1010 *-0.01440 .3461 *-0.0760 *$

(7) Cause_dm

$\begin{array}{lllllllr}0.0601 * & 0.0617^{*} & -0.1010^{*} & -0.0144 & 0.3461^{*} & -0.0760^{*} & 1 \\ 0.1506^{*} & 0.0785^{*} & 0.0559^{*} & 0.0442^{*} & 0.3100^{*} & 0.0753^{*} & 0.0187\end{array}$

(8) Discrep_dm

$\begin{array}{llllllll}0.3451 * & 0.4452 * & 0.0056 & 0.2069 * & 0.0936 * & 0.0629 * & 0.0654 *\end{array}$

(9) Log_Aud_Fee

-

(10) AudfirmFeeGrwthLdr
(11) IndFeeGrwthLdr

$\begin{array}{lllllllll}-0.0193 & -0.0212 & 0.0219 & 0.0091 & 0.0439 * & 0.0702 * & -0.0003 & 0.0549 * & 0.0158\end{array}$

(12) Audit_Delay

$\begin{array}{rrrrrrrr}-0.0322 & -0.0024 & -0.0106 & -0.0125 & 0.0178 & 0.0478 * & 0.0149 & -0.0 \\ -0.1670 * & -0.1813 * & 0.0629 * & -0.0814 * & -0.0271 & 0.0443 * & -0.0756 * & -0.0\end{array}$

$-0.1670 *-0.1813 * 0.0629 *-0.0814 *-0.02710 .0443 *-0.0756^{*}$

$-0.0049-0.0943 * 0.3936 *$

$-0.0335-0.3322 *-0.0197$

$-0.0419^{*}-0.1258^{*}-0.0433^{*}$

$-0.0315-0.0545^{*}-0.0362$

$-0.0252$

$-0.023-0.2875^{*}$

0.0322

(13) AbsAcc

Note: Correlations with $a *$ indicate that the relationship is significant at $p<0.05$ (two-tailed). 
TABLE 3

Estimating Audit Partner Fixed Effects on KAM Reporting Outcomes

\section{Panel A: Regression Results for KAM Volume}

Dependent Variable: Num_KAMs_dm

\begin{tabular}{|c|c|c|c|c|c|c|}
\hline \multirow[b]{2}{*}{ Variables } & \multicolumn{2}{|c|}{ Base Model } & \multicolumn{2}{|c|}{$\underline{\text { Audit Firm FE }}$} & \multicolumn{2}{|c|}{ Audit Partner FE } \\
\hline & Coef & t-stat & Coef & t-stat & Coef & t-stat \\
\hline Size & 0.047 & $(1.47)$ & 0.034 & (1.14) & 0.017 & $(0.58)$ \\
\hline Subs & 0.080 & $(1.02)$ & 0.112 & $(1.42)$ & $0.165^{* *}$ & $(2.26)$ \\
\hline$R O A$ & -0.145 & $(-0.59)$ & -0.073 & $(-0.29)$ & 0.004 & $(0.02)$ \\
\hline Sales_Vol & -0.000 & $(-0.84)$ & -0.000 & $(-0.52)$ & -0.000 & $(-1.02)$ \\
\hline Loss & $0.153^{* *}$ & $(2.19)$ & $0.159 * *$ & $(2.31)$ & $0.123^{*}$ & $(1.94)$ \\
\hline Leverage & 0.031 & $(1.41)$ & 0.028 & $(1.23)$ & 0.008 & $(0.44)$ \\
\hline BTM & 0.044 & $(0.87)$ & 0.051 & $(1.04)$ & $0.090 * *$ & $(2.25)$ \\
\hline$A c q$ & $0.269 * * *$ & $(4.24)$ & $0.270 * * *$ & $(4.35)$ & $0.225 * * *$ & $(4.07)$ \\
\hline Fin_Issue & 0.071 & $(1.41)$ & 0.062 & $(1.26)$ & 0.021 & $(0.46)$ \\
\hline $\operatorname{Rev}$ & -0.081 & $(-1.10)$ & -0.085 & $(-1.15)$ & -0.084 & $(-1.25)$ \\
\hline$I n v \_A R$ & 0.304 & $(0.82)$ & 0.366 & $(1.00)$ & $0.651 * *$ & (1.98) \\
\hline$G \bar{W} \_$Intan & 0.241 & $(1.15)$ & 0.274 & $(1.32)$ & 0.211 & $(1.06)$ \\
\hline GW_Impair & 1.111 & $(0.60)$ & 1.136 & $(0.59)$ & 1.509 & $(0.78)$ \\
\hline Intan_Impair & 3.173 & (1.11) & 2.726 & $(0.92)$ & 2.152 & $(0.69)$ \\
\hline PPE_Impair & $-1.500 * *$ & $(-2.03)$ & $-1.350 *$ & $(-1.72)$ & -0.823 & $(-1.15)$ \\
\hline$P P E^{-}$ & 0.189 & $(1.62)$ & $0.223^{* *}$ & $(2.00)$ & 0.165 & $(1.39)$ \\
\hline$R D \_E x p$ & -0.001 & $(-0.00)$ & -0.144 & $(-0.26)$ & -0.545 & $(-0.97)$ \\
\hline Pension & $0.302 * * *$ & $(2.82)$ & $0.294 * * *$ & $(2.86)$ & $0.385 * * *$ & $(3.51)$ \\
\hline Tax_Vol & 0.018 & $(0.87)$ & 0.019 & $(0.96)$ & -0.007 & $(-0.42)$ \\
\hline Invest & $-0.267 *$ & $(-1.89)$ & -0.211 & $(-1.57)$ & -0.189 & $(-1.46)$ \\
\hline Legal_Liability & 16.823 & $(1.51)$ & $19.805^{*}$ & $(1.82)$ & 14.678 & $(0.99)$ \\
\hline Log_Aud_Fee & $0.324 * * *$ & $(6.54)$ & $0.313^{* * *}$ & $(6.42)$ & $0.400 * * *$ & (7.55) \\
\hline DecYrEnd & -0.067 & $(-1.04)$ & -0.057 & $(-0.91)$ & 0.031 & $(0.55)$ \\
\hline Audptr_Ind_Spec & $0.460 * * *$ & $(4.14)$ & $0.425 * * *$ & $(3.80)$ & $0.470 * * *$ & $(4.55)$ \\
\hline Audptr_Econ_Bond & $-0.453 * * *$ & $(-2.74)$ & $-0.395^{* *}$ & $(-2.36)$ & $-0.410 * * *$ & $(-3.42)$ \\
\hline Audfirm_Ind_Spec & $0.930 * * *$ & $(2.65)$ & 0.475 & $(1.37)$ & 0.494 & $(1.42)$ \\
\hline Audfirm_Econ_Bond & 0.734 & $(0.48)$ & 0.521 & $(0.25)$ & -0.338 & $(-0.19)$ \\
\hline KAMReg & -0.037 & $(-0.45)$ & -0.067 & $(-0.82)$ & $-0.142 *$ & $(-1.90)$ \\
\hline MainMkt & -0.151 & $(-1.55)$ & -0.123 & $(-1.22)$ & -0.098 & $(-0.95)$ \\
\hline$O C F$ & -0.019 & $(-0.07)$ & 0.002 & $(0.01)$ & -0.289 & $(-1.15)$ \\
\hline Ptr_Busyness & 0.039 & $(0.69)$ & 0.039 & $(0.72)$ & & \\
\hline Big4 & -0.010 & $(-0.12)$ & & & & \\
\hline Constant & $-4.580 * * *$ & $(-9.00)$ & $-4.243 * * *$ & $(-8.37)$ & $-5.295^{* * *}$ & $(-6.00)$ \\
\hline
\end{tabular}

\begin{tabular}{lccc} 
Observations & 2,819 & 2,819 & 2,819 \\
Adjusted R-squared & 0.235 & 0.265 & 0.418 \\
Year FE & Yes & Yes & Yes \\
Industry FE & Yes & Yes & Yes \\
Audit Firm FE & No & Yes & Yes \\
Partner FE & No & No & Yes \\
\hline The symbols $* * * * *$, and $*$ denote significance at the 0.01, 0.05, and 0.10 levels, respectively (two-tailed for all t- \\
statistics). See Appendix A for variable definitions. See Table 1 for sample composition. We use high-dimensional \\
fixed-effect linear regression with heteroskedasticity robust standard errors clustered on client company.
\end{tabular}


TABLE 3

Estimating Audit Partner Fixed Effects on KAM Reporting Outcomes (continued)

Panel B: Regression Results for KAM Diversity

Dependent Variable: $w t d \_$Diversity

\begin{tabular}{|c|c|c|c|c|c|c|}
\hline \multirow[b]{2}{*}{ Variables } & \multicolumn{2}{|c|}{ Base Model } & \multicolumn{2}{|c|}{$\underline{\text { Audit Firm FE }}$} & \multicolumn{2}{|c|}{$\underline{\text { Audit Partner FE }}$} \\
\hline & Coef & t-stat & Coef & t-stat & Coef & t-stat \\
\hline Size & 0.004 & $(0.26)$ & -0.005 & $(-0.34)$ & -0.020 & $(-1.41)$ \\
\hline Subs & 0.044 & $(1.01)$ & 0.066 & $(1.59)$ & $0.074^{*}$ & $(1.90)$ \\
\hline$R O A$ & 0.016 & $(0.14)$ & 0.052 & $(0.45)$ & 0.120 & $(1.12)$ \\
\hline Sales_Vol & $-0.000^{*}$ & $(-1.74)$ & -0.000 & $(-1.41)$ & $-0.000 * * *$ & $(-3.34)$ \\
\hline Loss & 0.041 & $(1.14)$ & 0.039 & $(1.10)$ & 0.030 & $(0.86)$ \\
\hline Leverage & 0.007 & $(0.62)$ & 0.005 & $(0.45)$ & -0.004 & $(-0.40)$ \\
\hline BTM & -0.021 & $(-0.89)$ & -0.016 & $(-0.70)$ & -0.005 & $(-0.25)$ \\
\hline$A c q$ & $0.082 * *$ & $(2.21)$ & $0.083 * *$ & $(2.30)$ & 0.029 & $(0.89)$ \\
\hline Fin_Issue & -0.005 & $(-0.20)$ & -0.010 & $(-0.44)$ & -0.010 & $(-0.47)$ \\
\hline $\operatorname{Rev}$ & -0.040 & $(-1.21)$ & -0.043 & $(-1.27)$ & -0.039 & $(-1.20)$ \\
\hline$I n v_{-} A R$ & $0.584 * * *$ & $(3.71)$ & $0.617 * * *$ & $(3.92)$ & $0.568 * * *$ & $(3.62)$ \\
\hline$G W \_I n t a n$ & $0.412 * * *$ & $(3.81)$ & $0.431 * * *$ & $(4.06)$ & $0.279 * * *$ & $(2.76)$ \\
\hline GW_Impair & 0.166 & $(0.18)$ & 0.192 & $(0.21)$ & -0.095 & $(-0.10)$ \\
\hline Intan_Impair & -2.186 & $(-1.44)$ & -2.379 & $(-1.55)$ & -1.936 & $(-1.20)$ \\
\hline PPE_Impair & 0.190 & $(0.41)$ & 0.274 & $(0.59)$ & $0.786^{*}$ & $(1.72)$ \\
\hline$P P E$ & 0.093 & $(1.59)$ & $0.111 * *$ & $(2.00)$ & 0.032 & $(0.55)$ \\
\hline$R D \_\operatorname{Exp}$ & 0.260 & $(0.98)$ & 0.132 & $(0.51)$ & -0.377 & $(-1.29)$ \\
\hline Pension & 0.035 & $(0.62)$ & 0.035 & $(0.64)$ & 0.010 & $(0.20)$ \\
\hline Tax_Vol & 0.013 & $(1.02)$ & 0.013 & $(1.11)$ & 0.012 & $(1.28)$ \\
\hline Invest & -0.096 & $(-1.11)$ & -0.081 & $(-0.99)$ & $-0.141 *$ & $(-1.66)$ \\
\hline Legal_Liability & 0.078 & $(0.01)$ & 1.732 & $(0.32)$ & -2.259 & $(-0.39)$ \\
\hline Log_Aud_Fee & $0.163 * * *$ & $(6.31)$ & $0.155 * * *$ & $(6.09)$ & $0.177 * * *$ & $(5.45)$ \\
\hline DecYrEnd & $-0.061 *$ & $(-1.86)$ & $-0.056^{*}$ & $(-1.76)$ & -0.024 & $(-0.80)$ \\
\hline Audptr_Ind_Spec & $0.153 * * *$ & $(2.69)$ & $0.103^{*}$ & $(1.88)$ & $0.166 * * *$ & $(2.79)$ \\
\hline Audptr_Econ_Bond & -0.137 & $(-1.56)$ & -0.088 & $(-1.04)$ & -0.011 & $(-0.16)$ \\
\hline Audfirm_Ind_Spec & 0.258 & $(1.31)$ & -0.073 & $(-0.37)$ & -0.093 & $(-0.45)$ \\
\hline Audfirm_Econ_Bond & 0.394 & $(0.55)$ & 0.680 & $(0.79)$ & 1.188 & $(1.43)$ \\
\hline KAMreg & -0.001 & $(-0.03)$ & -0.021 & $(-0.46)$ & -0.036 & $(-0.84)$ \\
\hline MainMkt & 0.003 & $(0.07)$ & 0.023 & $(0.45)$ & -0.019 & $(-0.38)$ \\
\hline$O C F$ & $0.253 *$ & $(1.78)$ & $0.235^{*}$ & $(1.66)$ & -0.010 & $(-0.07)$ \\
\hline Ptr_Busyness & -0.007 & $(-0.23)$ & -0.008 & $(-0.26)$ & & \\
\hline Big4 & -0.010 & $(-0.26)$ & & & & \\
\hline Constant & $-1.414 * * *$ & $(-5.25)$ & $-1.198 * * *$ & $(-4.46)$ & $-1.513 * * *$ & $(-3.12)$ \\
\hline Observations & 2,819 & & 2,819 & & 2,819 & \\
\hline Adjusted R-squared & 0.356 & & 0.389 & & 0.497 & \\
\hline Year FE & Yes & & Yes & & Yes & \\
\hline Industry FE & Yes & & Yes & & Yes & \\
\hline Audit Firm FE & No & & Yes & & Yes & \\
\hline Partner FE & No & & No & & Yes & \\
\hline
\end{tabular}

The symbols ***,**, and * denote significance at the 0.01,0.05, and 0.10 levels, respectively (two-tailed for all $t$ statistics). See Appendix A for variable definitions. See Table 1 for sample composition. We use high-dimensional fixed-effect linear regression with heteroskedasticity robust standard errors clustered on client company. 


\section{TABLE 3}

\section{Estimating Audit Partner Fixed Effects on KAM Reporting Outcomes (continued)}

\section{Panel C: Regression Results for KAM Communication- Number of Words}

Dependent Variable: wrdsperKAM_dm

\begin{tabular}{|c|c|c|c|c|c|c|}
\hline \multirow[b]{2}{*}{ Variables } & \multicolumn{2}{|c|}{ Base Model } & \multicolumn{2}{|c|}{ Audit Firm FE } & \multicolumn{2}{|c|}{$\underline{\text { Audit Partner FE }}$} \\
\hline & Coef & t-stat & Coef & t-stat & Coef & t-stat \\
\hline Size & -2.452 & $(-0.76)$ & -3.691 & $(-1.20)$ & -2.127 & $(-0.74)$ \\
\hline Subs & 9.781 & $(1.23)$ & $14.817 *$ & $(1.94)$ & $17.323 * *$ & $(2.41)$ \\
\hline$R O A$ & -7.843 & $(-0.29)$ & -14.081 & $(-0.57)$ & -13.435 & $(-0.58)$ \\
\hline Sales_Vol & -0.006 & $(-1.06)$ & $-0.010 *$ & $(-1.73)$ & -0.002 & $(-0.37)$ \\
\hline Loss & 4.314 & $(0.65)$ & 3.297 & $(0.52)$ & 1.605 & $(0.28)$ \\
\hline Leverage & -0.217 & $(-0.12)$ & 0.980 & $(0.59)$ & 1.657 & (1.06) \\
\hline$B T M$ & $12.857 * * *$ & $(2.92)$ & $13.392 * * *$ & $(3.15)$ & $14.807 * * *$ & $(3.70)$ \\
\hline$A c q$ & $-13.924 * *$ & $(-2.21)$ & $-12.609 * *$ & $(-2.10)$ & -6.794 & $(-1.24)$ \\
\hline Fin_Issue & -3.455 & $(-0.66)$ & -1.927 & $(-0.37)$ & -2.102 & $(-0.44)$ \\
\hline $\operatorname{Rev}$ & -12.070 & $(-1.57)$ & -10.056 & $(-1.30)$ & -4.877 & $(-0.76)$ \\
\hline$I n v_{-} A R$ & -11.533 & $(-0.32)$ & -17.608 & $(-0.50)$ & -34.602 & $(-1.07)$ \\
\hline GW_Intan & -17.595 & $(-0.92)$ & -8.998 & $(-0.49)$ & -27.194 & $(-1.50)$ \\
\hline GW_Impair & $407.797 * *$ & $(2.29)$ & $416.264 * *$ & $(2.41)$ & $343.639 * *$ & $(2.22)$ \\
\hline Intan_Impair & 275.418 & $(0.72)$ & 228.723 & $(0.65)$ & -5.018 & $(-0.01)$ \\
\hline PPE_Impair & 150.682 & (1.14) & 131.062 & $(1.06)$ & 85.838 & $(0.70)$ \\
\hline$P P E$ & -9.490 & $(-0.83)$ & -7.683 & $(-0.73)$ & -1.580 & $(-0.17)$ \\
\hline$R D \_E x p$ & -16.406 & $(-0.29)$ & -58.526 & $(-1.10)$ & 20.317 & $(0.34)$ \\
\hline Pension & $-20.366^{* *}$ & $(-2.55)$ & $-18.950 * *$ & $(-2.43)$ & $-14.487 * *$ & $(-2.11)$ \\
\hline Tax_Vol & $-3.544 * *$ & $(-2.23)$ & $-3.949 * *$ & $(-2.44)$ & $-4.682 * * *$ & $(-2.94)$ \\
\hline Invest & 19.698 & (1.17) & 14.051 & $(0.89)$ & 12.401 & $(0.74)$ \\
\hline Legal_Liability & 485.892 & $(0.57)$ & 291.638 & $(0.37)$ & 144.305 & $(0.22)$ \\
\hline Log_Aud_Fee & $26.846 * * *$ & $(5.46)$ & $22.304 * * *$ & $(4.66)$ & $27.258 * * *$ & (4.64) \\
\hline DecYrEnd & $23.920 * * *$ & $(3.95)$ & $26.888 * * *$ & $(4.52)$ & $26.657 * * *$ & $(4.74)$ \\
\hline Audptr_Ind_Spec & -16.949 & $(-1.44)$ & $-22.909 *$ & $(-1.89)$ & $-23.748 * *$ & $(-2.15)$ \\
\hline Audptr_Econ_Bond & $34.311 * *$ & $(2.12)$ & $43.314 * * *$ & $(2.70)$ & 15.022 & $(1.17)$ \\
\hline Audfirm_Ind_Spec & $120.226^{* * *}$ & $(3.17)$ & $129.063 * * *$ & $(3.46)$ & $106.317 * * *$ & $(2.85)$ \\
\hline Audfirm_Econ_Bond & $\cdot 1,028.068 * * *$ & $(-6.57)$ & $-514.604 * * *$ & $(-4.20)$ & $-292.095 * *$ & $(-2.04)$ \\
\hline KAMreg & 4.608 & $(0.53)$ & 3.301 & $(0.39)$ & 4.969 & $(0.69)$ \\
\hline MainMkt & $27.164 * * *$ & $(2.88)$ & $24.819 * * *$ & $(2.75)$ & $33.981 * * *$ & $(3.47)$ \\
\hline$O C F$ & 30.314 & $(0.98)$ & 1.918 & $(0.06)$ & -8.643 & $(-0.31)$ \\
\hline Ptr_Busyness & -2.926 & $(-0.50)$ & 0.873 & $(0.16)$ & & \\
\hline Big4 & -8.001 & $(-0.91)$ & & & & \\
\hline Constant & $-344.186 * * *$ & $(-6.76)$ & $-273.569 * * *$ & $(-5.35)$ & $-375.498 * * *$ & $(-5.12)$ \\
\hline Observations & 2,819 & & 2,819 & & 2,819 & \\
\hline Adjusted R-squared & 0.121 & & 0.172 & & 0.350 & \\
\hline Year FE & Yes & & Yes & & Yes & \\
\hline Industry FE & Yes & & Yes & & Yes & \\
\hline Audit Firm FE & No & & Yes & & Yes & \\
\hline Partner FE & No & & No & & Yes & \\
\hline
\end{tabular}

The symbols ***,**, and $*$ denote significance at the 0.01, 0.05, and 0.10 levels, respectively (two-tailed for all $t$ statistics). See Appendix A for variable definitions. See Table 1 for sample composition. We use high-dimensional fixed-effect linear regression with heteroskedasticity robust standard errors clustered on client company. 


\section{TABLE 3 \\ Estimating Audit Partner Fixed Effects on KAM Reporting Outcomes (continued)}

\begin{tabular}{|c|c|c|c|c|c|c|}
\hline \multicolumn{7}{|c|}{ Panel D: Regression Results for KAM Communication- Fog Index } \\
\hline \multirow[b]{2}{*}{ Variables } & Base & odel & Audit & $\mathbf{n} \mathbf{F E}$ & \multicolumn{2}{|c|}{ Audit Partner FE } \\
\hline & Coef & t-stat & Coef & t-stat & Coef & t-stat \\
\hline Size & $-0.138 * *$ & $(-2.24)$ & $-0.145 * *$ & $(-2.53)$ & $-0.149 * * *$ & $(-2.97)$ \\
\hline Subs & -0.031 & $(-0.24)$ & -0.026 & $(-0.20)$ & -0.005 & $(-0.04)$ \\
\hline ROA & 0.211 & $(0.43)$ & 0.040 & $(0.08)$ & -0.092 & $(-0.22)$ \\
\hline Sales_Vol & $0.000 * * *$ & $(2.86)$ & $0.000^{* *}$ & $(2.09)$ & 0.000 & (1.17) \\
\hline Loss & -0.056 & $(-0.44)$ & -0.072 & $(-0.59)$ & 0.038 & $(0.35)$ \\
\hline Leverage & 0.037 & $(1.04)$ & $0.059^{*}$ & $(1.77)$ & $0.087 * * *$ & (3.07) \\
\hline BTM & 0.008 & $(0.12)$ & 0.030 & $(0.48)$ & 0.023 & $(0.36)$ \\
\hline$A c q$ & $-0.170 *$ & $(-1.73)$ & $-0.168 *$ & $(-1.73)$ & -0.025 & $(-0.27)$ \\
\hline Fin_Issue & 0.043 & $(0.46)$ & 0.108 & $(1.22)$ & 0.018 & $(0.22)$ \\
\hline $\operatorname{Rev}$ & $-0.394 * * *$ & $(-3.45)$ & $-0.362 * * *$ & $(-3.34)$ & $-0.313 * * *$ & $(-2.86)$ \\
\hline$I n v \_A R$ & 0.187 & $(0.36)$ & 0.051 & $(0.10)$ & 0.116 & $(0.25)$ \\
\hline$G W_{-}$Intan & -0.025 & $(-0.08)$ & 0.028 & $(0.09)$ & -0.209 & $(-0.69)$ \\
\hline GW_Impair & $-4.340^{*}$ & $(-1.69)$ & $-4.219 *$ & $(-1.67)$ & $-4.961 * * *$ & $(-2.58)$ \\
\hline Intan_Impair & 6.883 & $(1.15)$ & 5.999 & $(1.00)$ & 7.479 & $(1.38)$ \\
\hline$P P E_{-}$Impair & -0.896 & $(-0.27)$ & -0.775 & $(-0.24)$ & -0.429 & $(-0.20)$ \\
\hline$P P E$ & -0.309 & $(-1.52)$ & $-0.336 *$ & $(-1.71)$ & $-0.395 * *$ & $(-2.22)$ \\
\hline$R D \_E x p$ & -0.082 & $(-0.09)$ & -0.468 & $(-0.49)$ & 0.033 & $(0.04)$ \\
\hline Pension & 0.109 & $(0.82)$ & 0.115 & $(0.86)$ & 0.197 & $(1.57)$ \\
\hline Tax_Vol & -0.029 & $(-1.24)$ & $-0.042 *$ & $(-1.79)$ & -0.027 & $(-1.22)$ \\
\hline Invest & $0.913 * * *$ & $(3.49)$ & $0.870 * * *$ & $(3.33)$ & $1.073 * * *$ & $(3.96)$ \\
\hline Legal_Liability & -1.708 & $(-0.22)$ & -9.595 & $(-1.26)$ & -9.536 & $(-1.34)$ \\
\hline Log_Aud_Fee & $0.383 * * *$ & $(4.03)$ & $0.356 * * *$ & $(3.82)$ & $0.292 * * *$ & $(3.33)$ \\
\hline DecYrEnd & 0.062 & $(0.58)$ & 0.096 & $(0.95)$ & 0.122 & $(1.19)$ \\
\hline Audptr_Ind_Spec & $-0.670^{* * *}$ & $(-2.99)$ & $-0.547 * *$ & $(-2.50)$ & $-0.391 *$ & $(-1.84)$ \\
\hline Audptr_Econ_Bond & 0.383 & $(1.23)$ & 0.319 & $(1.06)$ & $0.454^{*}$ & $(1.86)$ \\
\hline Audfirm_Ind_Spec & $1.564 * *$ & (2.09) & $2.368 * * *$ & $(3.28)$ & $1.451 * *$ & $(2.03)$ \\
\hline Audfirm_Econ_Bond & $-15.358 * * *$ & $(-5.04)$ & $-9.712 * * *$ & $(-3.72)$ & -3.439 & $(-1.30)$ \\
\hline KAMreg & -0.133 & $(-0.85)$ & -0.105 & $(-0.69)$ & -0.126 & $(-0.96)$ \\
\hline MainMkt & $0.716 * * *$ & $(4.38)$ & $0.714 * * *$ & $(4.45)$ & $0.508 * * *$ & $(2.83)$ \\
\hline$O C F$ & 0.438 & $(0.77)$ & 0.102 & $(0.19)$ & 0.481 & $(0.99)$ \\
\hline Ptr_Busyness & $-0.221 * *$ & $(-2.15)$ & $-0.192 * *$ & $(-1.98)$ & & \\
\hline Big4 & $-2.052 * * *$ & $(-11.84)$ & & & & \\
\hline Constant & $-2.422 * * *$ & $(-2.61)$ & $-4.120 * * *$ & $(-4.29)$ & $-2.950 * *$ & $(-2.14)$ \\
\hline Observations & 2,819 & & 2,819 & & 2,819 & \\
\hline Adjusted R-squared & 0.143 & & 0.188 & & 0.362 & \\
\hline Year FE & Yes & & Yes & & Yes & \\
\hline Industry FE & Yes & & Yes & & Yes & \\
\hline Audit Firm FE & No & & Yes & & Yes & \\
\hline Partner FE & No & & No & & Yes & \\
\hline
\end{tabular}

The symbols ***,**, and $*$ denote significance at the $0.01,0.05$, and 0.10 levels, respectively (two-tailed for all $t$ statistics). See Appendix A for variable definitions. See Table 1 for sample composition. We use high-dimensional fixed-effect linear regression with heteroskedasticity robust standard errors clustered on client company. 
TABLE 3

Estimating Audit Partner Fixed Effects on KAM Reporting Outcomes (continued)

\section{Panel E: Regression Results for KAM Communication- Linguistic Cognitive Complexity}

\begin{tabular}{|c|c|c|c|c|c|c|}
\hline \multirow[b]{3}{*}{ Variables } & \multicolumn{4}{|c|}{ Dependent Variable: $C o g P r o c \_d m$} & \multirow{2}{*}{\multicolumn{2}{|c|}{ Audit Partner FE }} \\
\hline & \multicolumn{2}{|c|}{ Base Model } & \multicolumn{2}{|c|}{ Audit Firm FE } & & \\
\hline & Coef & t-stat & Coef & t-stat & Coef & t-stat \\
\hline Size & $-0.127 * *$ & $(-2.31)$ & $-0.120 * *$ & $(-2.19)$ & -0.074 & $(-1.49)$ \\
\hline Subs & -0.142 & $(-1.06)$ & -0.169 & $(-1.30)$ & $-0.235^{* *}$ & $(-1.97)$ \\
\hline$R O A$ & -0.497 & $(-1.06)$ & -0.485 & $(-1.07)$ & $-0.758 *$ & $(-1.74)$ \\
\hline Sales_Vol & $0.000 *$ & $(1.87)$ & 0.000 & $(1.51)$ & 0.000 & $(1.27)$ \\
\hline Loss & $-0.307 * *$ & $(-2.53)$ & $-0.304 * * *$ & $(-2.60)$ & $-0.201 *$ & $(-1.87)$ \\
\hline Leverage & 0.029 & $(0.87)$ & 0.036 & $(1.13)$ & 0.015 & $(0.55)$ \\
\hline$B T M$ & -0.073 & $(-0.94)$ & -0.059 & $(-0.80)$ & -0.046 & $(-0.65)$ \\
\hline$A c q$ & 0.073 & $(0.72)$ & 0.067 & $(0.68)$ & 0.046 & $(0.50)$ \\
\hline Fin_Issue & 0.004 & $(0.04)$ & 0.046 & $(0.58)$ & -0.034 & $(-0.45)$ \\
\hline $\operatorname{Rev}$ & -0.042 & $(-0.37)$ & -0.008 & $(-0.07)$ & 0.066 & $(0.58)$ \\
\hline$I n v \_A R$ & -0.301 & $(-0.59)$ & -0.453 & $(-0.93)$ & -0.279 & $(-0.64)$ \\
\hline$G W \_I n t a n$ & $0.621^{*}$ & $(1.81)$ & 0.524 & $(1.57)$ & $0.620^{*}$ & $(1.76)$ \\
\hline GW_Impair & 1.384 & $(0.60)$ & 1.401 & $(0.60)$ & 0.622 & $(0.28)$ \\
\hline Intan_Impair & 1.611 & $(0.31)$ & 0.792 & $(0.15)$ & -0.755 & $(-0.14)$ \\
\hline PPE_Impair & -0.343 & $(-0.27)$ & -0.240 & $(-0.18)$ & -0.387 & $(-0.21)$ \\
\hline$P P E$ & -0.228 & $(-1.11)$ & -0.241 & $(-1.22)$ & -0.167 & $(-0.84)$ \\
\hline$R D \_E x p$ & 0.298 & $(0.29)$ & 0.366 & $(0.37)$ & 0.341 & $(0.32)$ \\
\hline Pension & $0.409 * * *$ & $(2.97)$ & $0.386^{* * *}$ & (3.13) & $0.335 * * *$ & $(2.71)$ \\
\hline Tax_Vol & -0.022 & $(-0.68)$ & -0.021 & $(-0.67)$ & -0.029 & $(-1.00)$ \\
\hline Invest & -0.277 & $(-0.97)$ & -0.285 & $(-1.01)$ & -0.067 & $(-0.25)$ \\
\hline Legal_Liability & -0.896 & $(-0.09)$ & -5.533 & $(-0.60)$ & -14.476 & $(-1.52)$ \\
\hline Log_Aud_Fee & $0.294 * * *$ & $(3.70)$ & $0.305^{* * *}$ & $(3.89)$ & $0.349 * * *$ & $(3.91)$ \\
\hline DecYrEnd & 0.058 & $(0.53)$ & 0.092 & $(0.88)$ & 0.046 & $(0.47)$ \\
\hline Audptr_Ind_Spec & 0.028 & $(0.15)$ & 0.173 & $(0.90)$ & 0.172 & $(0.90)$ \\
\hline Audptr_Econ_Bond & -0.243 & $(-0.90)$ & -0.408 & $(-1.47)$ & $-0.464 * *$ & $(-2.23)$ \\
\hline Audfirm_Ind_Spec & 0.186 & $(0.29)$ & 0.542 & $(0.85)$ & -0.455 & $(-0.80)$ \\
\hline Audfirm_Econ_Bond & $-4.701 * *$ & $(-2.16)$ & $-4.406^{*}$ & $(-1.67)$ & 1.508 & $(0.67)$ \\
\hline KAMreg & 0.067 & $(0.52)$ & 0.096 & $(0.74)$ & 0.073 & $(0.64)$ \\
\hline MainMkt & 0.188 & $(0.96)$ & 0.228 & (1.18) & -0.058 & $(-0.29)$ \\
\hline$O C F$ & $1.436 * * *$ & $(2.68)$ & $1.422 * * *$ & $(2.67)$ & $1.424 * * *$ & $(2.77)$ \\
\hline Ptr_Busyness & 0.005 & $(0.05)$ & -0.029 & $(-0.30)$ & & \\
\hline Big4 & $-0.555^{* * *}$ & $(-3.57)$ & & & & \\
\hline Constant & $-2.457 * * *$ & $(-3.08)$ & $-3.123^{* * *}$ & $(-3.88)$ & $-4.300 * * *$ & $(-2.70)$ \\
\hline Observations & 2,819 & & 2,819 & & 2,819 & \\
\hline Adjusted R-squared & 0.028 & & 0.051 & & 0.245 & \\
\hline Year FE & Yes & & Yes & & Yes & \\
\hline Industry FE & Yes & & Yes & & Yes & \\
\hline Audit Firm FE & No & & Yes & & Yes & \\
\hline Partner FE & No & & No & & Yes & \\
\hline
\end{tabular}

The symbols ***,**, and * denote significance at the 0.01, 0.05, and 0.10 levels, respectively (two-tailed for all $t$ statistics). See Appendix A for variable definitions. See Table 1 for sample composition. We use high-dimensional fixed-effect linear regression with heteroskedasticity robust standard errors clustered on client company. 
TABLE 4

Testing the Explanatory Power of Audit Partner and Audit Firm Fixed Effects

\section{Panel A: Testing the Significance of Audit Partner Fixed Effects}

\begin{tabular}{|c|c|c|c|c|c|c|c|c|}
\hline & Num_KAMs_dm & wtd_Diversity & wrdsperKAM_dm & Fog_dm & CogProc_dm & Insight_dm & Cause_dm & Discrep_dm \\
\hline F-statistic & 8.00 & 8.32 & 9.34 & 8.16 & 7.97 & 9.00 & 9.58 & 9.92 \\
\hline p-val on F-stat & 0.000 & 0.000 & 0.000 & 0.000 & 0.000 & 0.000 & 0.000 & 0.000 \\
\hline Increase in adjusted $\mathrm{R}^{2}$ over audit firm FE Model (3) & $15.30 \%$ & $10.80 \%$ & $17.80 \%$ & $17.40 \%$ & $19.40 \%$ & $21.40 \%$ & $16.30 \%$ & $21.60 \%$ \\
\hline Percent increase in adjusted $\mathrm{R}^{2}$ over audit firm FE Model (3) & $57.74 \%$ & $27.76 \%$ & $103.49 \%$ & $92.55 \%$ & $380.39 \%$ & $163.36 \%$ & $187.36 \%$ & $270.00 \%$ \\
\hline Vuong Chi-Squared Statistic & 13.98 & 13.77 & 12.87 & 14.2 & 14.63 & 15.42 & 14.32 & 15.08 \\
\hline p-val on Vuong stat & 0.000 & 0.000 & 0.000 & 0.000 & 0.000 & 0.000 & 0.000 & 0.000 \\
\hline $\begin{array}{l}\text { Percent of sample partners with significant fixed effect } \\
\text { coefficients (compared to } 5 \% \text { tolerable error rate) }\end{array}$ & $16 \%$ & $18 \%$ & $16 \%$ & $25 \%$ & $22 \%$ & $18 \%$ & $38 \%$ & $17 \%$ \\
\hline
\end{tabular}

The symbols $* * * * *$, and $*$ denote significance at the $0.01,0.05$, and 0.10 levels, respectively. F-statistics report the results of exclusion restriction tests of whether the fixed-effect indicators for all partners are jointly significant to predicting KAM reporting outcomes. Increase in adjusted $R^{2}$ is calculated as the adjusted $R^{2}$ from the audit partner fixed-effects Model (1) minus the adjusted $R^{2}$ from the audit firm fixed-effects Model (3). The percent increase in adjusted $R^{2}$ divides this difference by the adjusted $R^{2}$ from the audit firm fixed-effects Model (3). Vuong Chi-Squared statistics are a likelihood ratio test of whether the change in the $R^{2}$ from the audit firm fixed-effects Model (3) to the audit partner fixed-effects Model (1) is statistically significant. The percentage of significant fixed-effect coefficients denotes the percent of sample partners whose fixed-effect indicator variables take on significant coefficients at a $p \leq 0.05$ level.

\section{Panel B: Testing the Significance of Audit Firm Fixed Effects}

\begin{tabular}{|c|c|c|c|c|c|c|c|c|}
\hline & $N u m \_K A M s \_d m$ & wtd_Diversity & wrdsperKAM_dm & Fog_dm & CogProc_dm & Insight_dm & Cause_dm & Discrep_dm \\
\hline F-statistic & 5.68 & 8.49 & 14.52 & 26.79 & 6.27 & 15.31 & 9.07 & 8.48 \\
\hline p-val on F-stat & 0.000 & 0.000 & 0.000 & 0.000 & 0.000 & 0.000 & 0.000 & 0.000 \\
\hline Increase in adj R-squared over base Model (2) & $3.00 \%$ & $3.30 \%$ & $5.10 \%$ & $4.50 \%$ & $2.30 \%$ & $5.00 \%$ & $1.80 \%$ & $5.20 \%$ \\
\hline Percent increase in R-Squared over base Model (2) & $12.77 \%$ & $9.27 \%$ & $42.15 \%$ & $31.47 \%$ & $82.14 \%$ & $61.73 \%$ & $26.09 \%$ & $185.71 \%$ \\
\hline Vuong Chi-Squared Statistic & 5.22 & 6.43 & 6.45 & 6.06 & 4.43 & 5.42 & 3.72 & 6.39 \\
\hline p-val on Vuong stat & 0.000 & 0.000 & 0.000 & 0.000 & 0.000 & 0.000 & 0.000 & 0.000 \\
\hline $\begin{array}{l}\text { Percent of sample audit firms with significant fixed effect } \\
\text { coefficients (compared to } 5 \% \text { tolerable error rate) }\end{array}$ & $20 \%$ & $20 \%$ & $70 \%$ & $50 \%$ & $30 \%$ & $70 \%$ & $50 \%$ & $40 \%$ \\
\hline
\end{tabular}

The symbols $* * * * *$, and $*$ denote significance at the $0.01,0.05$, and 0.10 levels, respectively. F-statistics report the results of exclusion restriction tests of whether the fixed-effect indicators for all audit firms are jointly significant to predicting KAM reporting outcomes. Increase in adjusted $R^{2}$ is calculated as the adjusted $R^{2}$ from the audit firm fixed-effects Model (1) minus the adjusted $R^{2}$ from the base Model (2) comprising control variables and industry-year fixed effects with no audit firm or audit partner fixed effects. The percent increase in adjusted $R^{2}$ divides this difference by the adjusted $R^{2}$ from the base Model (2). Vuong Chi-Squared statistics are a likelihood ratio test of whether the change in the adjusted $R^{2}$ from the base Model (2) to the audit firm fixed-effects Model (3) is statistically significant. The percentage of significant fixed-effect coefficients denotes the percent of audit firms whose fixed-effect indicator variables take on significant coefficients at a $p \leq 0.05$ level. 


\section{TABLE 5}

\section{Audit Partners' KAM Reporting Styles and Other Audit Outcomes}

\section{Panel A: Audit Engagement Fees}

\begin{tabular}{|c|c|c|c|c|c|c|c|c|c|c|c|c|c|c|}
\hline \multicolumn{15}{|c|}{ Dependent Variable: Log_Aud_Fees } \\
\hline Variables & Coef & t-stat & Coef & t-stat & Coef & t-stat & Coef & t-stat & Coef & t-stat & Coef & t-stat & Coef & t-stat \\
\hline Volume_Style & $0.072 * * *$ & $(2.54)$ & & & & & & & & & & & & \\
\hline Diversity_Style & & & $0.203 * * *$ & (3.34) & & & & & & & & & & \\
\hline CommStyle_Wrds & & & & & $0.001 *$ & $(1.78)$ & & & & & & & & \\
\hline CommStyle_Fog & & & & & & & $0.027 *$ & $(1.84)$ & & & & & & \\
\hline CommStyle_CogProc & & & & & & & & & 0.018 & (1.47) & & & & \\
\hline CommStyle_Cause & & & & & & & & & & & $-0.043^{*}$ & $(-1.83)$ & & \\
\hline CommStyle_Insight & & & & & & & & & & & & & $0.058 * * *$ & $(3.24)$ \\
\hline Size & $0.457 * * *$ & $(23.36)$ & $0.457 * * *$ & $(23.29)$ & $0.460 * * *$ & $(23.43)$ & $0.460 * * *$ & $(23.38)$ & $0.462 * * *$ & $(23.54)$ & $0.460 * * *$ & $(23.47)$ & $0.465 * * *$ & (23.54) \\
\hline Subs & $0.458 * * *$ & $(7.37)$ & $0.454 * * *$ & $(7.30)$ & $0.458 * * *$ & $(7.44)$ & $0.453^{* * *} *$ & $(7.33)$ & $0.449 * * *$ & $(7.23)$ & $0.451 * * *$ & $(7.38)$ & $0.438 * * *$ & (7.11) \\
\hline$R O A$ & $-0.470 * * *$ & $(-2.63)$ & $-0.456^{* * *}$ & $(-2.59)$ & $-0.476^{* * *}$ & $(-2.70)$ & $-0.477 * * *$ & $(-2.72)$ & $-0.478 * * *$ & $(-2.68)$ & $-0.473 * * *$ & $(-2.67)$ & $-0.477 * * *$ & $(-2.72)$ \\
\hline Sales_Vol & 0.000 & (1.37) & 0.000 & $(1.28)$ & 0.000 & $(1.38)$ & 0.000 & $(1.30)$ & 0.000 & (1.30) & 0.000 & $(1.45)$ & 0.000 & $(1.36)$ \\
\hline Loss & -0.037 & $(-0.82)$ & -0.033 & $(-0.74)$ & -0.039 & $(-0.86)$ & -0.032 & $(-0.72)$ & -0.031 & $(-0.70)$ & -0.038 & $(-0.84)$ & -0.024 & $(-0.55)$ \\
\hline Leverage & $0.035^{* *}$ & $(2.37)$ & $0.035 * *$ & (2.36) & $0.037 * *$ & $(2.49)$ & $0.038 * *$ & $(2.53)$ & $0.037 * *$ & $(2.46)$ & $0.036 * *$ & $(2.40)$ & $0.038 * *$ & (2.53) \\
\hline BTM & $-0.077 * *$ & $(-2.32)$ & $-0.083 * *$ & $(-2.51)$ & $-0.083 * *$ & $(-2.44)$ & $-0.086^{* *}$ & $(-2.54)$ & $-0.081 * *$ & $(-2.41)$ & $-0.083 * *$ & $(-2.43)$ & $-0.090 * * *$ & $(-2.66)$ \\
\hline$A c q$ & $0.256^{* * *} *$ & $(5.92)$ & $0.251 * * *$ & $(5.85)$ & $0.266 * * *$ & $(6.22)$ & $0.266^{* * * *}$ & $(6.29)$ & $0.259 * * *$ & $(6.00)$ & $0.260 * * *$ & $(6.10)$ & $0.257 * * *$ & $(6.02)$ \\
\hline$O C F$ & -0.288 & $(-1.34)$ & -0.311 & $(-1.48)$ & -0.286 & $(-1.34)$ & -0.272 & $(-1.28)$ & -0.269 & $(-1.26)$ & -0.285 & $(-1.33)$ & -0.260 & $(-1.23)$ \\
\hline$I n v \_A R$ & $0.706 * * *$ & $(3.31)$ & $0.674 * * *$ & $(3.25)$ & $0.651 * * *$ & $(3.06)$ & $0.661 * * *$ & $(3.10)$ & $0.667 * * *$ & (3.12) & $0.679 * * *$ & $(3.21)$ & $0.677 * * *$ & (3.14) \\
\hline Fin_Issue & -0.025 & $(-0.73)$ & -0.026 & $(-0.76)$ & -0.023 & $(-0.68)$ & -0.028 & $(-0.82)$ & -0.022 & $(-0.64)$ & -0.028 & $(-0.81)$ & -0.031 & $(-0.91)$ \\
\hline $\operatorname{Rev}$ & $0.133 * * *$ & $(2.90)$ & $0.134 * * *$ & $(2.97)$ & $0.136 * * *$ & (2.89) & $0.135^{* * *}$ & $(2.84)$ & $0.137 * * *$ & (2.91) & $0.132 * * *$ & (2.81) & $0.136 * * *$ & $(2.84)$ \\
\hline GW_Intan & $0.777 * * *$ & $(5.53)$ & $0.753 * * *$ & $(5.38)$ & $0.751 * * *$ & $(5.31)$ & $0.758 * * *$ & $(5.43)$ & $0.771 * * *$ & $(5.46)$ & $0.771 * * *$ & $(5.48)$ & $0.778 * * *$ & $(5.53)$ \\
\hline GW_Impair & 0.324 & $(0.35)$ & 0.242 & $(0.27)$ & 0.334 & $(0.37)$ & 0.325 & $(0.36)$ & 0.309 & $(0.34)$ & 0.403 & $(0.45)$ & 0.214 & $(0.24)$ \\
\hline Intan_Impair & $3.719 * *$ & $(2.53)$ & $4.007 * * *$ & $(2.81)$ & $3.864 * * *$ & $(2.78)$ & $4.063 * * *$ & $(2.87)$ & $3.782 * * *$ & $(2.66)$ & 4.120 *** & (2.91) & $4.013 * * *$ & $(2.88)$ \\
\hline PPE_Impair & $-0.750 *$ & $(-1.71)$ & $-0.782 *$ & $(-1.81)$ & $-0.832^{*}$ & $(-1.86)$ & $-0.842^{*}$ & $(-1.91)$ & $-0.798^{*}$ & $(-1.78)$ & $-0.785^{*}$ & $(-1.73)$ & $-0.879 *$ & $(-1.96)$ \\
\hline$P P E$ & 0.086 & (1.18) & 0.077 & (1.08) & 0.089 & $(1.21)$ & 0.083 & (1.14) & 0.086 & (1.18) & 0.078 & (1.06) & 0.080 & $(1.10)$ \\
\hline$R D \_E x p$ & $0.739 *$ & (1.87) & $0.672 *$ & (1.74) & $0.801 * *$ & $(2.05)$ & $0.816^{* *}$ & (2.08) & $0.808^{* *}$ & (2.07) & $0.794 * *$ & (2.03) & $0.837 * *$ & (2.16) \\
\hline Pension & $0.152^{* * *}$ & (2.43) & $0.141 * *$ & $(2.28)$ & $0.149 * *$ & $(2.35)$ & $0.152 * *$ & (2.38) & $0.145^{* *}$ & $(2.28)$ & $0.152 * *$ & (2.39) & $0.154 * *$ & $(2.40)$ \\
\hline Tax_Vol & $0.031 * *$ & $(2.42)$ & $0.035^{* * *} *$ & (2.69) & $0.033^{* *}$ & $(2.45)$ & $0.035^{* * *}$ & $(2.65)$ & $0.034 * *$ & $(2.55)$ & $0.033^{* *}$ & $(2.51)$ & $0.034 * *$ & $(2.51)$ \\
\hline Invest & $-0.950 * * *$ & $(-6.96)$ & $-0.962 * * *$ & $(-7.03)$ & $-0.970 * * *$ & $(-6.95)$ & $-0.967 * * *$ & $(-6.98)$ & $-0.951 * * *$ & $(-6.87)$ & $-0.974 * * *$ & $(-6.98)$ & $-0.952 * * *$ & $(-6.92)$ \\
\hline Legal_Liability & $12.353^{* *}$ & $(2.16)$ & $12.147 * *$ & $(2.15)$ & $12.362 * *$ & $(2.15)$ & $12.448 * *$ & $(2.12)$ & $11.998 * *$ & $(2.10)$ & $12.779 * *$ & (2.19) & $12.299 * *$ & $(2.11)$ \\
\hline Big4 & 0.001 & $(0.02)$ & 0.028 & $(0.55)$ & -0.008 & $(-0.15)$ & 0.053 & $(0.92)$ & -0.013 & $(-0.24)$ & 0.062 & (1.02) & 0.075 & (1.38) \\
\hline DecYrEnd & $0.147 * * *$ & (3.18) & $0.147 * * *$ & $(3.20)$ & $0.140 * * *$ & $(3.03)$ & $0.140 * * *$ & $(3.01)$ & $0.141 * * *$ & (3.04) & $0.135^{* * *} *$ & $(2.92)$ & $0.141 * * *$ & (3.05) \\
\hline KAMreg & 0.064 & $(1.27)$ & 0.066 & $(1.31)$ & 0.074 & (1.47) & 0.073 & $(1.46)$ & 0.075 & $(1.50)$ & 0.074 & (1.47) & 0.077 & (1.54) \\
\hline MainMkt & $0.166^{* *}$ & $(2.48)$ & $0.149 * *$ & $(2.25)$ & $0.167 * *$ & $(2.53)$ & $0.146 * *$ & (2.17) & $0.152 * *$ & $(2.27)$ & $0.152 * *$ & $(2.27)$ & $0.134 * *$ & $(2.00)$ \\
\hline Constant & $9.335 * * *$ & (78.59) & $9.315^{* * *} *$ & $(79.49)$ & $9.325 * * *$ & $(78.64)$ & $9.298 * * *$ & (77.36) & $9.338 * * *$ & $(78.22)$ & $9.309 * * *$ & $(76.62)$ & $9.289 * * *$ & (78.39) \\
\hline Observations & 2,769 & & 2,769 & & 2,769 & & 2,769 & & 2,769 & & 2,769 & & 2,769 & \\
\hline Adjusted R-squared & 0.882 & & 0.883 & & 0.882 & & 0.882 & & 0.882 & & 0.882 & & 0.883 & \\
\hline Year FE & Yes & & Yes & & Yes & & Yes & & Yes & & Yes & & Yes & \\
\hline Industry FE & Yes & & Yes & & Yes & & Yes & & Yes & & Yes & & Yes & \\
\hline Audfirm FE & No & & No & & No & & No & & No & & No & & No & \\
\hline Partner FE & No & & No & & No & & No & & No & & No & & No & \\
\hline
\end{tabular}

The symbols ***,**, and * denote significance at the 0.01, 0.05, and 0.10 levels, respectively (one-tailed for directional predictions on Volume_Style and Diversity_Style, two-tailed for all other variables). See Appendix A for variable definitions. See Table 1 for sample composition. We use high-dimensional fixed-effect linear regression with heteroskedasticity robust standard errors clustered on client company. 
TABLE 5

Audit Partners' KAM Reporting Styles and Other Audit Outcomes (continued)

Panel B: Audit Firm Fee Growth Leadership

\begin{tabular}{|c|c|c|c|c|c|c|c|c|c|c|c|c|c|c|}
\hline \multicolumn{15}{|c|}{ Dependent Variable: AudfirmFeeGrwthLdr } \\
\hline Variables & Coef & t-stat & Coef & t-stat & Coef & t-stat & Coef & t-stat & Coef & t-stat & Coef & t-stat & Coef & t-stat \\
\hline Volume_Style & 0.004 & $(0.36)$ & & & & & & & & & & & & \\
\hline Diversity_Style & & & -0.001 & $(-0.06)$ & & & & & & & & & & \\
\hline CommStyle_Wrds & & & & & $-0.000^{*}$ & $(-1.71)$ & & & & & & & & \\
\hline CommStyle_Fog & & & & & & & 0.006 & $(1.50)$ & & & & & & \\
\hline CommStyle_CogProc & & & & & & & & & $0.014 * * *$ & $(3.55)$ & & & & \\
\hline CommStyle_Cause & & & & & & & & & & & $0.018^{* *}$ & $(2.07)$ & & \\
\hline CommStyle_Insight & & & & & & & & & & & & & $0.025 * * *$ & $(4.44)$ \\
\hline Size & 0.002 & $(0.32)$ & 0.002 & $(0.34)$ & 0.002 & $(0.38)$ & 0.002 & $(0.32)$ & 0.003 & $(0.53)$ & 0.002 & $(0.32)$ & 0.004 & $(0.60)$ \\
\hline Subs & -0.010 & $(-0.49)$ & -0.011 & $(-0.51)$ & -0.012 & $(-0.55)$ & -0.011 & $(-0.51)$ & -0.015 & $(-0.70)$ & -0.009 & $(-0.42)$ & -0.017 & $(-0.80)$ \\
\hline$R O A$ & -0.024 & $(-0.29)$ & -0.024 & $(-0.29)$ & -0.025 & $(-0.31)$ & -0.023 & $(-0.28)$ & -0.027 & $(-0.33)$ & -0.027 & $(-0.33)$ & -0.022 & $(-0.27)$ \\
\hline Sales_Vol & 0.000 & $(0.93)$ & 0.000 & $(0.94)$ & 0.000 & $(0.84)$ & 0.000 & $(0.89)$ & 0.000 & $(0.78)$ & 0.000 & $(0.80)$ & 0.000 & $(0.97)$ \\
\hline Loss & -0.018 & $(-0.74)$ & -0.018 & $(-0.73)$ & -0.017 & $(-0.72)$ & -0.017 & $(-0.70)$ & -0.014 & $(-0.58)$ & -0.017 & $(-0.72)$ & -0.013 & $(-0.53)$ \\
\hline Leverage & $-0.021 * * *$ & $(-4.20)$ & $-0.021 * * *$ & $(-4.18)$ & $-0.021 * * *$ & $(-4.29)$ & $-0.021 * * *$ & $(-4.12)$ & $-0.020 * * *$ & $(-4.12)$ & $-0.020 * * *$ & $(-4.11)$ & $-0.021 * * *$ & $(-4.08)$ \\
\hline BTM & -0.004 & $(-0.23)$ & -0.004 & $(-0.24)$ & -0.003 & $(-0.22)$ & -0.005 & $(-0.30)$ & -0.004 & $(-0.26)$ & -0.004 & $(-0.23)$ & -0.007 & $(-0.46)$ \\
\hline Acq & -0.015 & $(-0.77)$ & -0.014 & $(-0.75)$ & -0.016 & $(-0.84)$ & -0.013 & $(-0.70)$ & -0.016 & $(-0.83)$ & -0.014 & $(-0.73)$ & -0.016 & $(-0.85)$ \\
\hline$O C F$ & -0.020 & $(-0.19)$ & -0.020 & $(-0.18)$ & -0.017 & $(-0.16)$ & -0.020 & $(-0.18)$ & -0.015 & $(-0.14)$ & -0.017 & $(-0.16)$ & -0.017 & $(-0.16)$ \\
\hline$I n v \_A R$ & 0.057 & $(0.67)$ & 0.055 & $(0.65)$ & 0.062 & $(0.73)$ & 0.053 & $(0.63)$ & 0.053 & $(0.63)$ & 0.052 & $(0.61)$ & 0.059 & $(0.70)$ \\
\hline Fin_Issue & -0.022 & $(-1.38)$ & -0.022 & $(-1.37)$ & -0.021 & $(-1.35)$ & -0.023 & $(-1.45)$ & -0.021 & $(-1.34)$ & -0.019 & $(-1.21)$ & -0.025 & $(-1.58)$ \\
\hline $\operatorname{Rev}$ & -0.010 & $(-0.61)$ & -0.010 & $(-0.61)$ & -0.011 & $(-0.64)$ & -0.010 & $(-0.58)$ & -0.007 & $(-0.44)$ & -0.009 & $(-0.54)$ & -0.010 & $(-0.57)$ \\
\hline GW_Intan & 0.005 & $(0.09)$ & 0.005 & $(0.08)$ & 0.011 & $(0.18)$ & 0.002 & $(0.04)$ & 0.004 & $(0.06)$ & 0.004 & $(0.07)$ & 0.009 & $(0.16)$ \\
\hline GW_Impair & -0.272 & $(-0.54)$ & -0.271 & $(-0.54)$ & -0.258 & $(-0.51)$ & -0.280 & $(-0.55)$ & -0.329 & $(-0.66)$ & -0.294 & $(-0.58)$ & -0.336 & $(-0.68)$ \\
\hline Intan_Impair & 1.527 & $(1.23)$ & 1.534 & $(1.23)$ & 1.514 & $(1.24)$ & 1.574 & $(1.26)$ & 1.440 & $(1.15)$ & 1.422 & (1.14) & 1.552 & $(1.26)$ \\
\hline PPE_Impair & -0.489 & $(-0.51)$ & -0.494 & $(-0.51)$ & -0.421 & $(-0.44)$ & -0.485 & $(-0.50)$ & -0.422 & $(-0.43)$ & -0.487 & $(-0.50)$ & -0.391 & $(-0.40)$ \\
\hline$P P E$ & 0.014 & $(0.43)$ & 0.014 & $(0.44)$ & 0.012 & $(0.39)$ & 0.014 & $(0.44)$ & 0.015 & $(0.47)$ & 0.016 & $(0.51)$ & 0.014 & $(0.44)$ \\
\hline$R D \_E x p$ & $-0.466^{* * *}$ & $(-2.64)$ & $-0.462 * * *$ & $(-2.61)$ & $-0.463^{* * *} *$ & $(-2.63)$ & $-0.458 * * *$ & $(-2.59)$ & $-0.458 * * *$ & $(-2.63)$ & $-0.463 * * *$ & $(-2.65)$ & $-0.443^{* *}$ & $(-2.49)$ \\
\hline Pension & $-0.041^{* *}$ & $(-2.02)$ & $-0.042 * *$ & $(-2.05)$ & $-0.042^{* *}$ & $(-2.06)$ & $-0.041 * *$ & $(-2.00)$ & $-0.044 * *$ & $(-2.21)$ & $-0.044 * *$ & $(-2.15)$ & $-0.039 *$ & $(-1.94)$ \\
\hline Tax_Vol & 0.011 & $(1.26)$ & 0.012 & $(1.27)$ & 0.012 & $(1.31)$ & 0.012 & (1.33) & 0.012 & $(1.31)$ & 0.012 & (1.27) & 0.012 & (1.29) \\
\hline Invest & -0.022 & $(-0.51)$ & -0.023 & $(-0.54)$ & -0.020 & $(-0.47)$ & -0.024 & $(-0.57)$ & -0.015 & $(-0.35)$ & -0.019 & $(-0.46)$ & -0.019 & $(-0.45)$ \\
\hline Legal_Liability & 0.682 & $(0.36)$ & 0.693 & $(0.37)$ & 0.692 & $(0.37)$ & 0.674 & $(0.36)$ & 0.338 & $(0.18)$ & 0.502 & $(0.27)$ & 0.604 & $(0.32)$ \\
\hline Big4 & $0.056 * * *$ & (2.84) & $0.056 * * *$ & $(2.81)$ & $0.059 * * *$ & (2.99) & $0.068 * * *$ & $(3.37)$ & $0.044 * *$ & $(2.21)$ & 0.032 & $(1.50)$ & $0.087 * * *$ & (4.26) \\
\hline DecYrEnd & 0.003 & $(0.19)$ & 0.003 & $(0.17)$ & 0.003 & $(0.16)$ & 0.003 & $(0.17)$ & 0.004 & $(0.27)$ & 0.004 & $(0.27)$ & 0.004 & $(0.24)$ \\
\hline KAMreg & 0.006 & $(0.22)$ & 0.007 & $(0.24)$ & 0.006 & $(0.23)$ & 0.006 & $(0.22)$ & 0.007 & $(0.25)$ & 0.006 & $(0.23)$ & 0.007 & $(0.26)$ \\
\hline MainMkt & $-0.058 * *$ & $(-2.02)$ & $-0.058 * *$ & $(-2.03)$ & $-0.061 * *$ & $(-2.13)$ & $-0.061 * *$ & $(-2.14)$ & $-0.064 * *$ & $(-2.26)$ & $-0.056^{*}$ & $(-1.96)$ & $-0.069 * *$ & $(-2.40)$ \\
\hline Constant & $0.165 * * *$ & $(3.59)$ & $0.165 * * *$ & $(3.60)$ & $0.166^{* * *} *$ & $(3.62)$ & $0.158 * * *$ & (3.43) & $0.174 * * *$ & $(3.80)$ & $0.175^{* * *} *$ & $(3.71)$ & $0.149 * * *$ & $(3.26)$ \\
\hline Observations & 2,623 & & 2,623 & & 2,623 & & 2,623 & & 2,623 & & 2,623 & & 2,623 & \\
\hline Adjusted R-squared & 0.034 & & 0.034 & & 0.035 & & 0.035 & & 0.039 & & 0.036 & & 0.040 & \\
\hline Year FE & Yes & & Yes & & Yes & & Yes & & Yes & & Yes & & Yes & \\
\hline Industry FE & Yes & & Yes & & Yes & & Yes & & Yes & & Yes & & Yes & \\
\hline Audfirm FE & No & & No & & No & & No & & No & & No & & No & \\
\hline Partner FE & No & & No & & No & & No & & No & & No & & No & \\
\hline
\end{tabular}

The symbols ***,**, and * denote significance at the 0.01, 0.05, and 0.10 levels, respectively (one-tailed for directional predictions on Volume_Style and Diversity_Style, two-tailed for all other variables). See Appendix A for variable definitions. See Table 1 for sample composition. We use high-dimensional fixed-effect linear regression with heteroskedasticity robust standard errors clustered on client company. 
TABLE 5

Audit Partners' KAM Reporting Styles and Other Audit Outcomes (continued)

\section{Panel C: Industry Fee Growth Leadership}

\begin{tabular}{|c|c|c|c|c|c|c|c|c|c|c|c|c|c|c|}
\hline \multicolumn{15}{|c|}{ Dependent Variable: IndFeeGrwthLdr } \\
\hline Variables & Coef & t-stat & Coef & t-stat & Coef & t-stat & Coef & t-stat & Coef & t-stat & Coef & t-stat & Coef & t-stat \\
\hline Volume_Style & $0.020 * *$ & $(2.03)$ & & & & & & & & & & & & \\
\hline Diversity_Style & & & $0.045 * *$ & $(2.11)$ & & & & & & & & & & \\
\hline CommStyle_Wrds & & & & & $-0.000 * * *$ & $(-3.10)$ & & & & & & & & \\
\hline CommStyle_Fog & & & & & & & 0.000 & $(0.03)$ & & & & & & \\
\hline CommStyle_CogProc & & & & & & & & & $0.008 *$ & $(1.95)$ & & & & \\
\hline CommStyle_Cause & & & & & & & & & & & $0.025 * * *$ & $(2.93)$ & & \\
\hline CommStyle_Insight & & & & & & & & & & & & & $0.014 * *$ & $(2.27)$ \\
\hline Size & $-0.011^{*}$ & $(-1.83)$ & $-0.011^{*}$ & $(-1.84)$ & -0.010 & $(-1.64)$ & $-0.011 *$ & $(-1.71)$ & -0.010 & $(-1.60)$ & $-0.011^{*}$ & $(-1.76)$ & -0.010 & $(-1.57)$ \\
\hline Subs & -0.013 & $(-0.66)$ & -0.013 & $(-0.68)$ & -0.016 & $(-0.80)$ & -0.014 & $(-0.72)$ & -0.016 & $(-0.82)$ & -0.011 & $(-0.58)$ & -0.018 & $(-0.89)$ \\
\hline$R O A$ & 0.042 & $(0.50)$ & 0.047 & $(0.56)$ & 0.041 & $(0.48)$ & 0.043 & $(0.50)$ & 0.041 & $(0.49)$ & 0.038 & $(0.45)$ & 0.044 & $(0.52)$ \\
\hline Sales_Vol & -0.000 & $(-0.09)$ & -0.000 & $(-0.23)$ & -0.000 & $(-0.32)$ & -0.000 & $(-0.11)$ & -0.000 & $(-0.23)$ & -0.000 & $(-0.33)$ & -0.000 & $(-0.11)$ \\
\hline Loss & -0.021 & $(-0.93)$ & -0.020 & $(-0.89)$ & -0.020 & $(-0.87)$ & -0.020 & $(-0.89)$ & -0.018 & $(-0.80)$ & -0.020 & $(-0.88)$ & -0.018 & $(-0.77)$ \\
\hline Leverage & -0.003 & $(-0.68)$ & -0.003 & $(-0.70)$ & -0.003 & $(-0.61)$ & -0.003 & $(-0.58)$ & -0.002 & $(-0.52)$ & -0.002 & $(-0.37)$ & -0.003 & $(-0.55)$ \\
\hline BTM & -0.015 & $(-0.94)$ & -0.016 & $(-1.01)$ & -0.015 & $(-0.97)$ & -0.016 & $(-1.00)$ & -0.016 & $(-1.01)$ & -0.015 & $(-0.98)$ & -0.017 & $(-1.12)$ \\
\hline$A c q$ & -0.024 & $(-1.58)$ & -0.025 & $(-1.63)$ & -0.025 & $(-1.64)$ & -0.023 & $(-1.48)$ & -0.024 & $(-1.53)$ & -0.022 & $(-1.44)$ & -0.024 & $(-1.55)$ \\
\hline$O C F$ & -0.141 & $(-1.36)$ & -0.147 & $(-1.41)$ & -0.134 & $(-1.29)$ & -0.138 & $(-1.33)$ & -0.136 & $(-1.31)$ & -0.134 & $(-1.30)$ & -0.137 & $(-1.30)$ \\
\hline$I n v \_A R$ & $-0.149 * *$ & $(-1.98)$ & $-0.159 * *$ & $(-2.13)$ & $-0.149 * *$ & $(-1.99)$ & $-0.159 * *$ & $(-2.14)$ & $-0.161 * *$ & $(-2.15)$ & $-0.164 * *$ & $(-2.20)$ & $-0.157 * *$ & $(-2.10)$ \\
\hline Fin_Issue & -0.015 & $(-0.94)$ & -0.014 & $(-0.93)$ & -0.013 & $(-0.86)$ & -0.014 & $(-0.90)$ & -0.014 & $(-0.88)$ & -0.010 & $(-0.66)$ & -0.016 & $(-1.02)$ \\
\hline $\operatorname{Rev}$ & 0.001 & $(0.07)$ & 0.002 & $(0.12)$ & 0.000 & $(0.02)$ & 0.001 & $(0.08)$ & 0.003 & $(0.17)$ & 0.003 & $(0.17)$ & 0.002 & $(0.10)$ \\
\hline$G W_{-}$Intan & 0.037 & $(0.66)$ & 0.031 & $(0.55)$ & 0.044 & $(0.78)$ & 0.034 & $(0.61)$ & 0.033 & $(0.60)$ & 0.033 & $(0.58)$ & 0.037 & $(0.66)$ \\
\hline GW_Impair & 0.102 & $(0.22)$ & 0.070 & $(0.15)$ & 0.124 & $(0.27)$ & 0.101 & $(0.22)$ & 0.070 & $(0.15)$ & 0.070 & $(0.15)$ & 0.065 & $(0.14)$ \\
\hline Intan_Impair & 1.891 & $(1.51)$ & 1.954 & $(1.58)$ & 1.901 & $(1.56)$ & 1.934 & $(1.57)$ & 1.880 & $(1.52)$ & 1.771 & $(1.43)$ & 1.943 & (1.58) \\
\hline PPE_Impair & -0.968 & $(-1.18)$ & -0.936 & $(-1.16)$ & -0.873 & $(-1.07)$ & -0.987 & $(-1.21)$ & -0.947 & $(-1.17)$ & -0.978 & $(-1.20)$ & -0.928 & $(-1.14)$ \\
\hline$P P E$ & 0.021 & $(0.70)$ & 0.019 & $(0.64)$ & 0.019 & $(0.64)$ & 0.021 & $(0.70)$ & 0.022 & $(0.73)$ & 0.025 & $(0.82)$ & 0.021 & $(0.71)$ \\
\hline$R D \_E x p$ & $-0.411 * *$ & $(-2.16)$ & $-0.423 * *$ & $(-2.23)$ & $-0.396 * *$ & $(-2.09)$ & $-0.395 * *$ & $(-2.09)$ & $-0.393 * *$ & $(-2.07)$ & $-0.396 * *$ & $(-2.11)$ & $-0.384 * *$ & $(-2.02)$ \\
\hline Pension & -0.008 & $(-0.45)$ & -0.011 & $(-0.61)$ & -0.010 & $(-0.55)$ & -0.010 & $(-0.54)$ & -0.011 & $(-0.64)$ & -0.013 & $(-0.71)$ & -0.008 & $(-0.46)$ \\
\hline Tax_Vol & 0.005 & $(0.62)$ & 0.006 & $(0.74)$ & 0.006 & $(0.72)$ & 0.005 & $(0.67)$ & 0.006 & $(0.69)$ & 0.005 & $(0.67)$ & 0.006 & $(0.68)$ \\
\hline Invest & -0.041 & $(-0.96)$ & -0.045 & $(-1.05)$ & -0.042 & $(-0.99)$ & -0.047 & $(-1.08)$ & -0.042 & $(-0.98)$ & -0.042 & $(-0.97)$ & -0.045 & $(-1.04)$ \\
\hline Legal_Liability & 0.702 & $(0.46)$ & 0.629 & $(0.42)$ & 0.748 & $(0.50)$ & 0.744 & $(0.49)$ & 0.546 & $(0.36)$ & 0.472 & $(0.31)$ & 0.695 & $(0.47)$ \\
\hline Big4 & $0.037^{*}$ & $(1.72)$ & $0.043 * *$ & $(2.00)$ & $0.043 * *$ & (1.98) & $0.038^{*}$ & $(1.70)$ & 0.031 & $(1.43)$ & 0.003 & $(0.14)$ & $0.056 * *$ & $(2.45)$ \\
\hline DecYrEnd & 0.018 & (1.18) & 0.018 & (1.17) & 0.016 & $(1.04)$ & 0.016 & $(1.05)$ & 0.017 & (1.11) & 0.019 & $(1.20)$ & 0.017 & (1.09) \\
\hline KAMreg & 0.000 & $(0.01)$ & 0.001 & $(0.04)$ & 0.003 & $(0.10)$ & 0.003 & $(0.11)$ & 0.003 & $(0.12)$ & 0.003 & $(0.09)$ & 0.003 & $(0.13)$ \\
\hline MainMkt & -0.045 & $(-1.58)$ & $-0.049 *$ & $(-1.75)$ & $-0.051 *$ & $(-1.80)$ & -0.046 & $(-1.64)$ & $-0.049 *$ & $(-1.75)$ & -0.043 & $(-1.54)$ & $-0.052 *$ & $(-1.85)$ \\
\hline Constant & $0.233 * * *$ & $(4.65)$ & $0.229 * * *$ & $(4.56)$ & $0.235 * * *$ & $(4.69)$ & $0.233 * * *$ & $(4.65)$ & $0.238 * * *$ & $(4.73)$ & $0.246 * * *$ & $(4.89)$ & $0.223 * * *$ & $(4.48)$ \\
\hline Observations & 2,623 & & 2,623 & & 2,623 & & 2,623 & & 2,623 & & 2,623 & & 2,623 & \\
\hline Adjusted R-squared & 0.010 & & 0.010 & & 0.012 & & 0.008 & & 0.010 & & 0.013 & & 0.010 & \\
\hline Year FE & Yes & & Yes & & Yes & & Yes & & Yes & & Yes & & Yes & \\
\hline Industry FE & Yes & & Yes & & Yes & & Yes & & Yes & & Yes & & Yes & \\
\hline Audfirm FE & No & & No & & No & & No & & No & & No & & No & \\
\hline Partner FE & No & & No & & No & & No & & No & & No & & No & \\
\hline
\end{tabular}

The symbols ***,**, and * denote significance at the 0.01, 0.05, and 0.10 levels, respectively (one-tailed for directional predictions on Volume_Style and Diversity_Style, two-tailed for all other variables). See Appendix A for variable definitions. See Table 1 for sample composition. We use high-dimensional fixed-effect linear regression with heteroskedasticity robust standard errors clustered on client company. 
TABLE 5

Audit Partners' KAM Reporting Styles and Other Audit Outcomes (continued)

\section{Panel D: Audit Delay}

\begin{tabular}{|c|c|c|c|c|c|c|c|c|c|c|c|c|c|c|}
\hline \multicolumn{15}{|c|}{ Dependent Variable: Audit_Delay } \\
\hline Variables & Coef & t-stat & Coef & t-stat & Coef & t-stat & Coef & t-stat & Coef & t-stat & Coef & t-stat & Coef & t-stat \\
\hline Volume_Style & 0.054 & $(0.15)$ & & & & & & & & & & & & \\
\hline Diversity_Style & & & -0.381 & $(-0.51)$ & & & & & & & & & & \\
\hline CommStyle_Wrds & & & & & 0.003 & $(0.83)$ & & & & & & & & \\
\hline CommStyle_Fog & & & & & & & 0.117 & $(0.65)$ & & & & & & \\
\hline CommStyle_CogProc & & & & & & & & & 0.106 & $(0.71)$ & & & & \\
\hline CommStyle_Cause & & & & & & & & & & & 0.144 & $(0.49)$ & & \\
\hline CommStyle_Insight & & & & & & & & & & & & & 0.146 & $(0.54)$ \\
\hline Size & $-1.239 * * *$ & $(-4.61)$ & $-1.236 * * *$ & $(-4.60)$ & $-1.234 * * *$ & $(-4.59)$ & $-1.237 * * *$ & $(-4.61)$ & $-1.222 * * *$ & $(-4.56)$ & $-1.238 * * *$ & $(-4.61)$ & $-1.225^{* * *}$ & $(-4.58)$ \\
\hline Subs & -0.992 & $(-1.32)$ & -1.011 & $(-1.35)$ & -0.963 & $(-1.29)$ & -1.001 & $(-1.34)$ & -1.026 & $(-1.38)$ & -0.980 & $(-1.30)$ & -1.031 & $(-1.38)$ \\
\hline$R O A$ & -6.315 & $(-1.55)$ & -6.356 & $(-1.56)$ & -6.351 & $(-1.56)$ & -6.335 & $(-1.56)$ & -6.352 & $(-1.56)$ & -6.335 & $(-1.56)$ & -6.328 & $(-1.56)$ \\
\hline Sales_Vol & $0.001 *$ & $(1.75)$ & $0.001 *$ & (1.77) & $0.001^{*}$ & (1.83) & $0.001 *$ & $(1.75)$ & $0.001^{*}$ & (1.71) & $0.001^{*}$ & $(1.72)$ & $0.001^{*}$ & (1.76) \\
\hline Loss & -1.165 & $(-1.24)$ & -1.165 & $(-1.24)$ & -1.186 & $(-1.27)$ & -1.148 & $(-1.23)$ & -1.136 & $(-1.21)$ & -1.160 & $(-1.24)$ & -1.134 & $(-1.21)$ \\
\hline Leverage & -0.126 & $(-0.50)$ & -0.121 & $(-0.49)$ & -0.123 & $(-0.49)$ & -0.120 & $(-0.48)$ & -0.121 & $(-0.49)$ & -0.121 & $(-0.48)$ & -0.122 & $(-0.49)$ \\
\hline BTM & 0.672 & $(0.70)$ & 0.675 & $(0.71)$ & 0.670 & $(0.70)$ & 0.652 & $(0.69)$ & 0.665 & $(0.70)$ & 0.670 & $(0.70)$ & 0.647 & $(0.68)$ \\
\hline$A c q$ & 0.740 & (1.19) & 0.759 & $(1.21)$ & 0.777 & (1.23) & 0.767 & $(1.22)$ & 0.735 & (1.17) & 0.749 & $(1.20)$ & 0.736 & (1.18) \\
\hline$O C F$ & $-12.576^{* *}$ & $(-2.37)$ & $-12.489 * *$ & $(-2.35)$ & $-12.621 * *$ & $(-2.37)$ & $-12.528 * *$ & $(-2.36)$ & $-12.521 * *$ & $(-2.35)$ & $-12.539 * *$ & $(-2.36)$ & $-12.520 * *$ & $(-2.36)$ \\
\hline$I n v \_A R$ & -2.072 & $(-0.72)$ & -2.124 & $(-0.73)$ & -2.175 & $(-0.75)$ & -2.131 & $(-0.73)$ & -2.117 & $(-0.73)$ & -2.133 & $(-0.74)$ & -2.078 & $(-0.72)$ \\
\hline Fin_Issue & 0.552 & $(0.94)$ & 0.570 & $(0.97)$ & 0.550 & $(0.93)$ & 0.525 & $(0.89)$ & 0.557 & $(0.94)$ & 0.571 & $(0.97)$ & 0.530 & $(0.90)$ \\
\hline $\operatorname{Rev}$ & -0.349 & $(-0.57)$ & -0.346 & $(-0.56)$ & -0.338 & $(-0.55)$ & -0.348 & $(-0.57)$ & -0.326 & $(-0.53)$ & -0.340 & $(-0.56)$ & -0.347 & $(-0.56)$ \\
\hline$G W_{-}$Intan & -1.728 & $(-0.78)$ & -1.711 & $(-0.77)$ & -1.821 & $(-0.83)$ & -1.793 & $(-0.81)$ & -1.729 & $(-0.78)$ & -1.740 & $(-0.79)$ & -1.712 & $(-0.78)$ \\
\hline GW_Impair & 19.855 & $(1.00)$ & 19.978 & $(1.01)$ & 19.843 & $(1.00)$ & 19.750 & $(1.00)$ & 19.561 & $(0.99)$ & 19.754 & $(1.00)$ & 19.517 & $(0.99)$ \\
\hline Intan_Impair & 35.266 & $(0.59)$ & 34.876 & $(0.59)$ & 35.136 & $(0.59)$ & 36.056 & $(0.61)$ & 34.820 & $(0.59)$ & 34.621 & $(0.58)$ & 35.644 & $(0.60)$ \\
\hline PPE_Impair & $63.624 * *$ & $(2.52)$ & $63.586^{* *}$ & $(2.52)$ & $63.304 * *$ & $(2.50)$ & $63.386 * *$ & $(2.50)$ & $63.536^{* *} *$ & $(2.51)$ & $63.561^{* *}$ & $(2.51)$ & $63.397 * *$ & $(2.50)$ \\
\hline$P P E$ & $-3.221 * *$ & $(-2.49)$ & $-3.206^{* *}$ & $(-2.48)$ & $-3.202 * *$ & $(-2.48)$ & $-3.231 * *$ & $(-2.50)$ & $-3.217 * *$ & $(-2.49)$ & $-3.197 * *$ & $(-2.48)$ & $-3.231 * *$ & $(-2.50)$ \\
\hline$R D \_E x p$ & $-24.784 * * *$ & $(-2.95)$ & $-24.562 * * *$ & $(-2.92)$ & $-24.657 * * *$ & $(-2.93)$ & $-24.626 * * *$ & $(-2.92)$ & $-24.688 * * *$ & $(-2.93)$ & $-24.729 * * *$ & $(-2.93)$ & $-24.628 * * *$ & $(-2.92)$ \\
\hline Pension & -0.005 & $(-0.01)$ & -0.008 & $(-0.01)$ & 0.000 & $(0.00)$ & 0.008 & $(0.01)$ & -0.026 & $(-0.04)$ & -0.023 & $(-0.04)$ & 0.008 & $(0.01)$ \\
\hline Tax_Vol & -0.632 & $(-1.51)$ & -0.634 & $(-1.50)$ & -0.636 & $(-1.51)$ & -0.623 & $(-1.48)$ & -0.628 & $(-1.49)$ & -0.629 & $(-1.50)$ & -0.629 & $(-1.50)$ \\
\hline Invest & -0.412 & $(-0.27)$ & -0.395 & $(-0.26)$ & -0.470 & $(-0.31)$ & -0.442 & $(-0.30)$ & -0.349 & $(-0.23)$ & -0.399 & $(-0.27)$ & -0.398 & $(-0.27)$ \\
\hline Legal_Liability & -8.654 & $(-0.15)$ & -9.098 & $(-0.15)$ & -9.073 & $(-0.15)$ & -8.621 & $(-0.15)$ & -10.969 & $(-0.18)$ & -9.657 & $(-0.16)$ & -8.822 & $(-0.15)$ \\
\hline Big 4 & 0.400 & $(0.52)$ & 0.308 & $(0.39)$ & 0.278 & $(0.36)$ & 0.594 & $(0.70)$ & 0.309 & $(0.40)$ & 0.234 & $(0.28)$ & 0.576 & $(0.68)$ \\
\hline DecYrEnd & $2.058 * * *$ & $(3.54)$ & $2.040 * * *$ & $(3.53)$ & $2.059 * * *$ & $(3.57)$ & $2.054 * * *$ & $(3.56)$ & $2.059 * * *$ & $(3.58)$ & $2.065^{* * *}$ & $(3.57)$ & $2.056^{* * * *}$ & $(3.57)$ \\
\hline KAMreg & -0.815 & $(-0.70)$ & -0.790 & $(-0.68)$ & -0.806 & $(-0.69)$ & -0.814 & $(-0.70)$ & -0.802 & $(-0.69)$ & -0.812 & $(-0.70)$ & -0.802 & $(-0.69)$ \\
\hline MainMkt & $-2.871 * * *$ & $(-2.59)$ & $-2.843 * *$ & $(-2.55)$ & $-2.825 * *$ & $(-2.54)$ & $-2.935 * * *$ & $(-2.62)$ & $-2.913 * * *$ & $(-2.62)$ & $-2.859 * *$ & $(-2.58)$ & $-2.942 * * *$ & $(-2.60)$ \\
\hline L1_Audit_Delay & $0.745^{* * *}$ & $(30.22)$ & $0.745^{* * *}$ & $(30.23)$ & $0.745^{* * *}$ & $(30.12)$ & $0.745^{* * *}$ & (30.03) & $0.746^{* * *}$ & $(30.25)$ & $0.745^{* * *} *$ & $(30.21)$ & $0.745^{* * *} *$ & $(30.17)$ \\
\hline Constant & $29.772 * * *$ & $(8.81)$ & $29.859 * * *$ & $(8.83)$ & $29.800 * * *$ & $(8.79)$ & $29.695 * * *$ & $(8.80)$ & $29.787 * * *$ & $(8.81)$ & $29.811 * * *$ & $(8.82)$ & $29.688 * * *$ & $(8.80)$ \\
\hline Observations & 2,718 & & 2,718 & & 2,718 & & 2,718 & & 2,718 & & 2,718 & & 2,718 & \\
\hline Adjusted R-squared & 0.776 & & 0.776 & & 0.776 & & 0.776 & & 0.776 & & 0.776 & & 0.776 & \\
\hline Year FE & Yes & & Yes & & Yes & & Yes & & Yes & & Yes & & Yes & \\
\hline Industry FE & Yes & & Yes & & Yes & & Yes & & Yes & & Yes & & Yes & \\
\hline Audfirm FE & No & & No & & No & & No & & No & & No & & No & \\
\hline Partner FE & No & & No & & No & & No & & No & & No & & No & \\
\hline
\end{tabular}




\section{TABLE 5}

Audit Partners' KAM Reporting Styles and Other Audit Outcomes (continued)

\section{Panel E: Audit Quality}

\begin{tabular}{|c|c|c|c|c|c|c|c|c|c|c|c|c|c|c|}
\hline \multicolumn{15}{|c|}{ Dependent Variable: $A b s A c c$} \\
\hline Variables & Coef & t-stat & Coef & t-stat & Coef & t-stat & Coef & t-stat & Coef & t-stat & Coef & t-stat & Coef & t-stat \\
\hline Volume_Style & 0.003 & $(1.08)$ & & & & & & & & & & & & \\
\hline Diversity_Style & & & 0.007 & $(1.38)$ & & & & & & & & & & \\
\hline CommStyle_Wrds & & & & & -0.000 & $(-0.06)$ & & & & & & & & \\
\hline CommStyle_Fog & & & & & & & 0.000 & $(0.08)$ & & & & & & \\
\hline CommStyle_CogProc & & & & & & & & & -0.001 & $(-0.77)$ & & & & \\
\hline CommStyle_Cause & & & & & & & & & & & 0.003 & $(1.02)$ & & \\
\hline CommStyle_Insight & & & & & & & & & & & & & -0.001 & $(-0.34)$ \\
\hline Size & $-0.004 * * *$ & $(-2.63)$ & $-0.004 * * *$ & $(-2.67)$ & $-0.004 * * *$ & $(-2.60)$ & $-0.004 * * *$ & $(-2.63)$ & $-0.004 * * *$ & $(-2.69)$ & $-0.004 * *$ & $(-2.57)$ & $-0.004 * * *$ & $(-2.68)$ \\
\hline Leverage & $-0.002 *$ & $(-1.69)$ & $-0.002 *$ & $(-1.71)$ & $-0.002 *$ & $(-1.67)$ & $-0.002 *$ & $(-1.66)$ & $-0.002^{*}$ & $(-1.69)$ & -0.002 & $(-1.62)$ & $-0.002 *$ & $(-1.66)$ \\
\hline$R O A$ & -0.028 & $(-0.40)$ & -0.027 & $(-0.40)$ & -0.028 & $(-0.41)$ & -0.028 & $(-0.41)$ & -0.028 & $(-0.41)$ & -0.028 & $(-0.41)$ & -0.028 & $(-0.41)$ \\
\hline Loss & $0.019 * *$ & $(2.24)$ & $0.019 * *$ & $(2.27)$ & $0.019 * *$ & $(2.27)$ & $0.019 * *$ & $(2.27)$ & $0.019 * *$ & $(2.25)$ & $0.019 * *$ & $(2.27)$ & $0.019 * *$ & $(2.26)$ \\
\hline$O C F$ & $-0.182 * * *$ & $(-3.09)$ & $-0.183^{* * *} *$ & $(-3.10)$ & $-0.182 * * *$ & $(-3.09)$ & $-0.182 * * *$ & $(-3.08)$ & $-0.182 * * *$ & $(-3.08)$ & $-0.182 * * *$ & $(-3.08)$ & $-0.182 * * *$ & $(-3.08)$ \\
\hline Big4 & $0.012^{*}$ & (1.89) & $0.014 * *$ & $(2.08)$ & $0.012 *$ & (1.90) & $0.012^{*}$ & (1.77) & $0.013 * *$ & $(2.00)$ & 0.009 & $(1.25)$ & 0.011 & (1.63) \\
\hline$B T M$ & $-0.014 * * *$ & $(-2.76)$ & $-0.014 * * *$ & $(-2.80)$ & $-0.014 * * *$ & $(-2.78)$ & $-0.014 * * *$ & $(-2.77)$ & $-0.014 * * *$ & $(-2.78)$ & $-0.014 * * *$ & $(-2.77)$ & $-0.014 * * *$ & $(-2.75)$ \\
\hline$L 1 \_A b s A c c$ & $0.204 * * *$ & $(5.51)$ & $0.204 * * *$ & $(5.53)$ & $0.204 * * *$ & $(5.49)$ & $0.204 * * *$ & $(5.51)$ & $0.204 * * *$ & $(5.51)$ & $0.203 * * *$ & $(5.50)$ & $0.204 * * *$ & $(5.53)$ \\
\hline Fin_Issue & $-0.012 * * *$ & $(-2.66)$ & $-0.012 * * *$ & $(-2.67)$ & $-0.012 * * *$ & $(-2.63)$ & $-0.012 * * *$ & $(-2.61)$ & $-0.012 * * *$ & $(-2.63)$ & $-0.011 * *$ & $(-2.52)$ & $-0.011 * *$ & $(-2.57)$ \\
\hline Sales_Vol & 0.000 & $(0.05)$ & -0.000 & $(-0.04)$ & 0.000 & $(0.02)$ & 0.000 & $(0.02)$ & 0.000 & $(0.07)$ & -0.000 & $(-0.06)$ & 0.000 & $(0.02)$ \\
\hline $\operatorname{Rev}$ & $0.009 * *$ & $(2.47)$ & $0.009 * *$ & $(2.44)$ & $0.009 * *$ & $(2.44)$ & $0.009 * *$ & $(2.44)$ & $0.009 * *$ & $(2.39)$ & $0.009 * *$ & $(2.44)$ & $0.009 * *$ & $(2.43)$ \\
\hline KAMreg & -0.012 & $(-1.59)$ & -0.012 & $(-1.59)$ & -0.011 & $(-1.55)$ & -0.011 & $(-1.55)$ & -0.011 & $(-1.56)$ & -0.011 & $(-1.55)$ & -0.011 & $(-1.55)$ \\
\hline MainMkt & 0.007 & $(0.97)$ & 0.006 & $(0.83)$ & 0.007 & $(0.93)$ & 0.007 & $(0.91)$ & 0.007 & $(0.96)$ & 0.007 & $(0.97)$ & 0.007 & $(0.95)$ \\
\hline DecYrEnd & -0.001 & $(-0.16)$ & -0.001 & $(-0.17)$ & -0.001 & $(-0.21)$ & -0.001 & $(-0.21)$ & -0.001 & $(-0.21)$ & -0.001 & $(-0.17)$ & -0.001 & $(-0.21)$ \\
\hline Constant & $0.086^{* * *}$ & $(6.45)$ & $0.084 * * *$ & $(6.26)$ & $0.086^{* * *} *$ & $(6.43)$ & $0.085 * * *$ & $(6.50)$ & $0.085 * * *$ & $(6.41)$ & $0.087 * * *$ & $(6.57)$ & $0.086 * * *$ & $(6.56)$ \\
\hline Observations & 2,437 & & 2,437 & & 2,437 & & 2,437 & & 2,437 & & 2,437 & & 2,437 & \\
\hline Adjusted R-squared & 0.267 & & 0.267 & & 0.267 & & 0.267 & & 0.267 & & 0.267 & & 0.267 & \\
\hline Year FE & Yes & & Yes & & Yes & & Yes & & Yes & & Yes & & Yes & \\
\hline Industry FE & Yes & & Yes & & Yes & & Yes & & Yes & & Yes & & Yes & \\
\hline Audfirm FE & No & & No & & No & & No & & No & & No & & No & \\
\hline Partner FE & No & & No & & No & & No & & No & & No & & No & \\
\hline
\end{tabular}

The symbols ***,**, and * denote significance at the 0.01, 0.05, and 0.10 levels, respectively (two-tailed for all t-statistics). See Appendix A for variable definitions. See Table 1 for sample composition. We use high-dimensional fixed-effect linear regression with heteroskedasticity robust standard errors clustered on client company. 
TABLE 6

The Association Between Partner KAM Reporting Style and Demographic Characteristics

\begin{tabular}{|c|c|c|c|c|c|c|c|c|c|c|c|c|c|c|}
\hline \multirow[b]{2}{*}{ Variables } & \multicolumn{2}{|c|}{ Volume_Style } & \multicolumn{2}{|c|}{ Diversity_Style } & \multicolumn{2}{|c|}{ CommStyle_Words } & \multicolumn{2}{|c|}{ CommStyle_Fog } & \multicolumn{2}{|c|}{ CommStyle_CogProc } & \multicolumn{2}{|c|}{ CommStyle_Cause } & \multicolumn{2}{|c|}{ CommStyle_Insight } \\
\hline & Coef & t-stat & Coef & t-stat & Coef & t-stat & Coef & t-stat & Coef & t-stat & Coef & t-stat & Coef & t-stat \\
\hline Female & 0.005 & $(0.03)$ & 0.056 & $(0.67)$ & 25.146 & $(1.75)$ & 0.552 & $(1.55)$ & 0.169 & $(0.45)$ & -0.033 & $(-0.18)$ & 0.310 & (1.32) \\
\hline Adv_Degree & $0.284 * *$ & $(2.08)$ & 0.023 & $(0.33)$ & -19.400 & $(-1.58)$ & 0.088 & $(0.29)$ & -0.361 & $(-1.12)$ & -0.091 & $(-0.58)$ & -0.124 & $(-0.62)$ \\
\hline Acct_Major & -0.157 & $(-1.20)$ & $0.147 * *$ & $(2.14)$ & -10.018 & $(-0.85)$ & 0.488 & $(1.66)$ & -0.102 & $(-0.33)$ & -0.121 & $(-0.80)$ & 0.295 & $(1.53)$ \\
\hline BigN_Exp & 0.274 & $(1.72)$ & $-0.221 * * *$ & $(-2.65)$ & 12.287 & $(0.85)$ & $-2.081 * * *$ & $(-5.85)$ & $1.009 * * *$ & $(2.68)$ & $1.127 * * *$ & $(6.15)$ & $-1.424 * * *$ & $(-6.07)$ \\
\hline Int_Second & -0.154 & $(-1.27)$ & -0.072 & $(-1.14)$ & 10.008 & $(0.91)$ & 0.285 & $(1.05)$ & $0.575 * *$ & $(2.01)$ & $0.313 * *$ & $(2.24)$ & 0.054 & $(0.30)$ \\
\hline Client_Second & -0.006 & $(-0.03)$ & 0.049 & $(0.55)$ & -2.350 & $(-0.15)$ & 0.410 & $(1.08)$ & 0.005 & $(0.01)$ & -0.357 & $(-1.83)$ & 0.331 & $(1.32)$ \\
\hline Prctc_Ldr & 0.084 & $(0.69)$ & 0.008 & $(0.13)$ & -10.614 & $(-0.97)$ & -0.170 & $(-0.63)$ & 0.039 & $(0.14)$ & 0.064 & $(0.46)$ & -0.279 & $(-1.57)$ \\
\hline Exp_Yrs & -0.005 & $(-0.53)$ & 0.006 & (1.11) & -0.328 & $(-0.37)$ & -0.018 & $(-0.85)$ & 0.011 & $(0.50)$ & -0.003 & $(-0.26)$ & 0.002 & $(0.12)$ \\
\hline Constant & -0.204 & $(-0.69)$ & 0.197 & (1.28) & 27.314 & $(1.03)$ & $2.473 * * *$ & $(3.76)$ & $-1.717 * *$ & $(-2.47)$ & $-0.622 *$ & $(-1.83)$ & $0.950 * *$ & $(2.19)$ \\
\hline Observations & 161 & & 161 & & 161 & & 161 & & 161 & & 161 & & 161 & \\
\hline Adjusted R-squared & 0.021 & & 0.041 & & 0.006 & & 0.185 & & 0.049 & & 0.221 & & 0.201 & \\
\hline
\end{tabular}

The symbols $* * *$ and $* *$ denote significance at the 0.01 and 0.05 , respectively (two-tailed for all t-statistics). See Appendix A for variable definitions. See Table 1 for sample composition. We use

linear regression with heteroskedasticity robust standard errors. 